\title{
Implementação do arcabouço WED-flow para controle de processos transacionais
}

\author{
Marcela Ortega Garcia
}

DiSSERTAÇÃO APRESENTADA

$\mathrm{AO}$

Instituto De MatemáticA E EstatísticA

DA

Universidade De SÃo PAUlo

PARA

OBTENÇÃO DO TÍTULO

DE

Mestre em CiênCIAS

Programa: Pós-Graduação em Ciência da Computação

Orientador: Prof. Dr. João Eduardo Ferreira

Durante o desenvolvimento deste trabalho a autora recebeu auxílio financeiro do CNPq e do NIH-USA

São Paulo, Março de 2013 


\section{Implementação do arcabouço WED-flow para controle de processos transacionais}

Esta versão da dissertação contém as correções e alterações sugeridas pela Comissão Julgadora durante a defesa da versão original do trabalho, realizada em 28/03/2013. Uma cópia da versão original está disponível no Instituto de Matemática e Estatística da Universidade de São Paulo.

Comissão Julgadora:

- Prof. Dr. João Eduardo Ferreira - IME-USP

- Prof. Dr. José Maria da Silva Monteiro Filho - UFC

- Prof. Dr. Fábio André Machado Porto - LNCC-RJ 


\section{Agradecimentos}

Agradeço ao meu orientador, professor João Eduardo Ferreira, pelos ensinamentos e por toda a atenção e paciência dedicadas a este trabalho. Sou muito grata pela confiança depositada em mim e por todas as oportunidades oferecidas desde a graduação.

Agradeço à professora Kelly Rosa Braghetto pela sua participação fundamental neste trabalho. Sou muito grata pela sua generosidade em compartilhar seus conhecimentos e experiências, por toda paciência, atenção e apoio dedicados ao meu mestrado e pelas inúmeras discussões técnicas que tivemos.

Agradeço ao professor Calton $\mathrm{Pu}$, do Georgia Institute of Technology, por me receber tão gentilmente e por toda atenção durante os meses em que foi meu orientador na Georgia Tech. Sou muito grata pela oportunidade a mim oferecida.

Agradeço aos membros do grupo DATA do IME-USP pelo apoio e contribuições diretas e indiretas a este trabalho. Em especial, agradeço ao Pedro Paulo Silva pela atenção e troca de experiências durante o desenvolvimento da WED-tool.

Agradeço ao Conselho Nacional de Desenvolvimento Científico e Tecnológico (CNPq) e ao National Institutes of Health (NIH-USA) pelo auxílio financeiro a este trabalho.

Agradeço aos meus pais, Josefa e Reginaldo, pelo apoio e dedicação para que eu pudesse me concentrar nos estudos. Agradeço também à minha irmã Mariana, meu irmão Felipe e à minha avó Maria pelo apoio incondicional durante toda minha vida.

Finalmente, agradeço aos meus amigos do IME-USP, em especial ao BCC 2006, pela amizade e companhia fundamentais nesses últimos sete anos. 


\section{Resumo}

\section{GARCIA, M. O. Implementação do Arcabouço WED-flow para Controle de Processos}

Transacionais. Dissertação de mestrado - Instituto de Matemática e Estatística, Universidade de São Paulo, São Paulo, 2013.

A área de gerenciamento de processos de negócio apresenta-se ativa e tem recebido atenção tanto da comunidade de pesquisa como da indústria. Uma das principais preocupações nessa área é a escolha da melhor abordagem para modelagem e implementação de processos de negócio. Atualmente, organizações possuem processos de negócio com complexas estruturas que são reavaliados e ajustados com frequência, exigindo flexibilidade das linguagens para modelagem de processos. Além disso, processos de negócio atuais também exigem ambientes para implementação capazes de garantir confiabilidade na execução de instâncias do processo modelado, especialmente em caso de falhas. Embora diversos modelos transacionais tenham sido propostos com o objetivo de garantir propriedades transacionais adaptadas ao contexto de processos de negócio, a implementação de processos transacionais ainda oferece um cenário com desafios teóricos e práticos. Neste trabalho apresentamos uma implementação da abordagem WED-flow para controle de processos transacionais. A WED-flow é uma abordagem que combina conceitos de modelos transacionais avançados, eventos e estados de dados com o objetivo principal de reduzir a complexidade no tratamento de exceções. A ferramenta de software desenvolvida é capaz de controlar a execução de instâncias de processos de negócio, permite a evolução incremental do modelo projetado e ainda disponibiliza a estrutura necessária para apoiar a implementação de mecanismos de recuperação para tratar interrupções em instâncias causadas por exceções.

Palavras-chave: gerenciamento de processos de negócio, processos transacionais, tratamento de exceções. 


\section{Abstract}

\section{GARCIA, M. O. An Implementation of WED-flow for Controlling Transactional Pro-}

cesses. Master's dissertation - Institute of Mathematics and Statistics, University of São Paulo, São Paulo, 2013.

Business processes management is an active area which have received increased attention from research and industry communities. A major concern is the selection of the best approach for modeling and implementing business processes. Nowadays, organizations have business processes with complex structures, which are reevaluated and adjusted frequently, requiring flexibility from modeling languages. In addition, current business processes also require implementation environments capable of ensuring execution reliability, especially in case of failures. Although several transactional models have been proposed in order to guarantee transactional properties adapted to the context of business processes, the implementation of transactional processes still offers a scenario with several theoretical and practical challenges. In this work, we present an implementation of WED-flow approach for controlling transactional processes. WED-flow is an approach which combines the concepts of advanced transactional models, events and data states for the purpose of reducing exception handling complexity. The developed software tool is able of controlling the execution of business processes instances, allows incremental evolution of the designed model and also provides the necessary structure to support recovery mechanisms implementation to handle instances interruptions caused by exceptions.

Keywords: business processes management, transactional processes, exception handling. 


\section{Sumário}

Lista de Abreviaturas $\quad$ ix

Lista de Figuras $\quad$ xi

Lista de Códigos-fonte $\quad$ xii

1 Introdução 1

1.1 Ciclo de vida de processos de negócios . . . . . . . . . . . . . . . 2

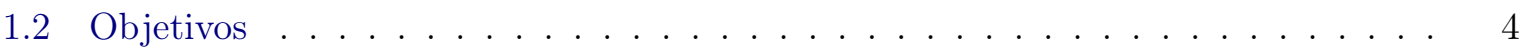

1.3 Contribuições . . . . . . . . . . . . . . . . . . . . . . . 4

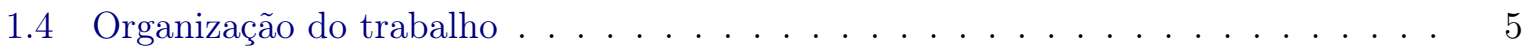

2 Modelagem baseada em grafos $\quad 7$

2.1 Teoria dos processos $\ldots \ldots \ldots \ldots \ldots \ldots$

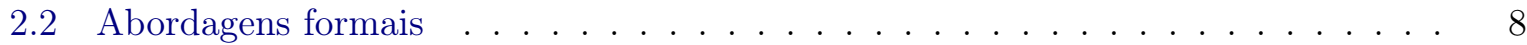

$2.2 .1 \quad$ Redes de Petri . . . . . . . . . . . . . . . . . . . . . . . 9

2.2 .2 Álgebra de processos . . . . . . . . . . . . . . . . . . . . . . . 11

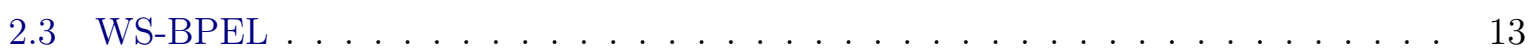

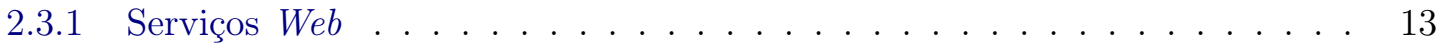

2.3.2 Web Services Business Process Execution Language . . . . . . . . . . . . . 14

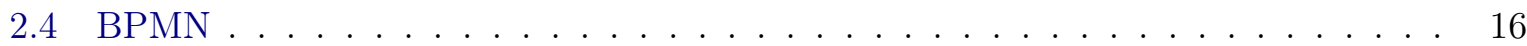

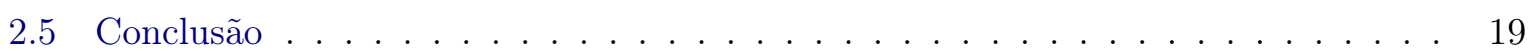

3 Modelagem baseada em regras $\quad 21$

3.1 Regras Evento-Condição-Ação . . . . . . . . . . . . . . . . . . . . . 21

3.1 .1 Regras ECA aplicadas a processos de negócio . . . . . . . . . . . . . 23

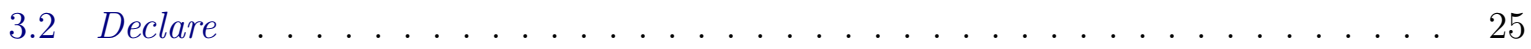

3.2 .1 Modelagem . . . . . . . . . . . . . . . . . . . 25

3.2 .2 Execução do processo . . . . . . . . . . . . . . . . . . 26

3.2 .3 Exemplo . . . . . . . . . . . . . . . . . . . . . . 27

3.3 Conclusão . . . . . . . . . . . . . . . . . . . . . . . . 27

4 Processos transacionais $\quad 29$

4.1 Transações . . . . . . . . . . . . . . . . . . . . . . . . . . . . 29 
$4.1 .1 \quad$ Propriedades ACID . . . . . . . . . . . . . . . . . . . . . 30

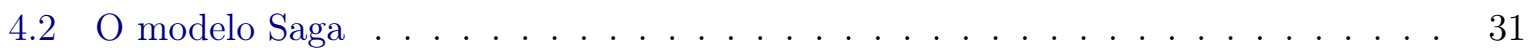

4.3 Semi-atomicidade . . . . . . . . . . . . . . . . . . . 32

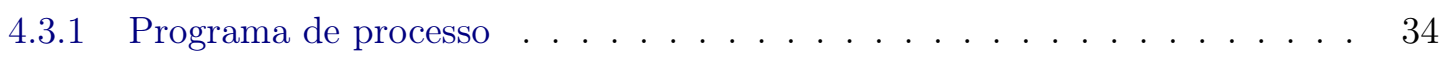

4.3 .2 Execução . . . . . . . . . . . . . . . . . . . . . . . . 35

4.4 Composição transacional de serviços . . . . . . . . . . . . . . . 36

4.4 .1 Modelo . . . . . . . . . . . . . . . . . . . . . 37

4.4 .2 Implementação . . . . . . . . . . . . . . . . . . . . . . . . . . . . . . . . . . . . . . . . . . . . .

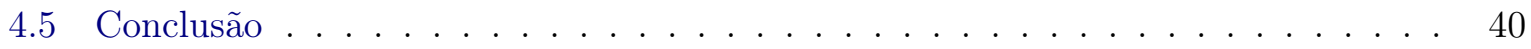

5 WED-flow $\quad 41$

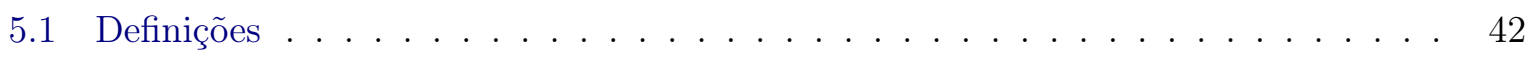

5.2 Exceções . . . . . . . . . . . . . . . . . . . . . . . . . . . . 44

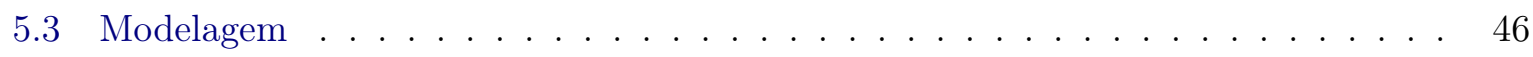

5.4 Exemplo . . . . . . . . . . . . . . . . . . . . . . . . . . 49

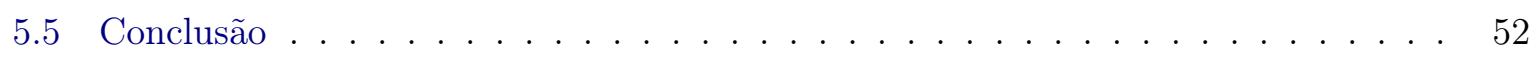

6 WED-tool $\quad 53$

6.1 Configuração: modelagem e manutenção . . . . . . . . . . . . . . . . 54

6.2 Controle de execução . . . . . . . . . . . . . . . . . . . . 57

6.3 Apoio à recuperação . . . . . . . . . . . . . . . . . . . . . . . . . . . 62

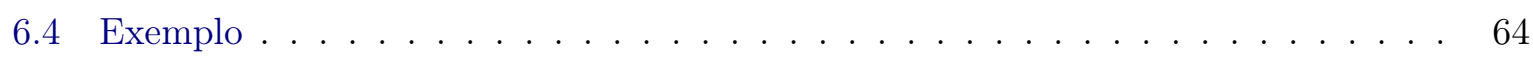

6.4 Modelo . . . . . . . . . . . . . . . . . . . . . . 64

6.4 .2 Execução . . . . . . . . . . . . . . . . . . . 66 66

6.4 .3 Alteração do modelo . . . . . . . . . . . . . . . . . . . . . . . 69

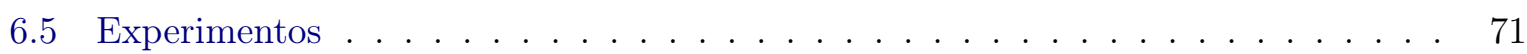

6.5.1 WED-flow de venda de livros . . . . . . . . . . . . . . . . . . 71

6.5 .2 Sequencial versus paralelo . . . . . . . . . . . . . . . . . 73

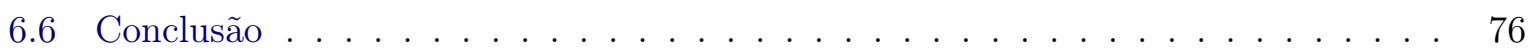

$\begin{array}{lll}7 & \text { Conclusões } & 79\end{array}$

7.1 Contribuições . . . . . . . . . . . . . . . . . . . . . . . . . . 80

7.2 Trabalhos futuros . . . . . . . . . . . . . . . . . . 80

$\begin{array}{lr}\text { A XML Schema } & 83\end{array}$

$\begin{array}{lll}\text { B Exemplos XML } & 91\end{array}$

$\begin{array}{ll}\text { C Classes associadas a WED-transitions } & 97\end{array}$

$\begin{array}{ll}\text { Referências Bibliográficas } & 99\end{array}$ 


\section{Lista de Abreviaturas}

$\begin{array}{ll}\text { ACID } & \text { Atomicidade, Consistência, Isolamento e Durabilidade } \\ \text { ACP } & \text { Algebra of Communicating Processes } \\ \text { ATS } & \text { Estados de Terminação Aceitos (do inglês Accepted Termination States) } \\ \text { AWIC } & \text { Application-Wide Integrity Constraint } \\ \text { BAM } & \text { Monitoramento de Atividades de Negócio (do inglês Business Activity Monitoring) } \\ \text { BD } & \text { Banco de Dados } \\ \text { BPA } & \text { Álgebra de Processos Básica (do inglês Basic Process Algebra) } \\ \text { BPEL4WS } & \text { Business Process Execution Language for Web Services } \\ \text { BPMN } & \text { Business Process Model and Notation } \\ \text { CCS } & \text { Calculus of Communicating Systems } \\ \text { CSP } & \text { Communicating Sequential Processes } \\ \text { ECA } & \text { Evento-Condição-Ação } \\ \text { ER } & \text { Entidade-Relacionamento } \\ \text { GPN } & \text { Gerenciamento de Processos de Negócio } \\ \text { LLT } & \text { Transações Longas (do inglês Long Lived Transaction) } \\ \text { LTL } & \text { Lógica Linear Temporal (do inglês Linear Temporal Logic) } \\ \text { OASIS } & \text { Organization for the Advancement of Structured Information Standards } \\ \text { OMG } & \text { Object Management Group } \\ \text { PN } & \text { Processo de Negócio } \\ \text { SGBD } & \text { Sistema Gerenciador de Banco de Dados } \\ \text { SGWf } & \text { Sistema de Gerenciamento de Workflows } \\ \text { STS } & \text { Conjunto de Estados de Terminação (do inglês Set of Termination States) } \\ \text { STR } & \text { Sistema de Transições Rotuladas (do inglês Labelled Transition System) } \\ \text { TCS } & \text { Composição Transacional de Serviços (do inglês Transactional Composite Service) } \\ \text { W3C } & \text { World Wide Web Consortium } \\ \text { WED-flow } & \text { Work, Event e Data-flow } \\ \text { WfMC } & \text { Workflow Management Coalition } \\ \text { WSFL } & \text { Web Services Flow Language } \\ & \end{array}$




\section{Lista de Figuras}

1.1 Ciclo de vida de um processo de negócio (Adaptada de [Wes12] e [vdAtHW03]). . 2

2.1 Grafo de processo da venda de um livro. . . . . . . . . . . . . . . . . . . 8

2.2 Rede de Petri do processo de venda de um livro. . . . . . . . . . . . . . . 10

2.3 Elementos da BPMN. . . . . . . . . . . . . . . . . . . . . . . . . . 17

2.4 Elementos da BPMN com comportamento específico. . . . . . . . . . . . 18

2.5 Exemplo de venda de livro em BPMN . . . . . . . . . . . . . . . . . 18

3.1 Exemplo de representação gráfica para o modelo de restrição resposta. . . . . . 26

3.2 Exemplo utilizando Declare. (Fonte:[vdAP06]) . . . . . . . . . . . . . . 27

4.1 Possíveis estados de um processo $P_{i}$. Fonte: $[\mathrm{SABS02}] \ldots \ldots \ldots$

4.2 Diagrama de transição de estados para serviços compensáveis. . . . . . . . . . . 37

5.1 Representação da composição dos elementos básicos de um WED-flow. . . . . . . 43

5.2 Entidades participantes do processo de venda de um livro. Linhas verticais tracejadas representam o procedimento de normalização. . . . . . . . . . . . . . . . 47

5.3 WED-states para o exemplo de venda de um livro. . . . . . . . . . . . . . 48

5.4 WED-states - Aborto da venda do livro. . . . . . . . . . . . . . . . . . . 49

5.5 Diagrama que ilustra o WED-flow para venda de livros. . . . . . . . . . . 50

6.1 Módulos da ferramenta WED-tool . . . . . . . . . . . . . . . 54

6.2 Diagrama entidade-relacionamento do sistema WED-tool . . . . . . . . . . . . . 54

6.3 Relações do BD associadas ao processo de negócio. . . . . . . . . . . . . 55

6.4 Relações do BD criadas para apoiar a execução do processo. . . . . . . . . . . . . 55

6.5 Exemplo de consulta contínua . . . . . . . . . . . . . . . 58

6.6 Exemplo da execução de WED-transitions em uma instância de WED-flow. . . . 60

6.7 Exemplo de atualização do estado atual de uma instância de WED-flow. . . . . . 60

6.8 Exemplo de disparo indevido de transição. . . . . . . . . . . . . . . . . . . . . 61

6.9 Exemplo de ocorrência de conflito de escrita. . . . . . . . . . . . . . 63

6.10 Relação de WED-conditions. . . . . . . . . . . . . . . . . . . . . . 65

6.11 Relação de WED-transitions. . . . . . . . . . . . . . . . . . . . 65

6.12 Relação de WED-flows. . . . . . . . . . . . . . . . . . . . . . 65

6.13 Relação de WED-triggers. . . . . . . . . . . . . . . . . . . . . . . 65 
6.14 Relação de instâncias de WED-flows. . . . . . . . . . . . . . . . . . . 66

6.15 Execução da instância 1. . . . . . . . . . . . . . . . . . . . . 67

6.16 Execução da instância 2. . . . . . . . . . . . . . . . . . . 67

6.17 Execução da instância $3 \ldots \ldots$. . . . . . . . . . . . . . . 67

6.18 Execução da instância 4. . . . . . . . . . . . . . . . . . . . . 68

6.19 Execução da instância 5. . . . . . . . . . . . . . . . . . . . 68

6.20 Relação de WED-states. . . . . . . . . . . . . . . . . . . . . . . . 69

6.21 Relação de histórico de execução de transições. . . . . . . . . . . . . . . . . . . 69

6.22 Relação de interrupções. . . . . . . . . . . . . . . . . . . . . . . . . . 69

6.23 Diagrama que ilustra o WED-flow para venda de livros depois da alteração. . . . 70

6.24 Gráfico do tempo de execução de instâncias para o exemplo de venda de livros. $\quad 72$

6.25 Gráfico do tempo de execução de instâncias para o exemplo de venda de livros. $\quad 72$

6.26 Modelo 1: WED-flow com transições sequenciais. . . . . . . . . . . . . . . . 73

6.27 Modelo 2: WED-flow com transições em paralelo. . . . . . . . . . . . . . . . . 73

6.28 Gráfico do tempo médio de execução de uma instância de WED-flow. . . . . . . . . 74

6.29 Gráfico do tempo total para a execução de um conjunto de instâncias de WED-flow. 74

6.30 Gráfico do tempo de criação e execução de instâncias. . . . . . . . . . . . . . . . 75 


\section{Lista de Códigos-fonte}

2.1 Estrutura básica simplificada da especificação de um processo em WS-BPEL . . . 14

2.2 Exemplo simplificado do corpo de um processo em WS-BPEL . . . . . . . . . . . 16

3.1 Exemplo de trigger no PostgreSQL (Adaptado de [Gro]) . . . . . . . . . . . . . 23

3.2 Exemplo de evento em XML ao qual um programa XChange reage (Adaptado de

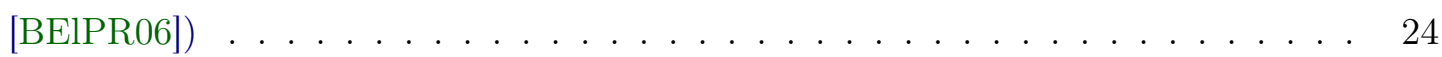

3.3 Exemplo de regra ECA utilizando XChange (Adaptado de [BElPR06]) . . . . . . 24

6.1 Trecho de XML contendo a especificação da WED-transition "t_exemplo". . . . . 56

6.2 Exemplo de classe associada a uma WED-transition. . . . . . . . . . . . . . 56

A.1 XML Schema para modelo WED-flow. . . . . . . . . . . . . . . . 83

A.2 XML Schema para alteração em modelo WED-flow. . . . . . . . . . . . . . . 87

B.1 Arquivo XML com a especificação do modelo WED-flow de venda de livros. . . . 91

B.2 Arquivo XML com a especificação para alteração do modelo WED-flow de venda de livros. . . . . . . . . . . . . . . . . . . . . . . . . . 94

C.1 Classes associadas a WED-transitions do WED-flow de venda de livros. . . . . . 97 


\section{Capítulo 1}

\section{Introdução}

Um processo de negócio (PN) é um conjunto de uma ou mais atividades que coletivamente realizam um objetivo de negócio [WfM99]. Os PNs usualmente são de longa duração e envolvem diversos usuários e ferramentas em ambientes heterogêneos e distribuídos. É importante ressaltar que processos de negócio não são limitados à área de negócio, aparecendo também na academia, órgãos governamentais e muitas outras organizações.

Embora alguns autores utilizem o termo workflow como sinônimo para o conceito de processo de negócio [BN09], neste trabalho, consideraremos as definições propostas pelo consórcio WfMC (Workflow Management Coalition) [WfM99]:

- Workflow é "a automação de um processo de negócio, no todo ou em parte, durante a qual documentos, informações ou tarefas são passadas de um participante ao outro por ações, de acordo com um conjunto de regras procedurais".

- Sistema de Gerenciamento de Workflows (SGWf) é "um sistema que define, cria e gerencia a execução de workflows por meio do uso de software, executado em uma ou mais máquinas, que está apto a interpretar a definição do processo, interagir com os participantes e, quando necessário, solicitar o uso de ferramentas de TI e aplicações" .

Tanto a definição de workflow como a de SGWf enfatizam a execução de processos. A implementação e execução de processos de negócio baseiam-se e dependem da definição do mesmo em forma de um processo operacional, o qual corresponde ao conjunto de atividades que compõem o processo e às relações existentes entre elas [Wes12]. Processos operacionais são especificados por meio de modelos de processos de negócio e estes são utilizados pelos SGWfs para realizar o controle da execução dos processos projetados.

Embora a execução do PN seja de extrema importância, a área de gerenciamento de processos de negócio apresenta um escopo mais amplo e também engloba outras fases relacionadas ao ciclo de vida de um processo de negócio. Aalst, Hofstede e Weske [vdAtHW03] definem o Gerenciamento de Processos de Negócio (GPN) como "apoio aos processos de negócio utilizando 
métodos, técnicas e software para projeto, execução, controle e análise de processos operacionais que envolvem pessoas, organizações, aplicações, documentos e outras fontes de informação".

\subsection{Ciclo de vida de processos de negócios}

A base do GPN é a definição do processo de negócio, contendo as atividades que o compõe e as restrições de execução entre elas. Uma vez definido, o processo de negócio pode ser analisado, melhorado e executado. O ciclo de vida de um processo de negócio é formado por quatro fases que relacionam-se entre si, retratadas na Figura 1.1, a qual foi adaptada de [Wes12] e [vdAtHW03].

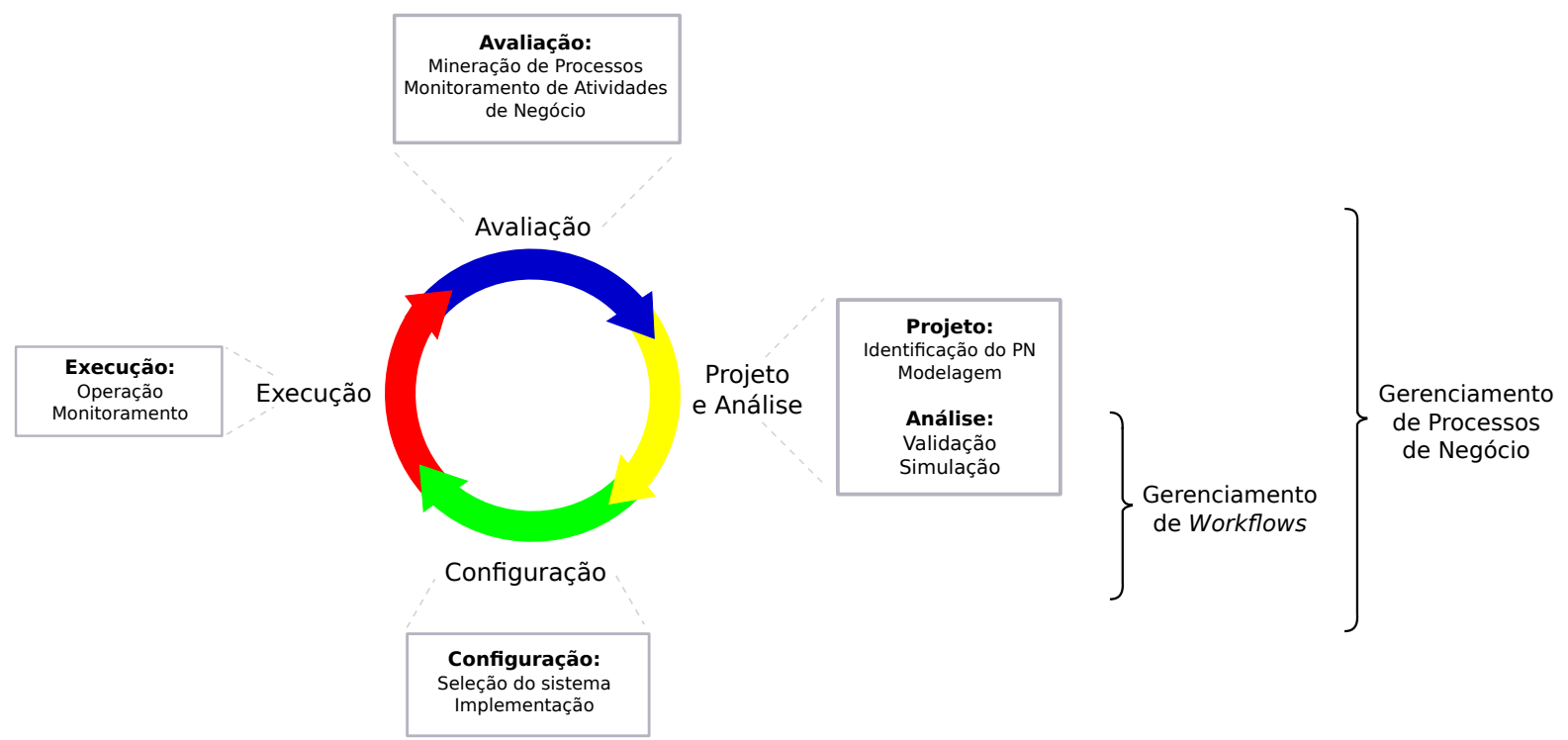

Figura 1.1: Ciclo de vida de um processo de negócio (Adaptada de [Wes12] e [vdAtHW03]).

A fase de projeto envolve a identificação das atividades que compõem o PN, assim como das relações temporais e causais entre elas. Com isso, o processo de negócio pode ser modelado, ou seja, é possível especificá-lo e representá-lo por meio de um modelo de processo de negócio utilizando uma linguagem de processo particular [vdAtHW03]. Após o desenvolvimento do modelo inicial do processo de negócio, pode-se analisá-lo e refiná-lo conforme seja necessário.

A modelagem de processos de negócio tem sido estudada durante muitas décadas e uma variedade de abordagens e produtos que atendem essa fase estão disponíveis, apresentando diferentes vantagens e desvantagens. Lu e Sadiq [LS07] afirmam que existem dois tipos de abordagens que têm sido predominantemente usadas para a modelagem de processos de negócio: aquelas que são baseadas em grafos e as baseadas em regras. Utilizando uma abordagem baseada em grafos, a definição do processo de negócio é composta por nós, que representam as atividades pertencentes ao processo, e arcos conectando os nós, que representam o fluxo de controle e as dependências de dados. Em contrapartida, em abordagens baseadas em regras, a lógica do processo é composta por um conjunto de regras que especificam propriedades das atividades que pertencem ao processo, como, por exemplo, precondição para sua execução. 
Uma vez que o modelo do processo de negócio tenha sido projetado, ele precisa ser implementado. Para tanto, a fase de configuração pode ser realizada de diversas maneiras, podendo incluir a escolha e configuração de um sistema de software que apoiará a execução do PN, como, por exemplo, um sistema de gerenciamento de workflows. O sistema precisa ser configurado de acordo com o ambiente organizacional e o processo de negócio cuja execução pretende-se controlar [Wes12].

A configuração de um sistema para gerenciamento de processos de negócio pode também envolver aspectos transacionais. O conceito de transação é vastamente conhecido na área de banco de dados, na qual o Sistema Gerenciador de Banco de Dados (SGBD) é responsável por garantir que a execução de um grupo de operações encapsuladas em uma transação respeite as propriedades ACID: atomicidade, consistência, isolamento e durabilidade. Tradicionalmente, SGWfs não são projetados para garantir propriedades transacionais [AAA+96], porém, alguns modelos transacionais avançados [JK97] almejam flexibilizar tais propriedades e adaptá-las ao contexto de GPN para garantir confiabilidade na execução de processos de negócio. Sendo assim, o conceito de processo transacional corresponde a processos de negócio que respeitam propriedades transacionais de acordo com um modelo particular.

Com o sistema configurado, instâncias do processo de negócio podem ser executadas. Uma instância é a representação de uma execução particular de um processo (ou de uma atividade pertencente ao processo), incluindo os dados associados ao processo (ou à atividade) [WfM99]. Assim, uma instância de um processo de negócio representa um caso concreto das operações realizadas por uma organização, sendo composta por instâncias de atividades [Wes12]. A instanciação de um processo de negócio tradicionalmente é realizada após a ocorrência de um evento, como, por exemplo, um cliente solicita a compra de um livro em uma livraria online. O sistema de gerenciamento de workflows é então responsável por controlar a execução da instância de acordo com o que foi especificado no modelo do processo de negócio.

$\mathrm{Na}$ fase de avaliação, o processo operacional é analisado para identificar problemas e encontrar possíveis melhorias. Registros de execução são avaliados utilizando técnicas de Monitoramento de Atividades de Negócio (BAM, do inglês Business Activity Monitoring) e mineração de processos com objetivo de verificar a qualidade do modelo e também a adequação do ambiente de execução [Wes12].

Como retratado na Figura 1.1, o enfoque do gerenciamento de workflow tradicional e, consequentemente, dos SGWfs está na metade inferior do ciclo de vida do processo de negócio. Consequentemente, os SGWfs atuais oferecem pouco apoio à fase de diagnóstico. Já o GPN inclui também a avaliação do processo, possibilitando a mineração de processos e o monitoramento de atividades de negócio.

Apesar dos significantes avanços e contribuições desenvolvidas nos últimos anos, a área de GPN continua ativa e apresenta diversos desafios à Ciência da Computação. Uma das grandes 
preocupações está na escolha da melhor abordagem para a modelagem, representação e execução de um processo de negócio. Atualmente, organizações possuem processos de negócio com complexas estruturas que são reavaliados e ajustados com frequência, exigindo flexibilidade e apresentando desafios às metodologias clássicas de GPN. Adicionalmente, também é necessário garantir confiabilidade na execução das instâncias do processo de negócio, especialmente em caso de falhas, exigindo que um tratamento de exceções adequado seja fornecido.

\subsection{Objetivos}

Embora diversas abordagens para modelagem e execução de processos de negócio sejam encontrados na literatura, a implementação de um modelo flexível, capaz de expressar estruturas complexas e baseado em propriedades transacionais para garantir confiabilidade na execução permanece como desafio. Entre outros aspectos que devem ser considerados na implementação, podemos destacar corretude na execução de processos de negócio, integridade de instâncias em execuções de atividades paralelas, rastreabilidade de instâncias de processos de negócio, apoio a diversos mecanismos de recuperação capazes de tratar cancelamentos, interrupções no sistema e exceções ocorridas durante a execução de atividades.

Tendo em vista os desafios referentes à implementação de um modelo flexível capaz de garantir confiabilidade na execução de instâncias, a abordagem WED-flow foi recentemente proposta [FTMP10] como um novo conceito para modelagem e execução de processos de negócio. Essa abordagem tem como principal objetivo adaptar e estender conceitos e algoritmos projetados para modelos transacionais para reduzir a complexidade no tratamento de exceções em workflows.

O objetivo principal deste trabalho é explorar os fundamentos da abordagem WED-flow e desenvolver o núcleo de uma ferramenta de software para controle de processos de negócio transacionais baseado nessa nova abordagem. Com o estudo da abordagem e implementação da ferramenta, almejamos a evolução da abordagem WED-flow por meio do aprimorando de seus fundamentos e desenvolvimento de novos conceitos, além de mostrar sua viabilidade prática. $\mathrm{O}$ software implementado é capaz de controlar a execução de processos transacionais e também fornecer a estrutura necessária para apoiar o desenvolvimento de mecanismos de recuperação e permitir a evolução incremental de modelos de processos de negócio.

\subsection{Contribuições}

A principal contribuição deste trabalho é a implementação do núcleo da ferramenta de software WED-tool. Para realização do desenvolvimento dessa ferramenta, podemos destacar as seguintes contribuições específicas:

- Aprimoramento de fundamentos e desenvolvimento de conceitos que compõem a abordagem WED-flow; 
- Tradução de modelos WED-flow para a linguagem XML e desenvolvimento de um XML Schema que descreve a estrutura do modelo;

- Implementação de uma ferramenta de software para controle processos de negócio transacionais modelados como WED-flows;

- Testes para avaliação inicial do desempenho da implementação desenvolvida.

A implementação desenvolvida foi objeto de duas publicações: um artigo [GBPF12] publicado no Journal of Information and Data Management e apresentado na $27^{\circ}$ edição do Simpósio Brasileiro de Banco de Dados e um artigo [GSBF12] publicado e apresentado na seção de demos do mesmo simpósio.

\subsection{Organização do trabalho}

Nos primeiros capítulos são apresentados conceitos e abordagens referentes à área de gerenciamento de processos de negócio. Enquanto o Capítulo 2 apresenta fundamentos e abordagens relacionados às linguagens para modelagem de processos baseadas em grafos, o Capítulo 3 aborda as linguagens baseadas em regras. Já o Capítulo 4 descreve fundamentos de transações e modelos que ressaltam a importância dos dados em um processo. Os Capítulos 5 e 6 apresentam o conteúdo referente ao objetivo principal deste trabalho. No Capítulo 5 exibimos um releitura da abordagem WED-flow, descrevendo em detalhes os fundamentos da mesma, e apresentamos um exemplo de processo de negócio modelado por meio da abordagem apresentada. O Capítulo 6 apresenta a WED-tool, detalhando a implementação considerada a principal contribuição deste trabalho. Adicionalmente, o Capítulo 6 descreve como o exemplo de processo de negócio apresentado no capítulo anterior foi implementado por meio do arcabouço desenvolvido e também apresenta testes iniciais para avaliação do desempenho da ferramenta. Finalmente, o Capítulo 7 conclui o trabalho. 


\section{Capítulo 2}

\section{Modelagem baseada em grafos}

Linguagens para modelagem de processos de negócio baseadas em grafos são amplamente utilizadas, principalmente devido à legibilidade. Tais linguagens utilizam elementos gráficos para especificar a definição do processo, como nós que representam os passos que compõem o processo e arcos que, conectando os nós, representam o controle de fluxo e a dependência dos dados. Dessa maneira, a definição do processo de negócio é feita de maneira precisa por meio da especificação explícita de todos os possíveis caminhos de execução, utilizando uma linguagem visual e intuitiva que pode ser entendida até por profissionais com pouco ou nenhum conhecimento técnico [LS07].

Neste capítulo introduziremos brevemente os fundamentos da teoria dos processos e discutiremos linguagens para modelagem de processos de negócio baseadas em grafos. A abordagem com base em grafos corresponde ao padrão industrial atual e é tradicionalmente utilizada por diversos sistemas de gerenciamento de processos de negócio [LS07].

\subsection{Teoria dos processos}

O comportamento de um sistema geralmente é composto por processos e dados. Enquanto processos são dinâmicos e ativos, os dados são estáticos e passivos, sendo manipulados pelos processos [Fok07]. Uma maneira de representar esse comportamento é a utilização de um Sistema de Transições Rotuladas (STR).

Um STR é basicamente formado por um conjunto de nós, chamados estados, e um conjunto de arestas rotuladas que representam as transições. Uma transição é definida pela tripla $\left(s, a, s^{\prime}\right)$, na qual $s$ e $s^{\prime}$ são estados e $a$ pertence a um conjunto de ações. Cada tripla pode ser denotada por $s \stackrel{a}{\rightarrow} s^{\prime}$ e indica que um estado $s$ pode passar a $s^{\prime}$ quando a ação $a$ for executada.

Um grafo de processo é um STR no qual um estado é selecionado para ser a raiz, ou seja, o estado inicial do processo. O conjunto de estados corresponde aos possíveis estados do sistema, enquanto as ações são as atividades disponíveis para execução.

Para a ilustrar o conceito de processo e também de grafo de processo, utilizaremos o exemplo da venda de um livro. O processo inicia quando um cliente realiza um pedido. Logo depois, a 
livraria inicia a validação do pedido analisando os dados informados. Se os dados são inválidos, o processo é abortado. Caso contrário, após a validação, o livro é reservado e, então, o pagamento já pode ser processado. Caso o pagamento seja recusado, uma notificação é enviada ao cliente e, posteriormente, o processamento do pagamento pode ser refeito. A notificação e o processamento podem ser executados repetidas vezes e, caso o pagamento não ocorra após o limite de tentativas ser excedido, a venda é abortada e o processo termina. Se o pagamento for realizado, o livro é enviado, os pontos do programa de fidelidade são contabilizados e o cliente notificado sobre o envio. As duas últimas atividades podem ser executadas em paralelo, ou seja, ao mesmo tempo ou em qualquer ordem. Após a execução de ambas, o pedido é fechado, alcançando seu estado final.

O conjunto de ações referentes ao processo descrito anteriormente é definido por $A=\left\{a_{1}, a_{2}, a_{3}\right.$, $\left.a_{4}, a_{5}, a_{6}, a_{7}, a_{8}\right\}$ e cada ação é identificada a seguir:

- $a_{1}$ : validar dados dos pedido;

- $a_{2}$ : reservar produto;

- $a_{3}$ : processar pagamento;

- $a_{4}$ : enviar produto;

- $a_{5}$ : atualizar programa fidelidade;

- $a_{6}$ : emitir notificação de envio;

- $a_{7}$ : fechar pedido;

- $a_{8}$ : emitir notificação sobre recusa de pagamento;

- $a_{9}$ : abortar venda.

O grafo de processo da venda de um livro é exibido na Figura 2.1.

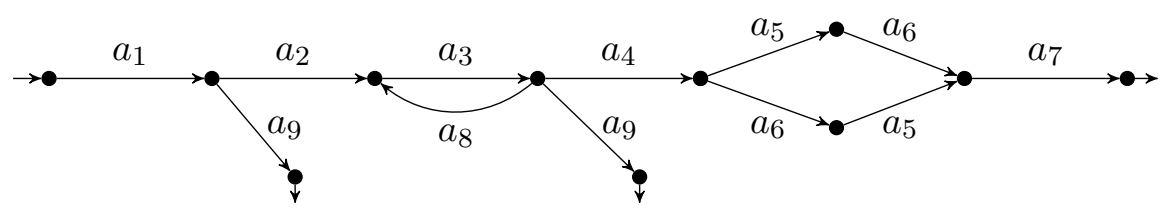

Figura 2.1: Grafo de processo da venda de um livro.

\section{$2.2 \quad$ Abordagens formais}

Algumas técnicas de modelagem de workflow são baseadas em arcabouços formais, como redes de Petri e Álgebra de Processos. O uso de conceitos formais possui grandes vantagens, 
sendo a precisão na definição do processo a mais valorizada [vdAvH04]. Em contraste às técnicas informais, a definição formal previne ambiguidades, incertezas e contradições. O formalismo ainda permite o uso de diferentes técnicas de análise, como de desempenho e verificação de propriedades lógicas.

\subsubsection{Redes de Petri}

O conceito de redes de Petri foi introduzido em 1962, por Carl Adam Petri, como uma ferramenta para modelar e analisar processos. Embora uma de suas grandes vantagens seja a representação gráfica de fácil compreensão, essa técnica se diferencia das outras por possuir forte base matemática e ser inteiramente formalizada [vdAvH04].

Graças à sólida base formal, é possível realizar a análise do sistema modelado, incluindo verificação de propriedades inerentes aos sistemas concorrentes, como relação de precedência entre eventos, sincronização e avaliação da existência de deadlocks. Há diversas técnicas e ferramentas disponíveis para análise de redes de Petri.

Uma rede de Petri é um tipo particular de grafo dirigido, bipartido, que é formado basicamente por dois componentes: lugares e transições. Esses dois elementos são os vértices do grafo associado à rede de Petri, no qual os lugares são representados por círculos e as transições por retângulos. Murata [Mur02] descreve uma rede de Petri como a quíntupla $R P=\left(P, T, F, W, M_{0}\right)$, na qual:

- $P=\left\{p_{1}, p_{2}, \ldots, p_{m}\right\}$ é um conjunto finito de lugares;

- $T=\left\{t_{1}, t_{2}, \ldots, t_{n}\right\}$ é um conjunto finito de transições;

- $F \subseteq(P \times T) \cup(T \times P)$ é um conjunto de arcos;

- $W: F \rightarrow\{1,2,3, \ldots\}$ é a função peso;

- $M_{0}: P \rightarrow\{0,1,2,3, \ldots\}$ é a marcação inicial;

- $P \cap T=\emptyset$;

- $P \cup T \neq \emptyset$

O lugar pode ser interpretado como o componente passivo da rede, geralmente associado ao estado do sistema ou alguma pré ou pós-condição. Esse elemento modela uma condição que deve ser satisfeita para que o disparo de uma ação seja realizado. Já a transição é o componente ativo correspondente a alguma ação, tarefa ou evento do sistema.

Lugares e transições são conectados por meio de arcos dirigidos. Da definição de rede de Petri, arcos que ligam lugares a outros lugares ou transições a outras transições não são permitidos. Cada arco possui um peso associado a ele, representado pela função $W$. Quando não há um valor explicitamente indicado no grafo, considera-se que o peso do arco é um. 
Com base nos arcos, é definido o lugar de entrada de uma transição: um lugar $p$ é um lugar de entrada para a transição $t$ se, e somente se, há um arco dirigido de $p$ para $t$. Analogamente, um lugar $p$ é um lugar de saída de uma transição $t$ se, e somente se, há um arco dirigido de $t$ para $p[\mathrm{vdAvH04]}$.

Os lugares podem conter fichas (ou marcas) que são representadas por pontos pretos e correspondem aos recursos disponíveis. Embora a estrutura de uma rede de Petri seja fixa, a distribuição das fichas entre os lugares varia, permitindo a modelagem do comportamento dinâmico da rede. O posicionamento das fichas na rede é determinado por uma marcação que atribui a cada lugar $p$ um número inteiro não negativo que corresponde ao número de fichas que o lugar contém. Concretamente, uma marcação $M$ é um vetor de tamanho $m$, no qual $m$ é o número de lugares da rede de Petri. O valor do elemento $i$ do vetor $M$ corresponde ao número de fichas que o lugar $i$ contém. A marcação de uma rede de Petri determina o estado da mesma e a marcação inicial, $M_{0}$, presente na definição da rede, representa o estado inicial.

O comportamento de um sistema pode ser descrito em termos de estados de sistema e suas alterações. A mudança de estado de uma rede de Petri ocorre por meio do disparo de transições (execução da ações), que segue as seguintes regras [Mur02]:

- Uma transição $t$ está ativa se cada lugar de entrada $i$ de $t$ contém pelo menos $w(i, t)$ marcas, sendo $w(i, t)$ o peso do arco de $i$ a $t$.

- Uma transição ativa pode ou não ser disparada.

- O disparo de uma transição ativa remove $w(i, t)$ marcas de cada lugar de entrada $i$ de $t$ e adiciona $w(t, o)$ marcas a cada lugar de saída $o$ de $t$, sendo $w(t, o)$ o peso do arco de $t$ a $o$.

As redes de Petri foram estendidas de diversas formas e aplicadas a vários tipos de problemas. Essas extensões são as bases formais mais utilizadas para especificação de workflows. Para exemplificar a modelagem de processos com redes de Petri, utilizaremos o exemplo da Seção 2.1.

A Figura 2.2 apresenta a rede de Petri referente ao exemplo da venda de um livro. Nela, a transição $t_{i}$ corresponde à atividade $a_{i}$, para $1 \leq i \leq 8$. Já as transições $t_{9}$ e $t_{9}^{\prime}$ correspondem à atividade $a_{9}$.

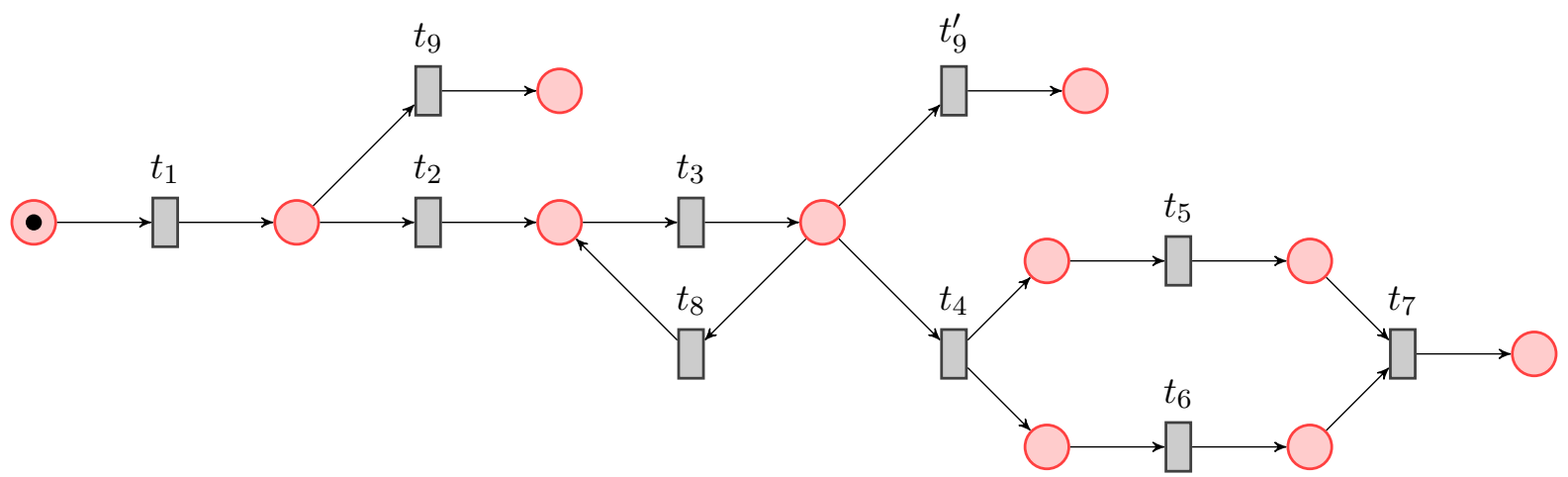

Figura 2.2: Rede de Petri do processo de venda de um livro. 


\subsection{2 Álgebra de processos}

Embora a álgebra de processos não seja uma abordagem baseada em grafos, ela foi desenvolvida para expressar grafos, descritos em sistemas de transições rotuladas, algebricamente, melhorando as técnicas de manipulação por meio da lógica equacional e reescrita de termos. Oferecendo um arcabouço para raciocínio formal sobre processos e dados, ela pode ser utilizada para detectar propriedades indesejáveis e formalmente derivar propriedades desejáveis de uma especificação de sistema [Fok07].

As bases da álgebra de processos foram desenvolvidas, independentemente, por Milner e Hoare. Milner desenvolveu a álgebra de processos CCS (Calculus of Communicating Systems) [Mil99], enquanto Hoare definiu a CSP (Communicating Sequential Processes) [Hoa78]. A álgebra de processos descrita neste trabalho é a ACP (Algebra of Communicating Processes) [BPS01], a qual está relacionada à CCS.

Uma álgebra de processos é composta por um conjunto de símbolos de ações (ou eventos), um conjunto de operações e um conjunto de axiomas descrevendo as propriedades dos operadores. As definições, regras de transição e axiomas a seguir foram retirados de [Fok07].

A assinatura de uma álgebra de processos é composta por:

- Um conjunto finito e não vazio $A$ de ações atômicas, representando comportamentos indivisíveis;

- Um operador binário + , chamado de composição alternativa. Se dois termos fechados (ou seja, termos que não contêm variáveis) $t_{1}$ e $t_{2}$ representam respectivamente processos $p_{1} \mathrm{e}$ $p_{2}$, então o termo fechado $t_{1}+t_{2}$ representa o processo que executa $p_{1}$ ou $p_{2}$;

- Um operador binário ·, chamado de composição sequencial. Se dois termos fechados $t_{1}$ e $t_{2}$ representam respectivamente processos $p_{1}$ e $p_{2}$, então o termo fechado $t_{1} \cdot t_{2}$ representa o processo que executa primeiro $p_{1}$ e depois $p_{2}$.

Cada processo finito pode ser representado por um termo fechado construído a partir do conjunto $A$ de ações atômicas, do operador + e do operador $\cdot$. Tais termos são denominados termos básicos de processo e a coleção de todos esses termos recebe o nome de Álgebra de Processos Básica (BPA, do inglês Basic Process Algebra).

A semântica operacional de uma linguagem descreve como uma sentença válida da linguagem deve ser interpretada em passos sequenciais. As regras de transição que constituem a semântica operacional da BPA são descritas na Tabela 2.1. Nelas, as variáveis $x, x^{\prime}, y$ e $y^{\prime}$ podem assumir qualquer valor da coleção de termos básicos de processos, enquanto $v$ corresponde a valores do conjunto $A$ de ações atômicas. 


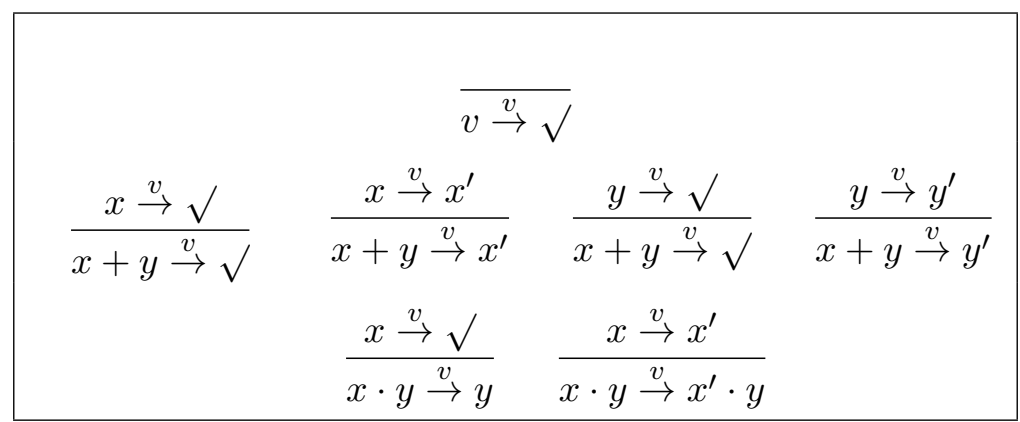

Tabela 2.1: Regras de transição da BPA

A regra de transição da primeira linha da Tabela 2.1 diz que cada ação atômica $v$ pode terminar com sucesso pela execução dela própria. As quatro regras seguintes, na segunda linha, expressam que $t+t^{\prime}$ executa $t$ ou $t^{\prime}$. As duas regras restantes, na última linha, expressam que $t \cdot t^{\prime}$ executa $t$ até que este seja terminado com sucesso e, após isso, inicia a execução de $t^{\prime}$.

Na Tabela 2.2 são exibidos os axiomas referentes à álgebra de processos básica.

\begin{tabular}{rrrr}
\hline$A_{1}$ & $x+y$ & $=y+x$ \\
$A_{2}$ & & $(x+y)+z$ & $=x+(y+z)$ \\
$A_{3}$ & $x+x$ & $=x$ \\
$A_{4}$ & & $(x+y) \cdot z$ & $=x \cdot z+y \cdot z$ \\
$A_{5}$ & & $(x . y) \cdot z$ & $=x \cdot(y . z)$ \\
\hline
\end{tabular}

Tabela 2.2: Axiomas para BPA

A maioria das álgebras de processos contém outros operadores e, para ilustrar como modelar o processo de venda de um livro exibido na Seção 2.1, utilizaremos também o operador binário "||" chamado entrelaçamento, introduzido por Milner [Mil82]. O termo $s \| t$ indica que os termos de processos $s$ e $t$ serão executados em paralelo. As regras de transição da Tabela 2.3 formalizam o comportamento do operador entrelaçamento.

$$
\begin{array}{cc}
\frac{x \stackrel{v}{\rightarrow} \sqrt{ }}{x \| y \stackrel{v}{\rightarrow} y} & \frac{x \stackrel{v}{\rightarrow} x^{\prime}}{x\left\|y \stackrel{v}{\rightarrow} x^{\prime}\right\| y} \\
\frac{y \stackrel{v}{\rightarrow} \sqrt{ }}{x \| y \stackrel{v}{\rightarrow} x} & \frac{y \stackrel{v}{\rightarrow} y^{\prime}}{x\|y \stackrel{v}{\rightarrow} x\| y^{\prime}}
\end{array}
$$

Tabela 2.3: Regras de transição para o operador entrelaçamento. 
Considerando o conjunto $A$ de atividades e o grafo de processo (Figura 2.1) é possível notar que a verificação do pagamento e o envio de notificação para o cliente podem ser executados repetidas vezes. Para representar este comportamento em álgebra de processos, o processo é dividido em subprocessos definidos por expressões recursivas. Assim, obtém-se a expressão algébrica $A P$ para o processo de venda de um livro:

$$
\begin{gathered}
A P=a_{1} \cdot\left(a_{9}+a_{2} \cdot a_{3} \cdot V\right) \\
V=a_{4} \cdot\left(a_{5} \| a_{6}\right) \cdot a_{7}+\left(a_{8} \cdot a_{3} \cdot V\right)+a_{9}
\end{gathered}
$$

Como descrito anteriormente, a álgebra de processos é um arcabouço para modelagem e verificação de sistemas concorrentes. Com o objetivo de implementar o controle de processos de negócio em um modelo relacional de dados foi definida a Navigation Plan Definition Language (NPDL) [Bra06]. A NPDL contém os operadores mais comuns da álgebra de processos e também define operadores adicionais que modelam comportamentos frequentes em processos de workflow.

A NPDL promove uma separação explícita entre o ambiente de especificação e o ambiente de execução de um workflow. Ela foi implementada como uma extensão da linguagem SQL e a execução dos passos que definem o workflow é controlada pela ferramenta NPTool (NavigationPlanTool) [BFP09].

\section{$2.3 \quad$ WS-BPEL}

BPEL4WS (Business Process Execution Language for Web Services) é uma linguagem baseada na WSFL (Web Services Flow Language) [L+01] da IBM e na XLANG [xla] da Microsoft, combinando as características de uma linguagem estruturada em blocos, herdadas da XLANG, com as correspondentes a grafos dirigidos, originadas da WSFL [WvdADtH02].

Em 2003, a versão 1.1 da linguagem foi enviada para a OASIS (Organization for the Advancement of Structured Information Standards) [oas] para uniformização e, em 2007, o comitê publicou o documento [Sta] que define a linguagem Web Services Business Process Execution Language, de abreviatura WS-BPEL. Embora o nome tenha sido alterado, a linguagem é comumente referida apenas como BPEL.

\subsubsection{Serviços $W e b$}

Segundo o W3C (World Wide Web Consortium) [w3c], um serviço é um recurso abstrato que é capaz de executar tarefas que formam uma funcionalidade coerente do ponto de vista dos fornecedores e solicitantes. Ainda de acordo com o W3C, um serviço Web é um sistema de software projetado para apoiar a interoperabilidade entre máquinas via uma rede. Outros sistemas interagem com um serviço Web por meio de mensagens, seguindo a especificação de sua interface. A disponibilização de serviços na Internet possibilita a reutilização dos mesmos e a 
criação de novas funcionalidades por meio da combinação de diversos serviços. A combinação de um conjunto de serviços Web visando atingir um objetivo específico é chamada de composição de serviços $\boldsymbol{W e}$ [WvdADtH02].

Entre as maneiras existentes para compor processos de negócio por meio de serviços Web, destacamos o conceito de orquestração. De acordo com o W3C, "uma orquestração define a sequência e condições em que um serviço $W e b$ invoca outros serviços Web a fim de realizar uma função útil" [w3c]. Em uma composição de serviços Web em forma de orquestração há um participante mestre intitulado orquestrador, o qual contém a lógica do processo de negócio e centraliza o controle da execução da composição, sendo responsável pela coordenação da atuação dos demais participantes.

\subsubsection{Web Services Business Process Execution Language}

A WS-BPEL é uma linguagem para especificar a orquestração de processos de negócio compostos por serviços Web. A principal função da linguagem concentra-se na implementação de processos, especificando a ordem de execução das atividades que constituem um processo, os participantes envolvidos no mesmo, as mensagens trocadas entre eles e o tratamento de falhas e exceções. Para tanto, a especificação de um processo de negócio em WS-BPEL é composta de quatro seções principais, descritas a seguir [Sta].

- Participantes: Definição dos diferentes serviços participantes que interagem com o processo BPEL durante toda sua execução.

- Variáveis: Seção que define as variáveis de dados utilizados pelo processo de negócio. As variáveis em um processo BPEL são utilizadas para armazenar, reformatar e transformar mensagens enviadas aos participantes e recebidas dos mesmos. As definições são feitas em termos de tipos de mensagem WSDL, elementos ou tipos simples de XML Schema.

- Tratadores de falhas: Definição das atividades que devem ser executadas em resposta às falhas resultantes da invocação de serviços de avaliação e de aprovação.

- Lógica de orquestração: Contém o corpo principal do processo com a descrição do comportamento normal do mesmo. Essa seção especifica a ordem na qual os participantes da composição são invocados.

O código 2.1 exibe a estrutura básica simplificada da especificação de um processo utilizando WS-BPEL, a qual é composta pelas quatro seções descritas acima.

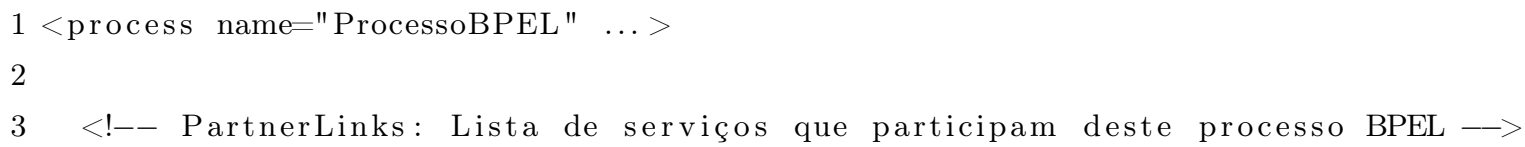




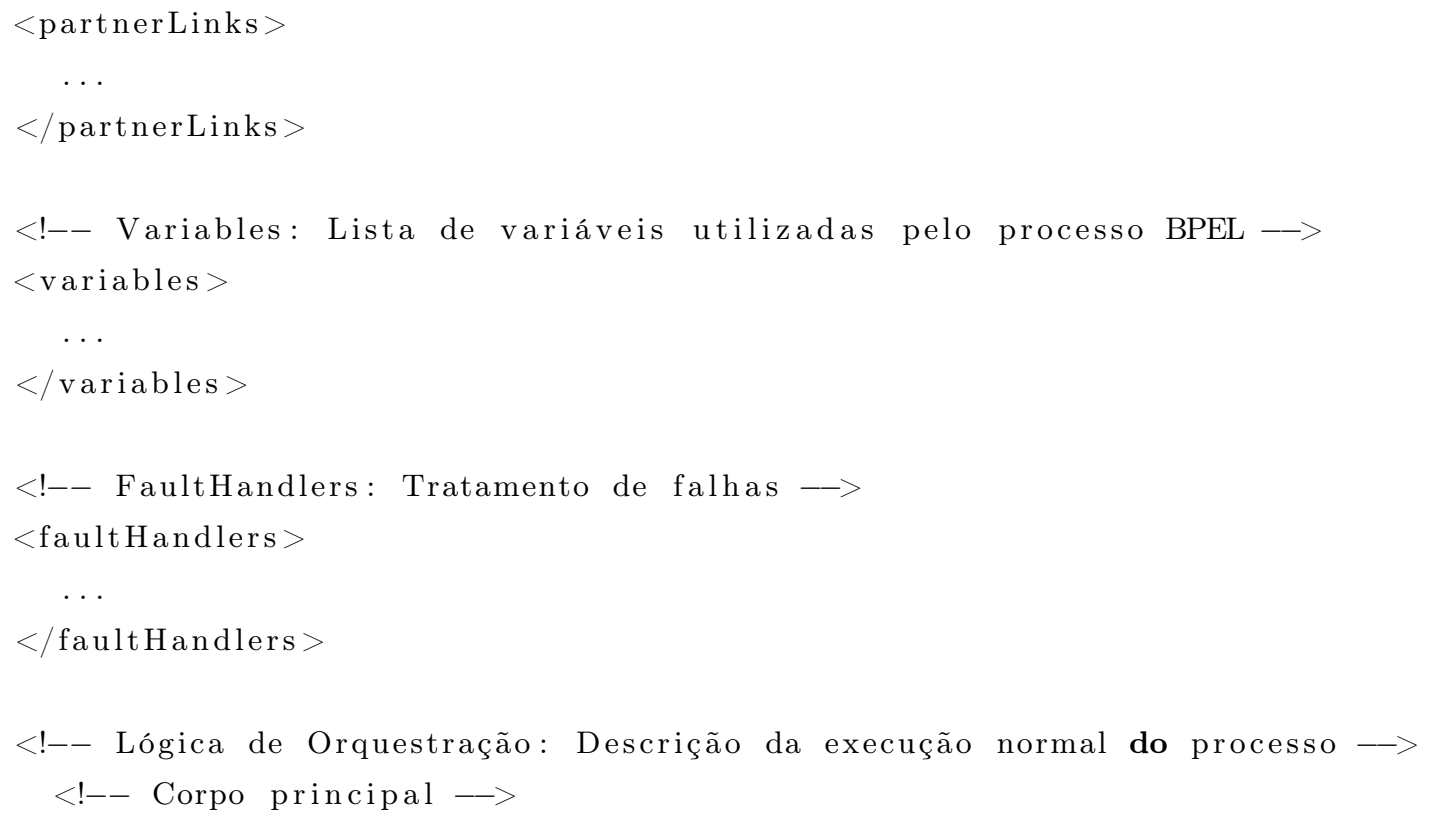

Código-fonte 2.1: Estrutura básica simplificada da especificação de um processo em WS-BPEL

A lógica de orquestração é definida no corpo principal do processo, no qual cada elemento é chamado de atividade. Cada atividade dentro de um processo pode ser primitiva ou estruturada. Enquanto as atividades referentes ao primeiro tipo são aquelas usadas para executar alguma operação, as atividades estruturadas são utilizadas para agrupar atividades básicas dentro de algumas estruturas de fluxo.

O conjunto de atividades primitivas contém as seguintes atividades:

- invoke: invoca uma operação em algum serviço Web;

- receive: espera uma mensagem de uma fonte externa;

- reply: responde para uma fonte externa;

- wait: aguarda por algum tempo;

- assign: copia dados de um lugar para outro;

- throw: indica erros na execução;

- terminate: finaliza a instância.

Para possibilitar estruturas de processo complexas, o grupo de atividades estruturadas contém, entre outros: while, para laços; flow, para execução paralela; sequence, para execução sequencial e switch, para especificar comportamento condicional. Atividades estruturadas podem ser agrupadas e combinadas de forma arbitrária, favorecendo a expressividade da linguagem. 
O Código 2.2 retrata um trecho simplificado do corpo de um processo BPEL para o exemplo de compra de livro, destacando como o fluxo de controle deve ser especificado. Nesse trecho, após a execução do serviço de envio do livro, os serviços referentes à atualização de estoque e à emissão de notificação de envio são invocados em paralelo (por meio da atividade flow) e, após o término de ambos, a execução do serviço para fechamento do pedido é solicitada.

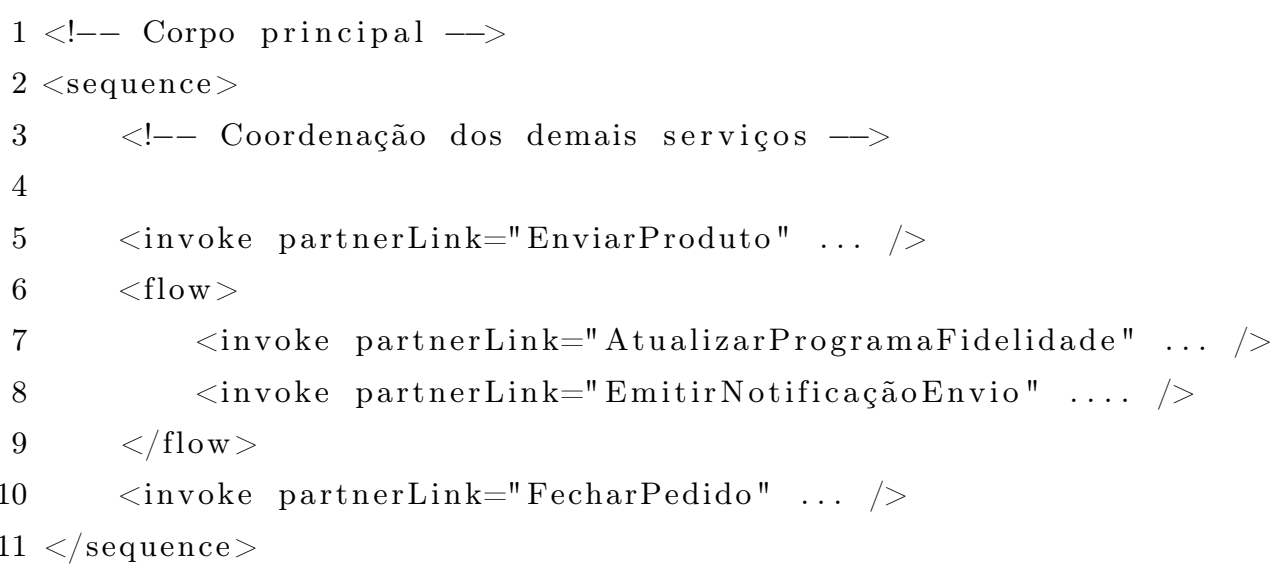

Código-fonte 2.2: Exemplo simplificado do corpo de um processo em WS-BPEL

Linguagens orientadas à programação, como a WS-BPEL, são expressivas e fornecem maior flexibilidade para a implementação de processos de negócio. Em particular, por ser responsabilidade de um comitê apoiado por vários participantes da indústria de TI, a WS-BPEL é utilizada por um número significativo de ferramentas (tanto proprietários como de código aberto). Adicionalmente, a linguagem é baseada em XML, portável e independente de plataforma.

A poderosa expressividade da linguagem pode ser interpretada como uma característica favorável, porém ela também é responsável por gerar sérios desafios à verificação formal [FTMP10]. Embora existam pesquisas acerca da verificação por meio do mapeamento da WS-BPEL em arcabouços formais, a verificação de modelos ainda é uma desvantagem das abordagens orientadas a linguagens de programação.

\subsection{BPMN}

Nos últimos anos, esforços foram aplicados no desenvolvimento de linguagens de execução para sistemas de gerenciamento de processos, como a WS-BPEL, descrita na seção anterior. O elemento principal dessas linguagens é a otimização para execução e interoperação de SGWfs, limitando o apoio a outras fases do GPN e dificultando a utilização das mesmas na modelagem e monitoramento de processos negócios.

A Business Process Model and Notation (BPMN) [OMG11] é um padrão desenvolvido pelo Object Management Group (OMG) para modelagem de processos de negócio. O principal objetivo da BPMN é fornecer uma notação que é facilmente compreensível por todos os usuários 
envolvidos no negócio, incluindo analistas que criam os primeiros rascunhos do processo, técnicos responsáveis pela implementação da tecnologia que irá executá-lo e os profissionais da área de negócios que irão gerenciar e monitorar os processos. Assim, a BPMN cria uma forma padronizada para expressar processos de negócio, auxiliando a implementação dos mesmos.

Com o objetivo de facilitar a modelagem e o entendimento do diagrama, os elementos que compõem a BPMN foram separados em cinco categorias básicas: objetos de fluxo, dados, objetos de conexão, swimlanes e artefatos. A categoria dos objetos de fluxo é composta pelos principais elementos gráficos para definição do comportamento de um processo de negócio e existem três variações presentes: eventos, atividades e gateways. Esses elementos são conectados por meio do objeto fluxo de sequência, presente na categoria objetos de conexão.

As definições de evento, atividade, gateway e fluxo de sequência são apresentadas a seguir, de acordo com o documento de especificação da BPMN [OMG11].

- Evento: Um evento é algo que acontece durante o curso de um processo. Os eventos afetam o fluxo do modelo e usualmente possuem uma causa ou um efeito. Há três tipos de eventos, de acordo com o momento em que ocorrem: evento de início, evento intermediário e evento de fim.

- Atividade: Uma atividade é um termo genérico que representa o trabalho que uma empresa realiza. Ela pode ser atômica ou composta e existem dois tipos: subprocesso e tarefa.

- Gateway: Um gateway é utilizado para controlar divergências e convergências do fluxo em um processo. Assim, esse elemento determina ramificação, sincronização e união de caminhos.

- Fluxo de sequência: Um fluxo de sequência é um objeto de conexão utilizado para indicar a ordem em que as atividades serão executadas em um processo. Cada fluxo possui apenas uma fonte e um destino.

A Figura 2.3 retrata a notação gráfica utilizada pela BPMN para eventos, atividades, gateways e fluxos de sequência.

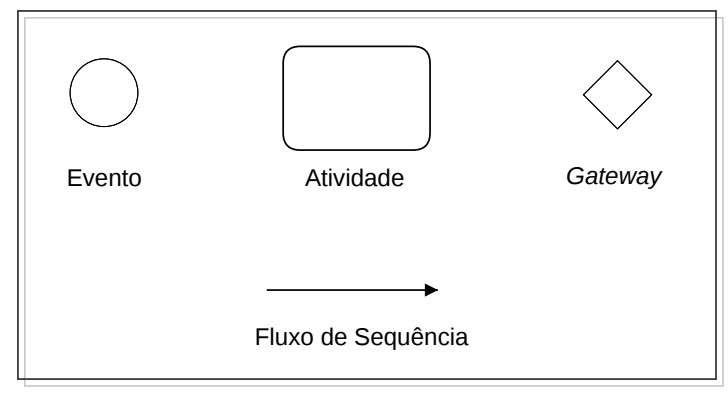

Figura 2.3: Elementos da BPMN. 
Embora os elementos acima sejam a base para projetar o fluxo de controle, existem diversas maneiras de detalhar o comportamento de um processo de negócio utilizando outros símbolos, todos descritos no documento publicado pela OMG [OMG11]. A Figura 2.4 exibe alguns elementos frequentemente utilizados na modelagem de processos de negócio e que serão utilizados no exemplo de venda de livros.

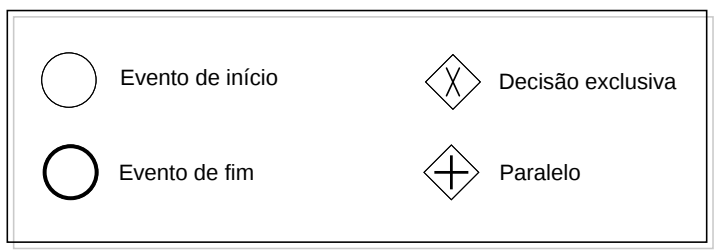

Figura 2.4: Elementos da BPMN com comportamento específico.

Eventos de início indicam onde um processo irá começar e eventos de fim indicam onde um caminho do processo irá terminar. Os gateways podem receber marcas internas que especificam o comportamento do gateway que está sendo utilizado. O gateway "decisão de exclusiva" é utilizado para criar (divergência) e unir (convergência) caminhos alternativos no fluxo do processo e o gateway "paralelo" é utilizado para criar (divergência) e sincronizar (convergência) fluxos paralelos.

A Figura 2.5 retrata o exemplo de processo de negócio de venda de livros modelado em BPMN. O evento inicial está associado à solicitação de compra por parte do cliente. A marca de um envelope indica que algum participante do processo de negócio precisa enviar uma mensagem para disparar a execução do processo. Nesse exemplo, também são usados o evento de fim e os gateways "decisão de exclusiva" e "paralelo", descritos anteriormente.

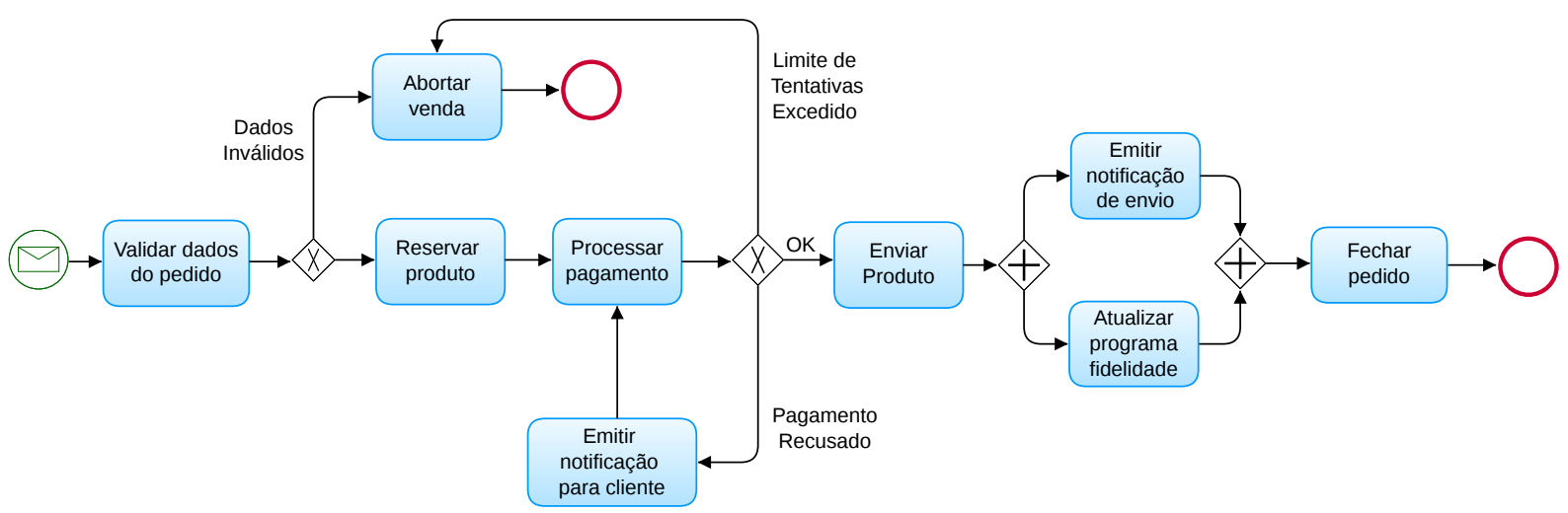

Figura 2.5: Exemplo de venda de livro em BPMN. 


\subsection{Conclusão}

Neste capítulo abordamos linguagens para modelagem de processos de negócio baseadas em grafos. Essas linguagens são amplamente utilizadas por SGWfs principalmente devido à legibilidade decorrente do uso de elementos gráficos. Por meio das linguagens de modelagem baseadas em grafos, a estrutura do processo do negócio é especificada de maneira precisa em modelos que descrevem explicitamente todos os possíveis caminhos de execução do PN.

Algumas técnicas de modelagem de processos de negócio são baseadas em arcabouços formais, como as redes de Petri. Além de apresentar representação gráfica de fácil compreensão, as redes de Petri possuem forte base matemática e são inteiramente formalizadas. A definição formal de um processo permite a utilização de diversas técnicas de análise do modelo projetado, possibilitando a deteç̧ão de propriedades indesejáveis.

As abordagens baseadas em grafos são tradicionalmente utilizadas e correspondem ao padrão industrial atual. Na Seção 2.3 abordamos conceitos relacionados a serviços Web e também descrevemos a linguagem de execução WS-BPEL, utilizada para especificar a orquestração de processos de negócio compostos por serviços Web. A WS-BPEL, que combina características de linguagens estruturadas em blocos e linguagens baseadas em grafos dirigidos, é de responsabilidade do comitê OASIS, o qual é formado e apoiado por participante da indústria de TI, como IBM e Microsoft. Já a Seção 2.4 aborda o padrão BPMN, desenvolvido pela OMG com o objetivo de criar uma forma padronizada de fácil compreensão para expressar processos de negócio, auxiliando a implementação dos mesmos. 


\section{Capítulo 3}

\section{Modelagem baseada em regras}

Atualmente, com um mercado global e competitivo, empresas precisam ajustar seus processos de negócio de forma adequada e oportuna. Com isso, a flexibilidade das abordagens tornou-se um importante tópico de pesquisa na área de GPN. A característica rígida das linguagens baseadas em grafos dificulta a alteração do processo de negócio, comprometendo a evolução do modelo projetado. Já em abordagens baseadas em regras, a lógica do processo é representada por um conjunto de regras [LS07], as quais descrevem as dependências estruturais, de dados e/ou recursos existentes entre as atividades pertencentes a um processo de negócio. Dessa maneira, o modelo não é estaticamente definido; o conjunto de regras é responsável por controlar o comportamento da execução das instâncias do PN.

Cada regra de um modelo é associada a uma ou mais atividades de negócio, especificando propriedades das mesmas, por exemplo, precondições para a execução da atividade. Assim, em tempo de execução, o sistema examina os dados da instância, avalia as condições e determina a ordenação da execução das atividades de acordo com as regras pré-definidas.

Neste capítulo, serão discutidas linguagens baseadas em regras para modelagem de processos de negócio, destacando principalmente a característica flexível que elas apresentam. Na Seção 3.1 descrevemos as regras Evento-Condição-Ação, utilizadas como fundamento para este trabalho, e também como elas podem ser aplicadas a processos de negócio. Já a Seção 3.2 descreve o SGWf Declare, abordando a modelagem e execução de PNs por meio desse sistema.

\subsection{Regras Evento-Condição-Ação}

Tradicionalmente, bancos de dados são utilizados como repositórios que armazenam informações que são utilizadas por uma aplicação. Os sistemas de gerenciamento de banco de dados respondem a comandos (por exemplo consultas, inserções, atualizações) executados por um usuário ou uma aplicação, sendo então, considerados passivos. Entretanto, como algumas situações críticas exigem respostas rápidas, os bancos de dados ativos adicionaram um comportamento ativo aos SGBDs [DBM88] por meio de regras compostas por três elementos: um evento, uma 
condição e uma ação (ECA). Uma regra ECA básica possui a seguinte sintaxe [LS07]:

\section{QUANDO evento SE condição ENTÃO ação}

O evento descreve um acontecimento e a condição examina o contexto em que esse acontecimento ocorreu. Já a ação descreve uma tarefa que deve ser executada caso a condição seja verdadeira. Em outras palavras, o significado da sintaxe de uma regra ECA é: quando o evento ocorrer, verifique a condição e, se for verdadeira, execute a ação [DGe95]. Características dos três elementos que compõem uma regra ECA foram extraídas de [DHW94] [DGe95] e sumariadas a seguir.

\section{- Evento}

Os eventos mais comuns em banco de dados ativos são referentes a modificações realizadas nos dados contidos no banco, como inserção de uma nova tupla, atualização de um atributo ou deleção de uma tupla existente. Entretanto, alguns sistemas também permitem que regras sejam executadas a partir de outros tipos de eventos, como os temporais, sejam eles absolutos (e.g., dia 23 de novembro de 2012 às 17h), relativos (e.g., 10 dias após um outro acontecimento) ou periódicos (e.g., todo sábado).

\section{- Condição}

A condição especifica um predicado ou uma consulta sobre os dados contidos no banco. A condição é dita satisfeita caso o predicado seja verdadeiro ou a consulta produza resultado diferente de vazio. Uma condição pode referir-se a atributos utilizados na descrição do evento e também a valores presentes antes e depois da ocorrência do evento.

\section{- Ação}

A ação é uma sequência de operações, as quais podem ser operações no banco de dados ou requisições externas a aplicações. Para sua execução, a ação pode utilizar os dados recuperados pela consulta referente à condição e também referir-se aos argumentos utilizados no evento.

Uma vez que todas as regras tenham sido definidas, o sistema de banco de dados deve monitorar os eventos relevantes. Quando é detectado a ocorrência de um evento relevante, o sistema notifica o componente responsável pela execução de regras. A execução de uma regra ECA corresponde à verificação da condição e, quando esta for satisfeita, execução da ação [DGe95].

Em SGBDs com mecanismos que possibilitam a implementação de regras ECA, essas regras são frequentemente chamadas de triggers [DGe95]. O Código 3.1 exemplifica como um trigger, nomeado "verificar_atualizacao", é criado no SGBD PostgreSQL. O evento associado ao exemplo refere-se a atualizações na relação "contas". A regra determina que, antes de uma tupla ser atualizada, se o valor do atributo "valor_final" for alterado de fato, a função "verifica_atualizacao_da_conta" deve ser executada [Gro]. 


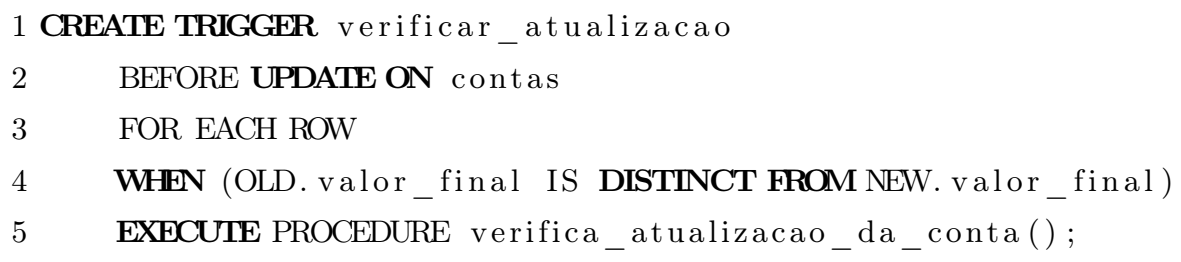

Código-fonte 3.1: Exemplo de trigger no PostgreSQL (Adaptado de [Gro])

\subsubsection{Regras ECA aplicadas a processos de negócio}

Na década de 90, sistemas de banco de dados ativos com mecanismos de regras ECA foram utilizados para coordenar a execução de tarefas em SGWfs [LS07]. Desde então, o paradigma ECA tem servido como fundamento para diversas linguagens de modelagem de processos de negócio baseadas em regras. Bry et al. [BElPR06] defendem que regras ECA oferecem uma abordagem flexível, adaptável e modular para a realização de processos de negócios. Dentre as características inerentes às regras ECA que facilitam a modelagem e execução de PNs, destacamos algumas a seguir.

- Requisitos de um processo de negócio são frequentemente descritos em forma de regras. Por exemplo, uma solicitação de cartão de crédito (evento) será aceita (ação) se o requerente possuir renda maior que $\mathrm{R} \$ 1500$ (condição).

- Regras ECA tem natureza flexível: elas são de fácil adaptação e alteração, conforme a necessidade de modificação nos requisitos do processos de negócio. Além disso, muitos sistemas permitem que regras sejam adicionadas, modificadas ou removidas sem a interrupção dos processos em execução.

- Erros e situações excepcionais podem ser descritos como eventos especiais. Assim, regras ECA permitem que exceções sejam tratadas como situações normais.

Bry et al. [BElPR06] também mostram a utilização da linguagem XChange para realização de processos de negócio. A XChange é uma linguagem baseada em regras ECA que segue uma abordagem declarativa para prover comportamento reativo na Web [xch]. Um programa XChange é mantido em um website e contém um conjunto de regras, as quais têm forma consulta de evento - consulta de condição - ação.

Eventos são representados como mensagens XML que são enviadas a programas XChange. Na ocorrência de um evento (i.e., uma mensagem XML representando um evento é recebida), o programa XChange age de acordo com as especificações das regras que o compõem. Para cada regra do conjunto, o evento é consultado pela consulta de evento, ou seja, essa consulta é executada sobre os dados referentes ao evento, contidos na mensagem XML. Além disso, a consulta de condição é realizada sobre os dados persistidos em algum recurso Web descrito na 
regra. Caso ambas as consultas devolvam resultados não vazios, a ação associada e especificada na regra é executada [xch]. Uma ação pode realizar atualizações no recurso Web (por meio de operações insert, delete, replace-by) ou gerar um novo evento (i.e., enviar uma mensagem para um outro programa XChange) [BElPR06].

O Código 3.2 em XML exemplifica um evento de solicitação de compra de um livro. A regra ECA descrita na linguagem XChange no Código 3.3 descreve como o programa deve reagir a esse evento. A regra é composta por três partes, associadas às palavras-chave ON, FROM e DO. O trecho após ON define a consulta de evento, a consulta de condição é especificada no trecho após FROM e a ação é descrita após DO. Nesse exemplo, a regra verifica se o cliente associado à mensagem recebida não está registrado na base de dados, representada pelo recurso Web. Se não estiver, executa a operação de inserção de um novo registro.

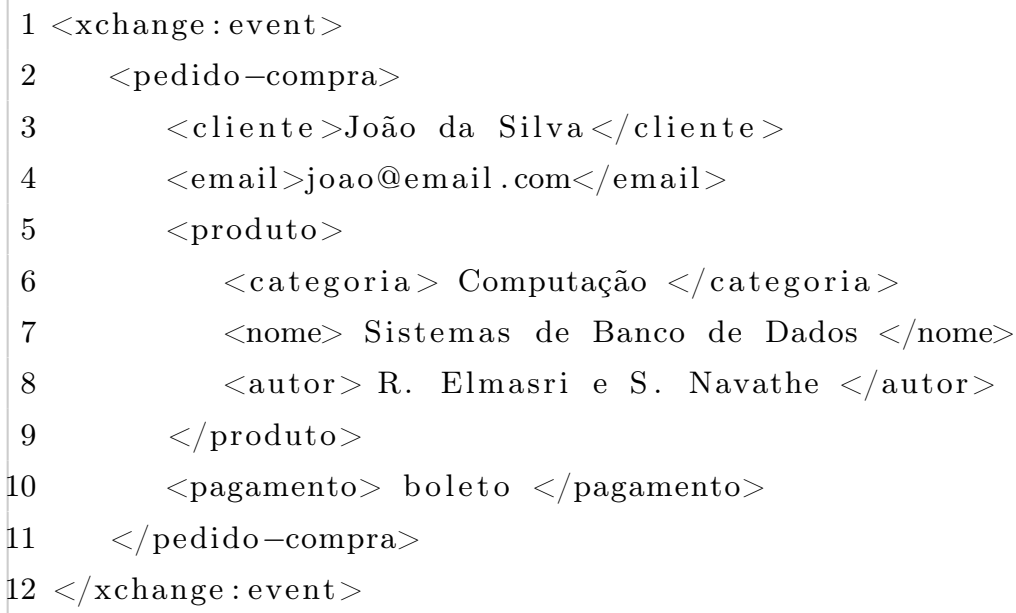

Código-fonte 3.2: Exemplo de evento em XML ao qual um programa XChange reage (Adaptado de [BElPR06])

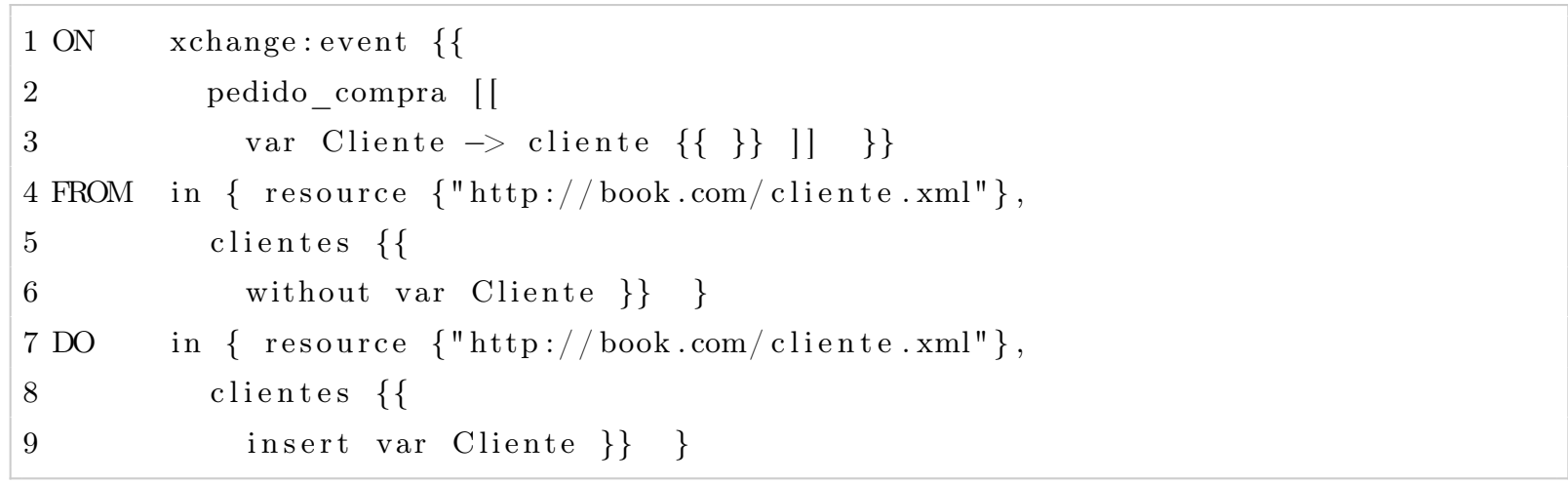

Código-fonte 3.3: Exemplo de regra ECA utilizando XChange (Adaptado de [BElPR06])

A linguagem XChange é rica e, seguindo o formato de regra consulta de evento - consulta de condição - ação e os conceitos associados a cada elemento, é possível expressar estruturas de controle de processos de negócio, como execução sequencial de atividades, execução paralela, sincronização e execução alternativa [BElPR06]. 


\section{$3.2 \quad$ Declare}

Sistemas de gerenciamento de workflows clássicos controlam a execução de instâncias de processos de negócio, sendo capazes de evitar execuções incorretas. Entretanto, para tanto, dependem da estruturação explícita dos processos e, por essa razão, apresentam dificuldade para atender alterações realizadas no modelo do PN. Considerando SGWfs restritivos para processos que requerem flexibilidade, Aalst et al. [vdAPS09] propõem uma abordagem declarativa baseada em restrições para balancear a necessidade de controle adequado de execução e de flexibilidade.

Utilizando a abordagem declarativa baseada em restrições, o modelo de um processo de negócio é visto como uma coleção de regras, com caráter restritivo, que implicitamente controlam o comportamento da execução do processo do negócio. Ao invés de definir em qual ordem as atividades devem ser executadas, a abordagem segue a ideia de que "tudo é possível desde que não tenha sido explicitamente proibido". Ou seja, qualquer ordenação de atividades que não viole as restrições definidas é permitida. Dessa maneira, não é necessário definir todos os possíveis caminhos de execução do processo de negócio. A partir das regras que restringem a execução, diversos caminhos são implicitamente determinados.

Declare é um SGWf baseado em restrições, o qual possui um núcleo formado por três componentes: Designer, Framework e Worklist. O primeiro componente é utilizado para criar modelos de restrições, projetar modelos de processos de negócio e verificar esses modelos. A execução de instâncias do modelo projetado é realizada pelo componente Framework. Cada usuário utiliza seu componente Worklist para acessar as instâncias ativas. Detalhes sobre a modelagem e execução de processos utilizando o Declare foram apresentados em [vdAPS07] e [vdAPS09], a partir dos quais sumarizamos os principais fundamentos.

\subsubsection{Modelagem}

O Declare utiliza um conjunto arbitrário de modelos de restrições personalizáveis. Esses modelos são criados no componente Designer e descrevem dependências entre as atividades pertencentes ao processo. Cada modelo de restrição possui um nome único, uma representação gráfica e uma especificação formal de sua semântica utilizando Lógica Linear Temporal (LTL, do inglês Linear Temporal Logic) [GH01]. LTL é um tipo especial de lógica que, além dos operadores lógicos clássicos, também possui operadores temporais como: sempre $(\square)$, eventualmente $(\diamond)$, até $(\sqcup)$ e próxima vez (o). Utilizando os modelos de restrições, usuários não precisam ter conhecimento avançado de LTL para utilizar o sistema, pois eles podem trabalhar apenas com a representação gráfica.

Um modelo de restrição pode ser visto como uma regra que descreve uma relação entre atividades genéricas. Na expressão LTL de um modelo, parâmetros são utilizados para descrever a relação desejada. Por exemplo, o modelo de restrição nomeado resposta é definido pela fórmula 
LTL $\square(A \Rightarrow \diamond(B))$, utilizando os parâmetros $A$ e $B$. A especificação formal de resposta indica que toda execução da atividade $A$ é eventualmente seguida por pelo menos uma execução da atividade $B$. A Figura 3.1 exibe uma representação gráfica para esse modelo.

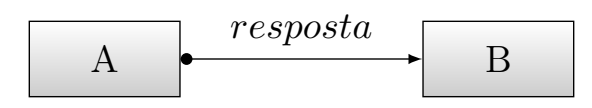

Figura 3.1: Exemplo de representação gráfica para o modelo de restrição resposta.

Uma vez definido no sistema, um modelo de restrição pode ser reutilizado para especificar restrições em diversos modelos de PNs. Na fase de modelagem do processo de negócio, cada restrição é criada substituindo os parâmetros (e.g., $A$ e $B$ ) de um definido modelo de restrição por atividades reais. Além disso, o projetista também deve especificar se a regra criada é uma restrição obrigatória ou opcional no contexto do PN associado.

\subsubsection{Execução do processo}

Após a modelagem do processo em forma de um conjunto restrições, o modelo é carregado no componente Framework do SGWf. Com isso, o processo modelado pode ser instanciado e o sistema controlará a execução das instâncias. As atividades pertencentes às instâncias podem ser executadas pelos usuários por meio de suas respectivas Worklists. O controle de execução das instâncias é realizado por meio da habilitação e execução de atividades, que é direcionado pelas restrições: tudo que não viola as restrições obrigatórias está habilitado para execução e todas as restrições obrigatórias devem ser satisfeitas no final da execução da instância.

Para uma instância ativa, cada restrição está em um dos três estados: satisfeita, temporariamente violada ou violada. Enquanto o estado "violado" indica que não é possível satisfazer a restrição, o estado "temporariamente violado" indica que ainda é possível satisfazer a regra por meio da execução de atividades apropriadas. Para controlar os estados das restrições em uma instância ativa e impedir a violação das restrições obrigatórias, o Declare constrói e mantém um autômato para cada restrição, o qual é gerado a partir da expressão em LTL [GH01].

Adicionalmente, para cada instância ativa, o sistema também cria um autômato para a conjunção das fórmulas LTL que definem as restrições, o qual possui diversas funções. Por meio do autômato da instância, é possível:

- Dirigir a execução da instância: a execução de uma atividade dispara transições no autômato, causando a mudança de estado;

- Determinar quais atividades estão habilitadas: apenas atividades que podem ser disparadas a partir do estado atual do autômato estão habilitadas para execução; 
- Determinar o estado da instância: se o estado atual do autômato é um estado final, a instância está satisfeita. Caso contrário, ela está temporariamente violada.

\subsubsection{Exemplo}

Os autores mostram em [vdAP06] um exemplo de um pequeno processo com três atividades modelado utilizando restrições, retratado na Figura 3.2a. O modelo é composto pelas tarefas abençoar, amaldiçoar e rezar e pela restrição resposta entre as duas últimas. As três atividades podem ser executadas um número arbitrário de vezes e a restrição resposta especifica que, toda vez que uma pessoa amaldiçoa, ela deve eventualmente rezar depois disso.

Para esse modelo, o autômato exibido na Figura 3.2b é criado. O autômato é composto de dois estados $\left(q_{1}\right.$ e $\left.q_{2}\right)$ e três tipos de transição. O estado $q_{1}$ é o inicial e o único de aceitação. A transição com rótulo rezar é aplicada quando a atividade de mesmo nome é executada, a transição verdadeiro refere-se a execução de qualquer atividade do processo e a transição !amaldiçoar é aplicada quando abençoar ou rezar são executadas. A partir da criação de um autômato como esse para cada instância do processo, como explicado anteriormente, é possível controlar a execução da mesma.

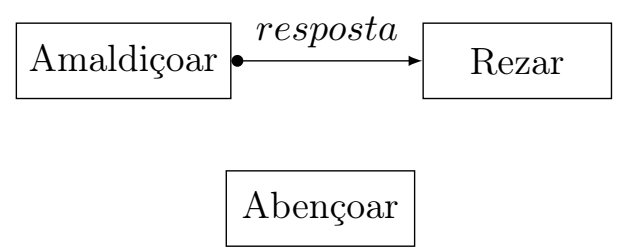

(a) Modelo

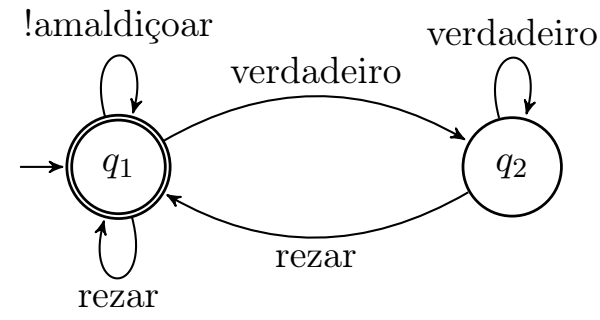

(b) Autômato da instância

Figura 3.2: Exemplo utilizando Declare. (Fonte:[vdAP06])

Embora o sistema Declare mostre que é possível haver um balanço entre o controle adequado e a flexibilidade, os autores advertem que a implementação apresenta problemas de desempenho para tratar especificações extensas de processos de negócio. A eficiência do SGWfs é comprometida devido à complexidade das técnicas de verificação de modelo utilizadas, referentes ao mapeamento das restrições em autômatos, os quais precisam ser mantidos pelo sistema.

\subsection{Conclusão}

Neste capítulo abordamos linguagens para modelagem de processos de negócio baseadas em regras. Em contraste à abordagem clássica baseada em grafos, essas linguagens não exigem que todos os possíveis caminhos de execução do processo de negócio seja explicitamente definidos. Visto que atualmente processos de negócio são modificados com frequência, muitos SGWfs clássicos são considerados rígidos e restritivos já que apresentam problemas para atender alterações 
realizadas no modelo do PN e dificultam a evolução do mesmo.

Utilizando abordagens baseadas em regras, a especificação do processo de negócio é realizada por meio da definição de um conjunto de regras responsáveis por controlar o comportamento do processo. Na Seção 3.1 discutimos as regras ECA que têm sido utilizadas como fundamento para muitas linguagens baseadas em regras. Uma regra ECA determina que, na ocorrência de um evento, uma condição deve ser avaliada e, caso satisfeita, uma ação deve ser executada. A natureza flexível dessas regras permite que elas sejam facilmente alteradas e, além disso, o conjunto de regras que define o PN também pode ser modificado com facilidade, favorecendo a evolução incremental do modelo projetado.

Na Seção 3.2 discutimos o SGWf Declare proposto com o intuito de balancear a necessidade de controle adequado de execução e de flexibilidade. No sistema apresentado, um PN é definido como um conjunto de restrições que determinam que "tudo é possível desde que não tenha sido explicitamente proibido". Uma restrição é descrita por meio de uma expressão lógica e a implementação apresentada baseia-se no mapeamento dessas expressões em autômatos para controlar a execução de instâncias do processo. Embora a solução proposta forneça flexibilidade, a eficiência da implementação é comprometida devido à complexidade das técnicas de verificação de modelo referentes ao mapeamento de regras em autômatos. 


\section{Capítulo 4}

\section{Processos transacionais}

Abordagens clássicas de gerenciamento de processos de negócio possuem dificuldade no tratamento de exceções. Embora sistemas atuais sejam capazes de controlar processos adequadamente, os SGWfs não possuem a capacidade de garantir a corretude e a confiabilidade da execução do workflow na presença de concorrência e falhas de atividades [AAA $\left.{ }^{+} 96\right]$ [BGG $\left.{ }^{+} 11\right]$. Não há apoio significativo à recuperação e tratamento de exceções, sendo necessário na maioria dos casos, intervenção de um usuário para solucionar problemas de concorrência ou especificar quais atividades precisam ser recuperadas.

O conceito de transação possui papel fundamental em diversas formas de sistema de informação, incluindo processos de negócio. Em contraste aos modelos e sistemas de gerenciamento de workflow que priorizam a automação de processos de negócio, os modelos transacionais são muitas vezes motivados pelo tratamento de exceções e procedimentos de recuperação em um ambiente concorrente.

Na primeira seção deste capítulo abordaremos o conceito de transação e também discutiremos as propriedades ACID: atomicidade, consistência, isolamento e durabilidade. Nas seções seguintes, discutiremos modelos transacionais que flexibilizam as propriedades ACID convencionais para adaptá-las ao contexto de gerenciamento de processos de negócio, almejando garantir confiabilidade na execução de processos.

\subsection{Transações}

Uma transação é um programa em execução que forma uma unidade lógica de processamento de dados [NE02]. O modelo transacional mais conhecido é o modelo ACID (sigla para atomicidade, consistência, isolamento e durabilidade), o qual é utilizado em sistemas gerenciadores de banco de dados para implementar controle de concorrência, recuperação e aplicação de restrições [Alo05].

No modelo transacional de banco de dados, as transações são vistas como funções que alteram o estado de um banco [Alo05]. O estado de um banco de dados é definido pelos valores 
de todos os itens de dados relevantes em conjunto com parâmetros de sistema do banco. Os estados produzidos pela execução de transações em um ambiente concorrente são garantidamente consistentes.

\subsubsection{Propriedades ACID}

No modelo transacional de banco de dados, uma transação é uma forma de encapsular operações para prover as propriedades ACID: atomicidade, consistência, isolamento e durabilidade. Por meio delas, o modelo é capaz de garantir a consistência do banco. As descrições das propriedades foram retiradas de [Alo05] e são apresentadas a seguir :

- Consistência: garante que uma transação iniciada a partir de um estado consistente, na ausência de concorrência, que é completamente executada sem falhas produz um estado consistente. Essa propriedade é aplicada por meio de restrições de integridade que verificam os valores escritos por um transação e a abortam caso alguma regra seja violada.

- Atomicidade: garante que a transação é executada por inteiro (deixando o banco de dados consistente) ou não é executada (banco de dados permanece no estado consistente inicial). Essa propriedade é aplicada através de mecanismos de recuperação que desfazem transações que precisam ser abortadas.

- Isolamento: garante que transações se comportarão como se estivessem sozinhas no sistema, mesmo que outras transações sejam executadas concorrentemente. Para prover essa propriedade, mecanismos de controle de concorrência determinam uma ordenação particular para a execução das transações.

- Durabilidade: garante que, se uma transação for executada com sucesso, as alterações realizadas por ela não serão perdidas.

Embora as propriedades ACID sejam adequadas no contexto de sistemas de banco de dados convencionais, elas tornam-se demasiadamente rígidas quando tratamos de processos de negócio. Um modelo transacional diferente se faz necessário já que processos descrevem operações mais complexas e variadas que as consideradas em um SGBD. Assim, o conceito de processo transacional corresponde a processos de negócio que respeitam propriedades transacionais de acordo com um modelo transacional particular.

Ao contrário das transações convencionais, processos podem terminar de muitas maneiras diferentes e todas corretas. O processo deve garantir sua consistência, sendo capaz de agir caso um determinado ponto não seja alcançado. Assim, a consistência não é uma propriedade aplicada pelo sistema e sim uma característica de projeto do processo de negócio.

A atomicidade é uma propriedade relevante no contexto de processos transacionais, embora não possua as mesmas características do modelo de banco de dados. No último, para garantir a 
atomicidade de uma transação, deve ser possível desfazê-la caso algum erro ocorra. Assim, antes da transação modificar qualquer dado, uma cópia é realizada para permitir que o estado do banco seja restaurado se a transação precisar ser abortada.

O procedimento de recuperação descrito anteriormente para transações em bancos de dados independe do que foi modificado, ou seja, toda transação segue o mesmo procedimento. Em processos transacionais, não há essa uniformidade. Situações em que o processo como um todo deve ser atômico são raras e, embora o término do processo seja desejado, não necessariamente queremos desfazê-lo por completo em caso de erro, sem deixar vestígios de sua execução [Alo05]. Além disso, o processo pode, por exemplo, retroceder parcialmente sua execução ou escolher um caminho entre diversas possibilidades.

Em diversos domínios, é indesejável que processos sejam isolados, tornando a propriedade de isolamento um obstáculo para o desenvolvimento de aplicações. O isolamento é inapropriado para garantir que um processo seja executado de maneira correta, pois processos de negócio reais interagem de diversos modos. Kot et al. [KGR $\left.{ }^{+} 10\right]$ defendem que a comunidade de banco de dados deve olhar além do isolamento, ressaltando a importância de comunicação e coordenação entre transações.

Finalmente, a durabilidade em processos transacionais refere-se tanto à persistência da execução do processo, sendo capaz de retomar a execução a partir do ponto no qual foi interrompida por uma falha, como aos traços da execução, possibilitando a reconstrução dos passos tomados pelo processo.

\subsection{O modelo Saga}

O modelo Saga é um dos pioneiros no tratamento do que hoje chamamos de processos transacionais [Alo05]. Garcia-Molina e Salem discutem problemas relacionados a Transações Longas (LLT, do inglês Long Lived Transaction), aquelas que possuem execução de longa duração por acessar diversos bancos de dados, ter computações demoradas, pausas para ler a entrada de usuários ou uma combinação desses fatores [GMS87].

O tratamento de transações longas como transações comuns exige que elas sejam executadas de maneira atômica para preservar a consistência do banco de dados. Assim, para garantir as propriedades ACID, o sistema deve bloquear o acesso aos objetos utilizados pela transação enquanto a mesma não é completamente executada, mantendo recursos do banco de dados ocupados por longos períodos de tempo e, consequentemente, atrasando o término de outras transações.

Os autores do modelo Saga defendem que, para algumas aplicações, é possível contornar o problema descrito relaxando a propriedade de atomicidade das transações convencionais e a adaptando ao contexto de transações longas. Dessa maneira, certas LLTs podem liberar os recursos antes do término de sua execução, sem prejudicar a consistência do banco. Isso é possível quando uma transação longa é formada por uma sequência de passos independentes. 
O termo saga refere-se a uma LLT que pode ser decomposta em uma coleção de sub-transações que podem ser intercaladas de qualquer maneira com outras transações [GMS87]. Individualmente, cada sub-transação é uma transação ACID convencional e, em conjunto, elas formam uma unidade que deve ser executada por completo. Sendo assim, qualquer execução parcial de uma saga é indesejável e, se ocorrer, deve ser compensada.

Para corrigir execuções parciais e assegurar a atomicidade de uma LLT, o modelo Saga utiliza o conceito de compensações. Cada transação $T_{i}$ pertencente a uma saga, deve possuir uma ação compensadora, representada pela transação $C_{i}$. A compensação pode assumir diversas formas e deve desfazer a transação do ponto de vista semântico, ou seja, deve compensar ações realizadas por $T_{i}$ e não necessariamente restaurar o banco de dados ao estado original.

Uma vez que passos compensadores $C_{1}, C_{2}, \ldots, C_{n-1}$ foram definidos para a saga formada pelas transações $T_{1}, T_{2}, \ldots, T_{n}$, uma das sequências a seguir será executada:

- Execução completa: $T_{1}, T_{2}, \ldots, T_{n}$

- Compensação: $T_{1}, T_{2}, \ldots, T_{j}, C_{j}, \ldots, C_{2}, C_{1}$, para algum $1<j<n$

Em caso de falhas, os passos compensadores são executados em ordem reversa aos passos normais para garantir que, após a execução de cada compensação, o estado do processo seja semanticamente equivalente ao estado produzido caso o processo tivesse sido executado até aquele ponto.

Conceitualmente, a maior contribuição do modelo Saga para processos transacionais é a noção de compensação associada a cada passo do processo [Alo05].

\subsection{Semi-atomicidade}

Considerando as características dos processos transacionais abordadas na Seção 4.1, Alonso et al. [SABS02] discutem os problemas de atomicidade e isolamento e propõem um modelo único para controle de concorrência e recuperação em processos transacionais. Eles defendem que uma importante vantagem na utilização de processos é tornar a lógica da aplicação explícita, facilitando a evolução e manutenção da mesma.

O modelo de sistema proposto considera uma arquitetura com duas camadas. A camada superior envolve a execução de processos transacionais, como especificados em programas de processo. Um programa de processo é uma coleção estruturada de atividades que correspondem a transações convencionais (que obedecem às propriedades ACID) e são executadas em aplicações transacionais. A camada inferior é formada pelas aplicações transacionais disponíveis e os autores assumem a existência de uma arquitetura convencional de gerenciamento de transações [SABS02].

O modelo Saga impõe uma estrutura que possibilita duas opções de finalização: execução ou compensação completas do processo. No entanto, Alonso et al. [SABS02] defendem que um 
processo pode conter diversas alternativas para finalização com êxito e, adicionalmente, possuir atividades sem retorno. Quando uma atividade sem retorno é executada, o retrocesso do processo torna-se impossível pois não há uma atividade capaz de compensá-la, exigindo que a execução do processo prossiga até o fim. Assim, se houver uma falha em uma atividade após um ponto sem retorno, a execução de tal atividade deve ser retomada ou um caminho diferente deve ser escolhido para finalizar a execução do processo.

Devido às particularidades dos processos, a estrutura imposta pelo modelo Saga é considerada muito rígida. Desse modo, o modelo de transações flexíveis [ZNBB94] propõe o conceito de semi-atomicidade, cuja ideia é estender o modelo Saga com a possibilidade da execução de caminhos alternativos [Alo05]. Baseando-se em extensões do modelo de transações flexíveis, o modelo proposto por Alonso et al.[SABS02] é capaz de garantir a corretude na execução de um único processo. Tal propriedade será discutida a seguir com fundamentos apresentados em [SABS02].

Um programa de processo é formado por um conjunto de atividades parcialmente ordenadas, no qual cada atividade corresponde a uma transação convencional e opera como uma caixa preta, fornecendo apenas um valor de retorno que indica se sua execução finalizou com sucesso ou ocorreu alguma falha. Com base nesse resultado, o gerenciador é capaz de coordenar a execução das atividades pertencentes ao programa de processo e, consequentemente, controlar a execução do mesmo.

Seja $A^{*}$ o conjunto formado por todas as atividades disponíveis no sistema. As atividades em $A^{*}$ diferem em relação à garantia de término e são considerados três casos, baseados no modelo de transações flexíveis [ZNBB94]:

- Compensável: uma atividade $a$ é compensável se existe uma atividade (chamada compensadora) que semanticamente desfaz os efeitos da execução de $a$. Para uma atividade compensável $a \in A^{*}$, a atividade compensadora é denotada por $a^{-1} \in A^{*}$.

- Pivô: uma atividade é um pivô quando ela não é compensável. Uma vez que uma atividade pivô tenha sido executada com sucesso, não é possível retroceder por compensação e, portanto, a execução deve prosseguir.

- "Reexecutável"1: uma atividade é reexecutável quando sua execução, garantidamente, terminará com sucesso após um número finito de invocações.

Além das atividades que formam o conjunto $A^{*}$, existem mais duas atividades com funções especiais: $C$ denota o commit ${ }^{2}$ do processo e $A$ denota seu aborto. Com isso, o conjunto $\hat{A}$ é definido por: $\hat{A}:=A^{*} \cup\{C, A\}$.

\footnotetext{
${ }^{1}$ Palavra adaptada do termo em inglês retriable.

${ }^{2}$ Termo bastante difundido; não será traduzido.
} 


\subsubsection{Programa de processo}

Um programa de processo executa atividades de acordo com o resultado da execução das atividades anteriores. Assim, um programa de processo pode ser visto como uma árvore na qual os nós representam as atividades e as arestas correspondem às restrições de ordenação entre elas. Um caminho na árvore reflete os efeitos de uma possível execução do processo.

Caso um programa de processo permita a execução concorrente de atividades, estas são agrupadas e parcialmente ordenadas em um mesmo nó da árvore ao invés de criar nós distintos. Nós que representam um grupo de atividades são chamados de nó de múltipla atividade e os nós de atividade única são chamados de singleton ${ }^{3}$. Tanto os nós de múltipla atividade como os singleton são totalmente ordenados de acordo com os nós anteriores e subsequentes na árvore. Isto é, se um nó $n_{1}$ precede $n_{2}$, todas as atividades de $n_{1}$ devem terminar antes da execução de qualquer atividade de $n_{2}$. A ordenação definida pela união da ordem induzida pela árvore com as ordens parciais internas aos nós de múltipla atividade é chamada de ordenação forte.

Além da ordenação parcial referente a nós de múltipla atividade, um programa de processo pode solicitar que a execução concorrente das atividades internas a um nó seja equivalente a uma ordenação particular da mesmas. Essa ordenação é chamada de fraca e, quando definida, é responsabilidade dos sistemas subjacentes. Assim, cada nó de múltipla atividade está associado a uma ordenação forte parcial e a uma solicitação de ordenação fraca. Se as atividades estiverem fortemente ordenadas, o programa de processo invocará a execução delas repeitando essa ordenação e, se houver uma ordenação fraca solicitada, os sistemas subjacentes se responsibilizarão pela ordenação necessária.

A estrutura da árvore, gerada de acordo com a ordenação forte das atividades, determina os possíveis caminhos de execução do processo. A primeira atividade não compensável em um caminho partindo da raiz é um pivô primário do processo e este marca um ponto sem retorno. Pivôs devem ser representados como nós de atividade única e, para garantir o término da execução do processo após o commit de uma atividade pivô, deve existir pelo menos um caminho, chamado de término assegurado, que parte do pivô e é composto apenas por atividades reexecutáveis. Assim, após a execução do pivô, é possível tentar diferentes alternativas de caminhos (seguindo os filhos do pivô) e, caso todas falhem, executar o caminho de término assegurado para concluir a execução do processo. Para isso, os filhos de um nó pivô são ordenados de maneira que o último esteja associado ao término assegurado.

As ideias exploradas anteriormente são formalizadas na definição seguinte. Um programa de processo é uma tupla $P P=(N, E \ll,<, P i v, \triangleleft)$, na qual:

- $N$ é um conjunto de nós. Cada nó $n \in N$ é formado por um conjunto $T_{n} \subseteq A^{*}$ de atividades. Se a cardinalidade do conjunto de atividades for 1 , o nó é chamado de singleton. Caso contrário, é chamado de múltipla atividade. Associado a cada nó de múltipla atividade

\footnotetext{
${ }^{3}$ Termo bastante difundido; não será traduzido.
} 
$n \in N$, existem duas ordenações para as atividades correspondentes: ordem parcial forte, $\ll_{n}$, e ordem parcial fraca, $<_{n}$.

- $E$ é um conjunto de arestas dirigidas que, em conjunto com $N$, formam uma árvore. Cada aresta $e=\left(n_{1}, n_{2}\right) \in E$ corresponde a uma restrição de ordenação forte.

- A ordenação forte, «, é a união da ordenação induzida pelas arestas da árvore com as ordens parciais, $\ll_{n}$, com $n \in N$, internas aos nós de múltipla atividade.

- A ordenação fraca, $<$, é a união das ordens parciais fracas, $<_{n}$, com $n \in N$, de todos os nós de múltipla atividade.

- Piv é um conjunto de nós singleton no qual cada nó corresponde a uma atividade não compensável. Os primeiros nós de Piv em caminhos que partem da raiz da árvore são chamados de pivôs primários do processo.

- A ordem preferencial, denotada por $\triangleleft$, define a ordenação dos filhos de cada membro de Piv. O último filho deve ser raiz do caminho de término assegurado.

Da definição de programa de processo podemos concluir que, se a execução deste não atingiu um pivô primário, é possível abortá-la por meio das atividades compensadoras. Caso contrário, se um pivô foi executado, o processo deve prosseguir e sempre há uma alternativa de caminho que poderá ser executada com sucesso. Com isso, um programa de processo em conformidade com a definição anterior possui término garantido. Tal propriedade dos processos transacionais é uma generalização da atomicidade das transações ACID.

\subsubsection{Execução}

A execução de um programa de processo é denominada processo e pode conter atividades abortadas, compensadoras ou execuções de subprocessos abortadas. O caminho na árvore representa os atuais efeitos de um processo, isto é, as atividades que foram executadas corretamente e não foram compensadas. O ponto alcançado pelo processo é denominado estado do processo e existem cinco possibilidades. As alterações associadas aos estados são exibidas na Figura 4.1 e as características de cada um são descritas a seguir:

- Executando: Uma vez inicializado, o processo está no estado executando.

- Abortando: O aborto de uma atividade antes do commit do pivô do processo, $p_{i_{0}}$, causa a alteração do estado para "abortando". Nesse estado são executadas as atividades compensadoras para retroceder o processo.

- Abortado: Após a execução das atividades compensadoras com sucesso, o processo está no estado abortado. 
- Completando: Após o commit do pivô do processo, o estado muda de "executando" para "completando". Nesse estado o programa tentará executar um dos possíveis subprocessos filhos do pivô. O estado "completando" é acompanhando pelo índice da alternativa que está sendo executada no momento.

- Committed: A partir do estado "completando", se um dos subprocessos de $P_{i}$ termina com sucesso, o processo também deve terminar por meio da atividade de commit, representada por $C_{i}$. Então, o processo muda para o estado committed.

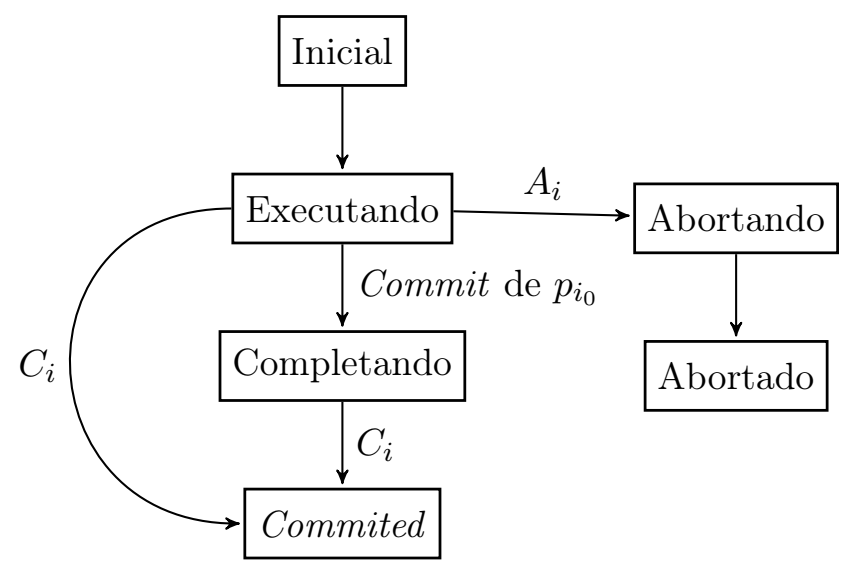

Figura 4.1: Possiveis estados de um processo $P_{i}$. Fonte: [SABS02]

Os conceitos apresentados possibilitam maior flexibilidade e permitem a automação de um processo por meio da indicação do que deve ocorrer em cada ponto. Contudo, a complexidade de programação aumenta significativamente já que é necessário identificar passos compensáveis, reexecutáveis e pivôs, além de combiná-los de maneira adequada e estabelecer caminhos alternativos que compõem um processo bem definido [Alo05]. Embora ferramentas possam ser utilizadas, o programador é o responsável pela transformação da semântica do processo em uma estrutura correta, o que pode ser uma tarefa complexa.

\subsection{Composição transacional de serviços}

Atualmente, observa-se o crescimento da demanda pela exposição de processos de negócio internos de empresas em forma de serviços. Os serviços são autônomos visto que são disponibilizados na Internet por diferentes organizações que possuem suas próprias regras. Devido à heterogeneidade dos serviços, tornou-se um desafio prever o comportamento de um PN formado por uma composição de serviços, especialmente em caso de falhas $\left[\mathrm{BGG}^{+} 11\right]$.

Bhiri et al. $\left[\mathrm{BGG}^{+} 11\right]$ afirmam que as tecnologias atuais de serviços Web não são capazes de garantir, de maneira eficiente, que as instâncias de um PN sejam executadas corretamente na ocorrência de falhas de tarefas. Objetivando atender o problema apresentado, os autores 
descrevem um modelo transacional para composição de serviços Web que pretende integrar o poder expressivo de modelos de workflow à confiabilidade de modelos transacionais avançados.

\subsubsection{Modelo}

De acordo com o modelo transacional para composição de serviços $W e b$ proposto por [ $\left.\mathrm{BGG}^{+} 11\right]$, um serviço Web transacional é um serviço Web com comportamento que manifesta propriedades transacionais. Também baseado no modelo de transações flexíveis [ZNBB94], um serviço pode ser caracterizado como compensável, pivô ou "reexecutável", de acordo com as definições exibidas na Seção 4.3. Utilizando as propriedades citadas, é possível caracterizar um serviço de acordo com sua possibilidade de falha e capacidade de compensação, propriedades consideradas relevantes para a confiabilidade de execução.

Todo serviço pode ser associado a um diagrama de transição de estados, gerado de acordo com as propriedades transacionais. Cada serviço tem um conjunto mínimo de estados (inicial, abortado, ativo, cancelado, com falha ${ }^{4}$, completo) e um conjunto mínimo de transições (abortar, ativar, cancelar, falhar e completar). Adicionalmente, um serviço compensável possui também o estado compensado e a transição compensar. Já um serviço "reexecutável", além do conjunto mínimo, possui a transição tentar novamente ${ }^{5}$. A Figura 4.2 ilustra o diagrama de transição de estados de serviços caracterizados como compensáveis.

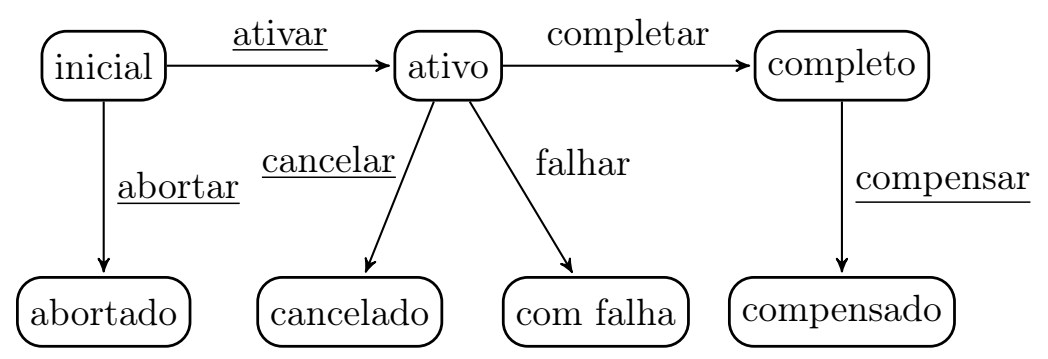

Figura 4.2: Diagrama de transição de estados para serviços compensáveis.

As transições associadas a um serviço podem sem classificadas em dois grupos: transições externas ou internas. As transições externas são disparadas por entidades externas e, por meio delas, é possível especificar como a composição de serviços deve ser orquestrada, ou seja, como a execução dos serviços que compõem o processo deve ser coordenada. Esse primeiro grupo é formado pelas transições ativar, abortar, cancelar e compensar, as quais estão sublinhadas na Figura 4.2. Já o grupo de transições internas (formado por completar, falhar e tentar novamente) contém as transições que são disparadas pelo próprio serviço.

Uma composição transacional de serviços (TCS, do inglês Transactional Composite (Web) Service) é uma composição formada por serviços Web transacionais, ou seja, que apresentam propriedades transacionais conforme descrito no início desta seção. Formalmente, um TCS é

\footnotetext{
${ }^{4}$ Adaptação para o termo em inglês failed.

${ }^{5}$ Adaptação para o termo em inglês retry.
} 
definido como um par tcs $=(E S$, Prec $)$, no qual ES é o conjunto de serviços Web transacionais que o compõe e Prec é uma função que define, para cada transição externa de cada serviço, uma precondição para sua ativação. Concretamente, a função Prec especifica, para cada $s \in E S$, precondições para a habilitação das transições ativar, abortar, cancelar e compensar. Por meio da definição do conjunto de precondições é possível determinar como a composição de serviços tcs deve ser orquestrada, já que as precondições expressam relações de dependência entre os serviços de uma composição. As dependências consideradas pelo modelo são detalhadas a seguir:

- Ativação: Uma dependência de ativação do serviço $s_{1}$ para $s_{2}$ indica que a finalização de $s_{1}$ pode disparar a ativação de $s_{2}$. Essa dependência é definida por meio da condição de ativação de um serviço $s, A c t C o n d(s)$, especificando quando o serviço $s$ será disparado como sucessor de um outro serviço.

- Alternativa: Uma dependência alternativa do serviço $s_{1}$ para $s_{2}$ indica que a falha de $s_{1}$ pode disparar a ativação de $s_{2}$. Essa dependência é definida por meio da condição de alternativa de um serviço $s$, AltCond(s), especificando quando o serviço $s$ será disparado como alternativa a um outro serviço.

- Aborto: Uma dependência de aborto do serviço $s_{1}$ para $s_{2}$ indica que a falha, cancelamento ou aborto de $s_{1}$ pode disparar o aborto de $s_{2}$. Essa dependência é definida por meio da condição de aborto de um serviço $s, \operatorname{AbrCond}(s)$.

- Compensação: Uma dependência de compensação do serviço $s_{1}$ para $s_{2}$ indica que a falha ou compensação de $s_{1}$ pode disparar a compensação de $s_{2}$. Essa dependência é definida por meio da condição de compensação de um serviço $s, C p s C o n d(s)$.

- Cancelamento: Uma dependência de cancelamento do serviço $s_{1}$ para $s_{2}$ indica que a falha de $s_{1}$ pode disparar o cancelamento de $s_{2}$. Essa dependência é definida por meio da condição de cancelamento de um serviço $s, \operatorname{CnlCond}(s)$.

De acordo com as dependências definidas entre os serviços de uma composição TCS, é possível gerar a função Prec associada à composição. De maneira concreta, por meio das dependências, a precondição de execução para cada transição externa de um serviço $s$ pode ser definida:

- ativar: Prec(s.ativar ()$)=\operatorname{ActCond}(s) \cup \operatorname{AltCond}(s)$ determina quando $s$ será ativado;

- abortar: Prec(s.abortar ()$)=\operatorname{AbrCond}(s)$ determina quando $s$ será abortado;

- compensar: Prec(s.compensar ()$)=\operatorname{Cps} C o n d(s)$ determina quando $s$ será compensado;

- cancelar: Prec(s.cancelar ()$)=$ CnlCond $(s)$ determina quando $s$ será cancelado. 
As dependências descritas podem ser divididas em 2 grupos: dependências de controle e dependências transacionais. As dependências de ativação e aborto formam o primeiro grupo e as dependências alternativa, de compensação e cancelamento são chamadas de transacionais. A classificação das dependências expressa os fluxos de controle e transacional de uma TCS os quais, unidos, definem a TCS.

O fluxo de controle de uma TCS especifica a ordenação parcial entre os serviços da composição e, formalmente, é definido como uma TCS que apenas define dependências de controle (i.e., para essa TCS, AltCond $(s)=\operatorname{CpsCond}(s)=\operatorname{CnlCond}(s)=\perp$ ). Já o fluxo transacional especifica os mecanismos de recuperação da TCS e é formalmente definido como uma TCS que apenas define dependências transacionais (i.e., para essa TCS, $\operatorname{Prec}(\operatorname{s.ativar}())=\operatorname{AltCond}(s)$ e $\operatorname{Prec}(\operatorname{s.abortar}())=\perp)$.

Por meio dos fluxos de controle e transacional, é possível definir os conjuntos de estados de terminação sem e com falhas, respectivamente. O estado de uma instância de uma TCS composta por $n$ serviços é definido pela tupla $\left(e_{1}, e_{2}, e_{3}, \ldots, e_{n}\right)$, na qual $e_{i}$ é o estado do serviço $s_{i}$ para essa instância. O conjunto de estados de terminação sem falhas é definido a partir do fluxo de controle da TCS e corresponde aos estados alcançados após execuções sem falhas de serviços. Já o conjunto de estados de terminação com falhas é definido a partir do fluxo transacional da TCS e refere-se aos estados alcançados após execuções em que ocorreram a falha de componentes.

Todos os possíveis estados de terminação (união dos estados sem e com falha) para as instâncias de uma TCS formam o Conjunto de Estados de Terminação (STS, do inglês Set of Termination States), da referida composição, o qual é utilizado para validar a especificação da TCS de acordo com os requisitos de confiabilidade. Para garantir a execução correta das instâncias da TCS projetada, o conceito de atomicidade é relaxado e adaptado ao contexto das composições de serviços por meio da propriedade nomeada Estados de Terminação Aceitos (ATS, do inglês Accepted Termination States).

A propriedade ATS é utilizada como critério de corretude para a execução de instâncias de processos de negócio descritos com uma TCS. Um estado de terminação aceito é um estado no qual o projetista aceita que a execução da instância finalize. Por meio do conjunto de ATS, o projetista expressa os requisitos de confiabilidade da composição (transacional) de serviços Web. Uma TCS cs é dita válida quando todos os possíveis estados de terminação são considerados estados aceitos, ou seja, quando $S T S(c s) \subseteq A T S$.

\subsubsection{Implementação}

Os autores também descreveram uma implementação para validar a abordagem apresentada. A ferramenta desenvolvida, cuja arquitetura é dividida em três partes principais, permite a especificação, validação e execução de TCS. A primeira parte da ferramenta é composta por uma interface gráfica para a especificação da composição, a segunda é o componente que valida o 
modelo projetado e a terceira controla a execução das composições válidas.

O projetista, por meio da interface gráfica baseada em grafos, deve especificar a composição de serviços e também os requisitos de confiabilidade, os quais são descritos por meio do conjunto de estados de terminação aceitos ATS. O componente de validação é responsável por verificar se a composição de serviços projetada é valida em relação ao conjunto ATS especificado. Uma vez que uma composição seja considerada válida, esta pode ser instanciada e a engine de execução controlará a execução dos serviços. O desenvolvimento da terceira parte, a engine de execução, foi realizado a partir do sistema de workflow Bonita [Bon]. O software gerencia propriedades transacionais clássicas e foi adaptado para permitir a inclusão das propriedades transacionais utilizadas pelo modelo desenvolvido (pivô, compensável e "reexecutável").

\subsection{Conclusão}

Neste capítulo abordamos modelos transacionais que almejam flexibilizar as propriedades ACID, adaptando-as ao contexto de GPN para garantir confiabilidade na execução de processos de negócio, especialmente em caso de falhas.

O modelo Saga apresenta o conceito de compensação. Cada atividade do processo de negócio é vista como uma transação convencional e deve possuir um atividade compensadora que desfaz semanticamente os efeitos de sua execução. Caso uma falha ocorra, a execução de uma instância pode ser desfeita por meio da execução das atividades compensadoras. Dessa maneira, o modelo aceita apenas duas opções de finalização: execução ou compensação completas do processo.

Considerando o modelo Saga restritivo, o conceito de semi-atomicidade estende esse modelo incluindo a possibilidade de execução de caminhos alternativos. Classificando as atividades como compensável, reexecutável ou pivô, é possível compor caminhos de execução alternativa que serão executados caso algum outro caminho falhe. Embora a flexibilidade no tratamento de exceções seja maior, a complexidade na modelagem aumenta significativamente já que é necessário classificar os passos do processo e combiná-los de maneira adequada.

Utilizando o conceito de semi-atomicidade, o modelo de composição transacional de serviços discutido na Seção 4.4 classifica cada serviço $W e b$ como compensável, reexecutável ou pivô e o associa a um diagrama de transição de estados, gerado de acordo com a classificação. De acordo com os estados dos serviços que formam uma instância da composição, é possível determinar o estado da mesma. Assim, o critério de corretude para a execução de instâncias é definido por um conjunto de estados de terminação aceitos, especificado no modelo da composição. Na implementação apresentada, a modelagem de uma TCS é baseada em grafos, o que limita a flexibilidade da abordagem e, além disso, o conceito de semi-atomicidade adotado aumenta a complexidade da modelagem. 


\section{Capítulo 5}

\section{WED-flow}

WED-flow (Work, Event and Data-flow) [wed] é uma abordagem alternativa para modelagem e implementação de processos de negócio, a qual tem sido desenvolvida pelo grupo de pesquisa DATA (do inglês Database Modeling, Transactions, and Data Analysis) [dat] do IMEUSP. Recentemente proposta em [FWMP10] e estendida em [FTMP10] e [FBT ${ }^{+}$12], a abordagem WED-flow está inserida no contexto de linguagens baseadas em regras, descritas no Capítulo 3, e de propriedades transacionais, discutidas no Capítulo 4. O principal objetivo da WED-flow é reduzir a complexidade no tratamento de exceções por meio da evolução incremental dos modelos de processos de negócio e de mecanismos de recuperação.

Eventos, condições, transições e dados são elementos de um processo de negócio, visto de diferentes perspectivas. Embora os quatro elementos sejam igualmente importantes, na prática, raramente são tratados da mesma maneira. A abordagem WED-flow baseia-se em três importantes afirmações para integrar tais elementos:

- Para cada evento deve ser definido um conjunto de transições que modifica o estado atual dos dados;

- Qualquer estado de dado que for consultado, modificado ou gerado por uma transição deve ser representado explicitamente e armazenado permanentemente;

- Todas as transições que alteram o estado dos dados devem ser disparadas por um evento e somente serão executadas quando um determinado conjunto de condições for satisfeito.

Conceitualmente, a definição e a captura de eventos por meio de triggers é o ponto de partida da abordagem. A ocorrência de um evento inicia a validação de um conjunto de condições sobre valores de atributos que, quando satisfeitas, habilitam a execução de transições. Os valores dos atributos definem os estados de dados antes e depois do tratamento do evento, isto é, da execução da transição.

O modelo WED-flow é baseado em um conjunto de pares condição-transição que, em tempo de execução, determinam quais atividades serão executadas em uma instância do processo de 
negócio. Quando um novo estado de dado é fornecido como estado inicial de uma instância, ele é processado pelo conjunto de pares condição-transição e, caso a condição seja satisfeita, a transição associada é disparada. A execução de uma transição produzirá um novo estado de dado para a instância, o qual também será avaliado e poderá disparar outras transições, dando prosseguimento à execução da instância do WED-flow e determinando o fluxo de controle da mesma.

\subsection{Definições}

As principais definições em que a abordagem WED-flow baseia-se foram inicialmente publicadas em [FTMP10] e aprimoradas durante o desenvolvimento deste trabalho. A versão atualizada das definições foi publicada em $\left[\mathrm{FBT}^{+} 12\right]$ e será apresentada a seguir.

\section{- WED-attributes}

Uma aplicação computacional pode utilizar diversos bancos de dados autônomos. Entretanto, nem todos os atributos desses bancos são de interesse para o processo de negócio. Cada aplicação possui um conjunto de atributos que são utilizados para definir o fluxo de tarefas e que são alterados durante a execução do processo. Com isso, denotamos por WED-attributes a tupla $\mathcal{A}=\left\langle a_{1}, a_{2}, \ldots, a_{n}\right\rangle$, onde cada $a_{i}$ (com $1 \leq i \leq n$ ) é um atributo de interesse da aplicação.

\section{- WED-state}

Um $W E D$-state é uma tupla $\left\langle v_{1}, v_{2}, \ldots, v_{n}\right\rangle$, onde $v_{i}$ (com $\left.1 \leq i \leq n\right)$ é um valor para o $i$-ésimo atributo de $\mathcal{A}$. Se considerarmos os WED-attributes como atributos de uma relação de um banco de dados, um WED-state é uma tupla específica (ou seja, uma linha) dessa relação. O conjunto $\mathcal{S}$ é o conjunto de todos os possíveis WED-states de uma aplicação e é definido formalmente por $\mathcal{S}=\left\{\left\langle v_{1}, v_{2}, \ldots, v_{n}\right\rangle \mid \forall i \in[1 ; n], v_{i} \in \operatorname{dominio}\left(a_{i}\right)\right\}$, no qual $a_{i}$ é o $i$-ésimo atributo de $\mathcal{A}$ e domínio $\left(a_{i}\right)$ é o conjunto de valores que esse atributo pode assumir.

\section{- WED-condition}

Uma WED-condition é um conjunto de predicados definidos sobre os WED-attributes de uma aplicação. O conjunto $\mathcal{C}$ representa o conjunto de todas as WED-conditions definidas para a aplicação. Sendo $s \in \mathcal{S}$ um WED-state e $c \in \mathcal{C}$ uma WED-condition, dizemos que $s$ satisfaz $c$ se os valores dos atributos de $s$ tornam os predicados de $c$ verdadeiros.

\section{- WED-transition}

Uma WED-transition $t$ é uma função $t: \mathcal{S} \rightarrow \mathcal{S}$, ou seja, uma função que recebe um WED-state como entrada e produz outro WED-state como saída. A especificação de uma 
WED-transition $t$ inclui um conjunto de atributos $\mathcal{U}_{t}=\left\{u_{1}, u_{2}, \ldots, u_{m}\right\}$, tal que $u_{i}$ (com $1 \leq i \leq m \leq n)$ é um elemento de $\mathcal{A}$, o qual indica quais atributos são atualizados por $t$. Denotamos por $\mathcal{T}$ o conjunto de todas as WED-transitions definidas para a aplicação.

Uma WED-transition pode ser vista como uma transação convencional que é implementada com base no modelo Saga. Assim, para uma transição $t \in \mathcal{T}$ pode ser projetada uma WED-compensation, definida como uma função $c_{t}: \mathcal{S} \rightarrow \mathcal{S}$ que compensa $t$, desfazendo semanticamente os efeitos de sua execução. Dessa maneira, a execução de $c_{t}$ sobre um WED-state gerado pela execução de $t$ deve produzir um WED-state equivalente ao usado como entrada para a execução de $t$. Ou seja, se $t\left(s_{i}\right)=s_{f}$, então $c_{t}\left(s_{f}\right)=s_{i}^{\prime}$, sendo $s_{i}^{\prime}$ equivalente a $s_{i}\left(\operatorname{com} s_{i}, s_{f}\right.$ e $\left.s_{i}^{\prime} \in \mathcal{S}\right)$ [SBF12].

\section{- WED-trigger}

Um WED-trigger é um par $g=\langle c, t\rangle$, no qual $c$ é uma WED-condition de $\mathcal{C}$ e $t$ uma WED-transition de $\mathcal{T}$. Quando um WED-state $s \in \mathcal{S}$ satisfaz a condição $c, g$ é responsável por disparar a transição $t$. O conjunto $\mathcal{G}$ representa o conjunto de todos os WED-triggers definidos para a aplicação.

\section{- WED-flow}

Um WED-flow é uma tripla $\left\langle\mathcal{G}^{\prime}, c_{i}, c_{f}\right\rangle$, onde $\mathcal{G}^{\prime} \subseteq \mathcal{G}$ é um conjunto de WED-triggers e $c_{i}$ e $c_{f}$ são WED-conditions. A condição $c_{i}$ é a condição inicial do WED-flow, a qual define o conjunto de WED-states iniciais válidos, e a condição $c_{f}$ é a condição final do WEDflow, a qual define o conjunto de WED-states finais válidos. Quando um novo WED-state é fornecido como inicial, uma nova instância do WED-flow é criada para manipular esse estado.

Partindo das definições acima, um WED-flow pode ser visto como uma composição de pares condição-transição que avaliam e produzem estados de dados. Concretamente, as WEDtransitions são disparadas quando WED-states satisfazem suas WED-conditions associadas. Cada execução de uma WED-transition produz um novo WED-state como saída, o qual pode disparar a execução de outra(s) WED-transition(s) do WED-flow. A Figura 5.1 ilustra como se relacionam os elementos básicos de um WED-flow.

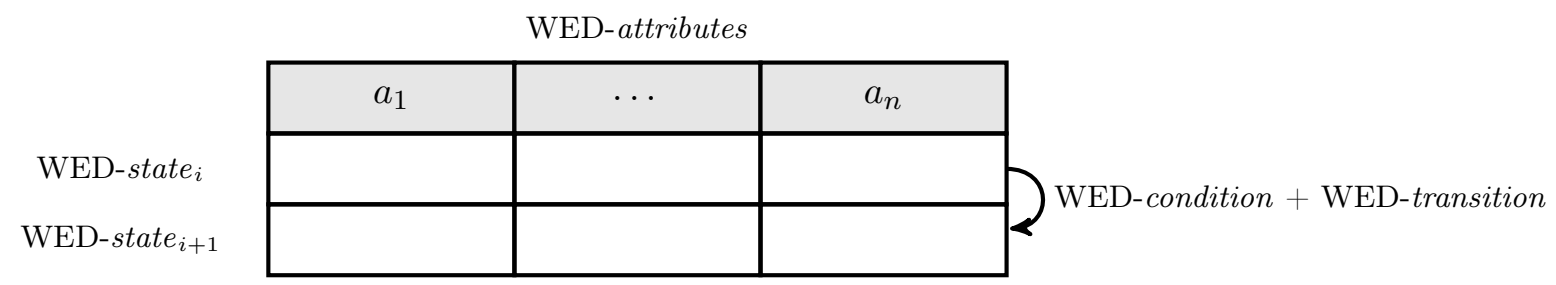

Figura 5.1: Representação da composição dos elementos básicos de um WED-flow. 
O conjunto de todas as transições de estados realizadas em uma instância de WED-flow compõem o histórico de execução dessa instância. Uma entrada do histórico armazena informações sobre a execução de uma WED-transition e pode ser representada pela tupla $\left\langle s_{c}, t, s_{i}, s_{o}\right\rangle$, na qual:

- $s_{c}$ indica o WED-state que satisfez a condição responsável pelo disparo de $t$;

- $t$ indica a WED-transition que foi executada;

- $s_{i}$ indica o WED-state fornecido como entrada para $t$;

- $s_{o}$ indica o WED-state produzido como saída de $t$.

Assim, o histórico de execução de uma instância de WED-flow é formalmente definido como a sequência $\left\langle e_{1}, e_{2}, \ldots, e_{k}\right\rangle$, onde cada $e_{i}$ (com $\left.1 \leq i \leq k\right)$ é uma entrada do histórico. A partir do histórico de uma instância, podemos recuperar o estado atual da mesma, definido como o WED-state $s_{o}$ da última entrada de seu histórico. Caso $s_{o}$ seja um estado final válido, ou seja, satisfaça a condição final do WED-flow, a execução da instância está finalizada.

\subsection{Exceções}

Uma exceção é uma situação não modelada por um sistema de informação ou um desvio entre o que foi planejado e o que acontece de fato [LSKM00]. No contexto de processos de negócio, podemos dizer que uma exceção é uma situação para a qual não existem regras aplicáveis, definidas na modelagem inicial de um PN [Saa93], e que ocorre durante a execução de uma instância desse processo.

Exceções podem ser classificadas de diversas maneiras. De acordo com o escopo deste trabalho, destacamos duas categorias, abordadas em [Saa93]: (i) exceções esperadas que representam as situações que não são consideradas normais no processo de negócio, porém sabe-se que elas podem ocorrer, tornando possível a criação de mecanismos para tratá-las; (ii) exceções não esperadas ou exceções verdadeiras que caracterizam falhas de modelagem e casos não previstos nela.

O tratamento de exceções refere-se à identificação de uma situação de exceção e à escolha e execução de uma ação pertinente a ela [Saa93]. Tal tratamento é um desafio aos modelos e sistemas GPN que, em sua maioria, abordam aquelas exceções cujo tratamento pode ser previamente definido no momento da modelagem. Existem algumas soluções para o tratamento de exceções não esperadas, porém poucos sistemas as suportam [SBF12].

Devido à grande diversidade de erros que podem ocorrer durante a execução de uma instância de processo de negócio, o tratamento de exceções tende a exigir mais esforços quando comparado aos procedimentos normais do PN. Pode ser inviável projetar regras para todas as possíveis situações excepcionais durante a modelagem, fase na qual muitas vezes o processo não está 
claramente definido para os desenvolvedores [SBF12]. Consequentemente, muitos processos de negócio deixam diversas exceções indefinidas, resultando em falhas na execução de instâncias.

A abordagem WED-flow é capaz de reduzir a complexidade do tratamento de exceções por meio da representação explícita de estados de dados e transições entre os mesmos, com base em eventos e condições. Visto que é difícil identificar todas as possíveis exceções na primeira versão do modelo, a abordagem permite que o WED-flow projetado seja alterado com facilidade, possibilitando a inclusão de tratamento de exceções esperadas e favorecendo a evolução incremental do modelo. Além disso, para os casos de exceções verdadeiras que não precisam ser integradas ao modelo, a abordagem suporta mecanismos de recuperação backward e forward para tratar a instância em questão e conduzi-la à execução planejada.

As definições apresentadas a seguir, referentes à consistência de uma instância de WED-flow, foram produzidas durante o desenvolvimento deste trabalho e da dissertação de mestrado de Pedro Paulo S. B. Silva [Sil13], realizados paralelamente.

Uma instância de WED-flow é dita inconsistente quando uma exceção é detectada durante sua execução [SBF12]. A abordagem WED-flow reconhece como exceção a falha de execução de uma WED-transition ou a produção de um WED-state inconsistente durante a execução de instâncias. A consistência de um WED-state é determinada em função das definições $A W I C$ Consistent e Transaction-Consistent, apresentadas em $\left[\mathrm{FBT}^{+} 12\right]$ e exibidas a seguir:

\section{- WED-state AWIC-Consistent}

Application-Wide Integrity Constraints (AWICs) são restrições de integridade que envolvem todos os bancos de dados autônomos utilizados pela aplicação. Uma AWIC pode ser definida como um conjunto de predicados sobre os WED-attributes da aplicação. Por conveniência, os AWICs de uma aplicação são definidos como o conjunto $\mathcal{W}$, tal que $\mathcal{W} \subseteq \mathcal{C}$. Quando um dado WED-state $s \in \mathcal{S}$ satisfaz todas as condições em $\mathcal{W}, s$ é considerado $A W I C$ Consistent.

\section{- WED-state Transaction-Consistent}

Seja $s \in \mathcal{S}$ um WED-state que pertence à instância $i$ do WED-flow $f=\left\langle\mathcal{G}_{f}, c_{i f}, c_{f}\right\rangle$. O estado $s$ é transaction-consistent se respeita pelo menos uma das seguintes propriedades:

$-\exists\left\langle c_{g}, t_{g}\right\rangle \in \mathcal{G}_{f}$, tal que $s$ satisfaz $c_{g}$. Em outras palavras, $s$ habilita o disparo de pelo menos uma transição na instância $i$;

- Existe pelo menos uma transição atualmente em execução na instância $i$. Essa propriedade implica que, mesmo que $s$ não habilite o disparo de uma transição, ele não será o último estado da instância já que as outras transições em execução produzirão novos estados para $i$. 


\section{- WED-state Inconsistente}

Um WED-state é dito inconsistente se este não é $A W I C$-consistent e nem transactionconsistent.

\subsection{Modelagem}

Com a WED-flow, não é necessário definir o fluxo de controle do processo explicitamente. Nessa abordagem, um processo de negócio é disparado por um evento, o qual inicia a captura de estados de dados, verificação de condições e, quando apropriado, transições de estados. Isto é, o fluxo de controle é consequência da satisfação de condições ao decorrer da execução do processo. Assim, a modelagem de processos de negócio é feita de forma declarativa, por meio da especificação dos elementos que compõem o WED-flow: WED-attributes, WED-conditions, WED-transitions e WED-triggers.

O processo de modelagem utilizando a abordagem WED-flow é composto por três fases principais, detalhadas em [FTMP10]:

- Separação do processo de negócio em duas partes: caminho normal e tratamento de exceções (aquelas esperadas);

- Modelagem de ambas as partes em uma composição dos quatro conceitos fundamentais (eventos, dados, condições e transições);

- Escrita do modelo WED-flow utilizando uma linguagem concreta de especificação. O resultado será interpretado e convertido automaticamente em programas executáveis por meio de ferramentas de software.

Na primeira fase, é necessário identificar os eventos que compõem o processo de negócio e então dividi-los em eventos normais e de exceção. Esta separação resulta da observação de que a maioria dos processos de negócio apresenta um objetivo de negócio bem definido e um claro caminho para atingi-lo, por meio de uma sequência de transições de estados.

Eventos normais compõem o menor conjunto de eventos necessários para atingir o objetivo principal do processo de negócio. A partir dos eventos normais, é possível formar uma sequência, ordenada de acordo com o momento em que cada evento ocorre, a qual chamamos de caminho normal, citado previamente.

As exceções são determinadas por eventos que podem acontecer em algum ponto do caminho normal e que desviam a execução do processo deste caminho, caracterizando a ocorrência de algum erro, de casos raros ou eventos conhecidos que não fazem parte do caminho ideal. Para o processo de negócio de venda de livros, o reconhecimento de dados inválidos que acarreta o aborto da venda é considerado uma exceção. 
A segunda fase corresponde à modelagem do processo de negócio utilizando os conceitos básicos da abordagem WED-flow, detalhados na Seção 5.1. Para cada evento identificado na fase anterior, seja normal ou de exceção, WED-states, WED-conditions e WED-transitions devem ser definidos. A modelagem do caminho normal e do tratamento de exceções esperadas são descritos a seguir.

\section{Modelagem do caminho normal}

Os eventos normais estão vinculados a diferentes entidades ou classes de dados, sendo que cada uma possui uma sequência específica de estados de dados válidos. Para o exemplo de processo de venda de livros, podemos identificar três entidades (cliente, livro e pedido) que apresentam sequências de estados de dados distintas, exibidas na Figura 5.2. Nessa figura, os estados de dados são representados por hexágonos e, como pode-se notar pelo tamanho dos polígonos, as durações dos estados de dados pertencentes às sequências são variadas. Dessa maneira, as sequências correspondentes às entidades precisam ser normalizadas. Nesse procedimento, os estados das diferentes sequências são vinculados de acordo com a ordenação temporal, permitindo a criação de WED-states. Na Figura 5.2, as linhas verticais tracejadas representam o procedimento de normalização e cada coluna formada por elas representa um WED-state do caminho normal. Assim, com o encadeamento de WED-states, formamos o caminho normal da perspectiva de estados de dados.

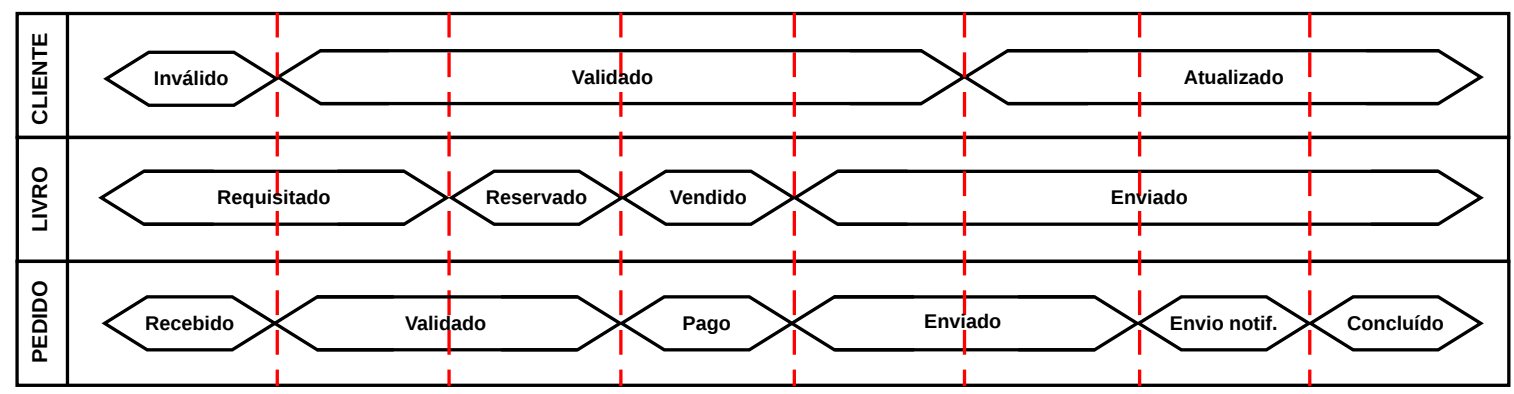

Figura 5.2: Entidades participantes do processo de venda de um livro. Linhas verticais tracejadas representam o procedimento de normalização.

Após formar a sequência de WED-states ordenada temporalmente, é preciso relacionar condições e transições a cada WED-state pertencente à sequência. Isto é, definir quais transições levam de um estado a outro e também quais condições permitem a execução de cada transição. Concretamente, as condições são modeladas como WED-conditions e as transições como WEDtransitions. Além disso, também é necessário modelar os WED-triggers, pares WED-conditionWED-transition, responsáveis pelo disparo da transição quando a condição associada é satisfeita.

O WED-flow de venda de um livro inicia-se pelo evento de recebimento do pedido realizado por um cliente. A sequência de WED-states que compõem o caminho normal é produzida em decorrência da execução das transições de validação de dados do pedido $\left(t_{1}\right)$, reserva de pro- 
duto $\left(t_{2}\right)$, processamento de pagamento $\left(t_{3}\right)$, envio do produto $\left(t_{4}\right)$, atualização do programa de fidelidade $\left(t_{5}\right)$, notificação do envio ao cliente $\left(t_{6}\right)$ e, finalmente, fechamento do pedido $\left(t_{7}\right)$. A Figura 5.3 exibe uma representação gráfica das transições de WED-states que compõem o caminho normal do processo de venda de livros. Os valores sublinhados indicam os atributos que foram atualizados pela execução de cada WED-transition $t_{i}(\operatorname{com} 1 \leq i \leq 7)$.

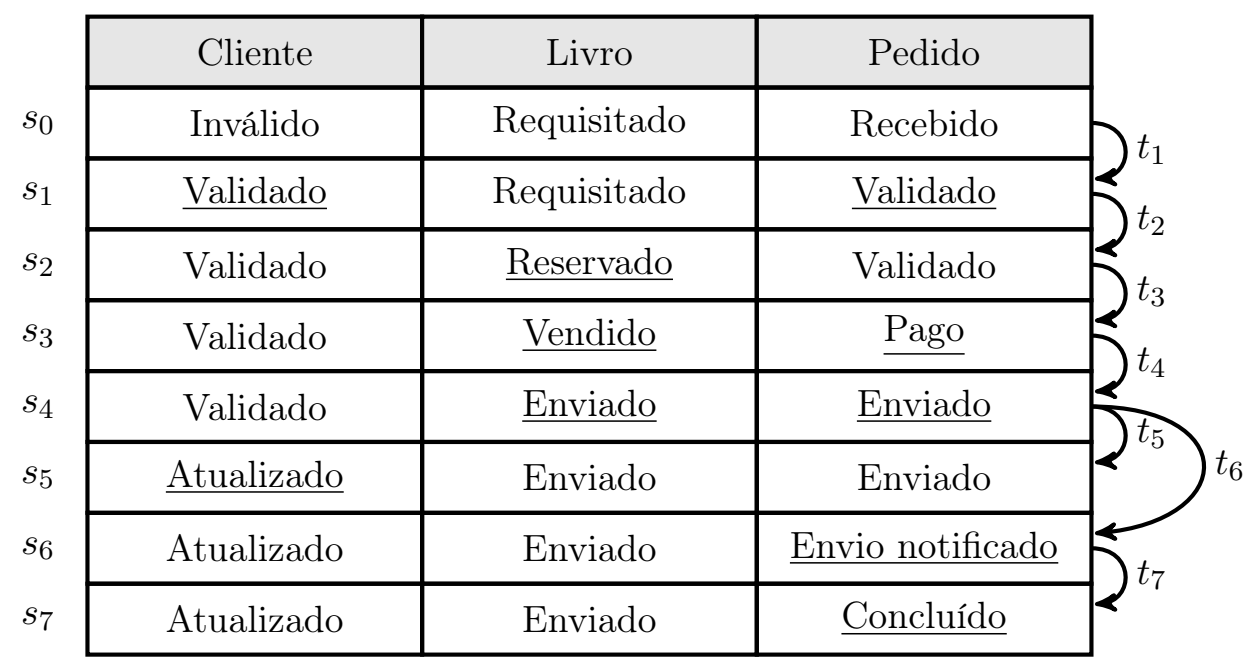

Figura 5.3: WED-states para o exemplo de venda de um livro.

Em resumo, a modelagem de eventos normais pode ser dividida em cinco etapas:

- Análise da sequência de estados de dados para cada entidade/classe de dados;

- Normalização das sequências de acordo com a ordenação temporal, criando WED-states;

- Encadeamento de WED-states, criando o caminho normal;

- Descrição de condições relacionadas aos eventos;

- Descrição de transições relacionadas às condições.

\section{Modelagem do tratamento de exceções esperadas}

O tratamento de exceções possui uma modelagem semelhante já que, para cada uma, WEDstates, WED-conditions e WED-transitions também devem ser definidos. Entretanto, existem algumas particularidades que precisam ser consideradas.

Quando uma exceção ocorre, o fluxo de execução sai do caminho ideal e portanto, há a produção de um WED-state que não pertence ao caminho normal, composto pelo conjunto de estados exibido na Figura 5.3. Além disso, uma vez que o fluxo foi desviado, este pode não retornar ao caminho normal e com isso, o tratamento da exceção pode exigir a criação de novos WED-states, assim como WED-conditions e WED-transitions. 
Para o exemplo de venda de livros, o recebimento de dados inválidos pode ser visto como um evento de exceção esperada e portanto, seu tratamento pode ser incluído no modelo WED-flow. Neste caso, a transição que constata que os dados do pedido são inválidos produzirá um WEDstate que não pertence ao caminho normal, caracterizando a exceção. Assim, é possível projetar WED-conditions para capturar o estado correspondente à exceção e também WED-transitions para tratar a ocorrência da mesma e conduzir a execução da instância ao caminho normal.

A Figura 5.4 exibe a sequência de WED-states referente à execução de uma instância de WED-flow com a ocorrência de uma exceção. O WED-state inicial $s_{0}$ dispara a WED-transition de validação de dados que, para essa instância, constata que os dados recebidos são inválidos. Como resultado, a transição $t_{1}$ produz o WED-state $s_{1}$ que não pertence ao caminho normal, caracterizando uma exceção. O estado $s_{1}$, por sua vez, habilita o disparo da WED-transition de aborto de venda, $t_{8}$, que foi projetada para tratamento de uma exceção esperada. Essa transição, no fim de sua execução, produz o WED-state $s_{2}$, o qual representa o cancelamento da venda, finalizando a execução da instância.

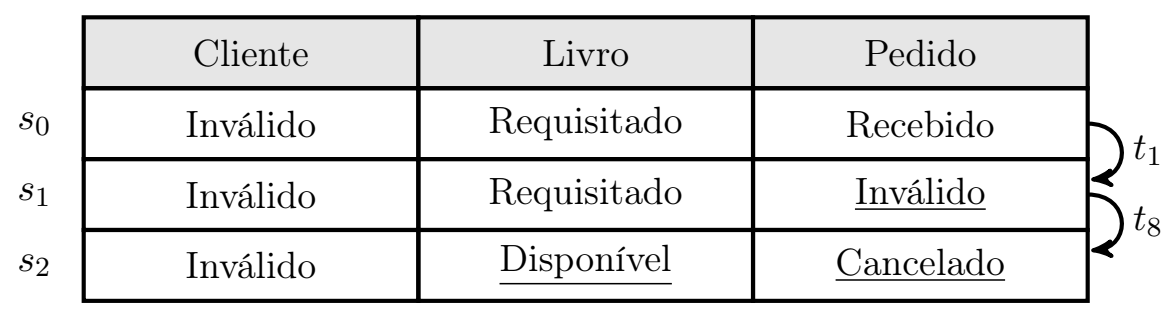

Figura 5.4: WED-states - Aborto da venda do livro.

A última fase do processo de modelagem utilizando a abordagem WED-flow corresponde à tradução do modelo projetado em uma linguagem concreta de especificação, a qual se faz necessária para a implementação do processo de negócio. A especificação do WED-flow projetado será interpretada e convertida em programas que controlam a execução do processo de negócio. Tanto a escrita da especificação do modelo em linguagem concreta como a interpretação e conversão do mesmo por meio de ferramentas de software são objetos de estudo deste trabalho e serão abordados no próximo capítulo.

\subsection{Exemplo}

Nesta seção descrevemos o modelo do processo de negócio de venda de livros, utilizado como exemplo neste trabalho, produzido por meio da abordagem WED-flow. A Figura 5.5 retrata uma visualização geral da composição de WED-conditions e WED-triggers, pares que são responsáveis pela formação do modelo.

No diagrama abaixo, as elipses representam estados do processo, nomeados de acordo com a característica principal que apresentam, e os retângulos representam as WED-transitions que 
compõem o processo. As setas tracejadas rotuladas com identificadores de WED-conditions, que conectam estados a transições, indicam que o estado satisfaz a condição e, consequentemente, habilita o disparo da transição associada. Já as setas que conectam transições a estados representam a produção de um novo estado por meio da execução de uma transição; as setas pontilhadas indicam que aquela transição pode produzir diferentes estados, criando diferentes opções de caminhos de execução. O círculo com a marcação $A N D$ representa a combinação de dois (ou mais) estados. Por fim, os estados nomeados "Pedido concluído" e "Pedido cancelado" são os estados finais do processo, os quais satisfazem a condição final do WED-flow.

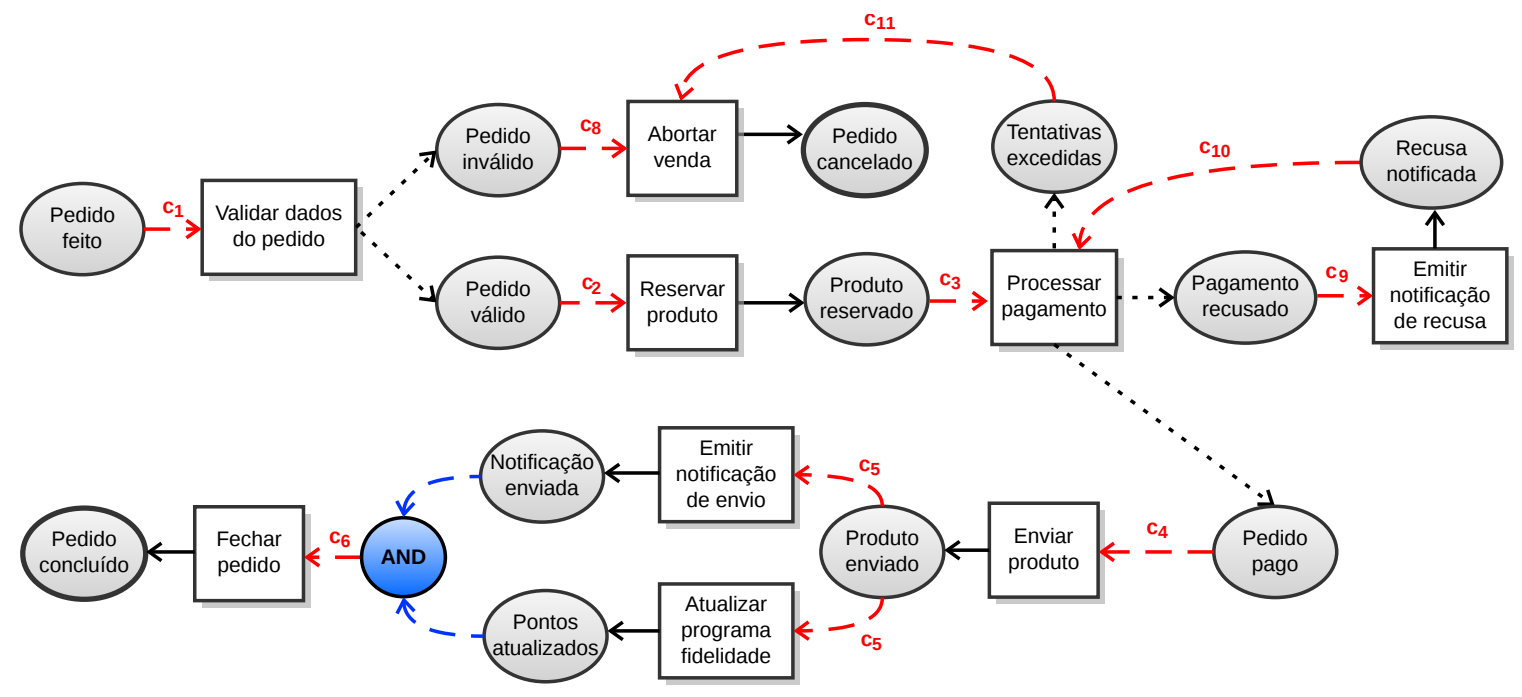

Figura 5.5: Diagrama que ilustra o WED-flow para venda de livros.

Todos os elementos que compõem o WED-flow do processo de negócio de venda de livros, representado na figura acima, são descritos a seguir:

\section{WED-attributes:}

$\mathcal{A}=\langle$ id_cliente, cliente, pontos, id_produto, produto, id_pedido, pedido, pagamento $\rangle$

WED-conditions $-\mathcal{C}=\left\{c_{1}, c_{2}, \ldots, c_{10}, c_{11}\right\}$

- $\boldsymbol{c}_{\mathbf{1}} \rightarrow c \_$novo_pedido $:($cliente $=$'Inválido' AND pedido $=$'Recebido')

- $\boldsymbol{c}_{2} \rightarrow c \_$_pdido_valido $:($cliente $=$'Validado' AND pedido $=$'Validado' $)$

- $c_{3} \rightarrow c \_p r o d u t o \_r e s e r v a d o:($ produto $=$ 'Reservado')

- $\boldsymbol{c}_{\mathbf{4}} \rightarrow c \_p e d i d o \_p a g o:($ pedido $=$ 'Pago')

- $\boldsymbol{c}_{5} \rightarrow c \_$produto_enviado $:($pedido $=$'Enviado' AND produto = 'Enviado')

- $\boldsymbol{c}_{6} \rightarrow c \_p e d i d o \_t r a t a d o:($ pedido $=$ 'Envio notificado' AND cliente $=$ 'Atualizado')

- $\boldsymbol{c}_{\mathbf{7}} \rightarrow c_{\_}$pedido_finalizado $:($pedido $=$'Concluído' OR pedido $=$'Cancelado') 
- $c_{8} \rightarrow c \_p e d i d o \_i n v a l i d o:($ pedido $=$ 'Inválido')

- $c_{9} \rightarrow c \_p a g a m e n t o \_r e c u s a d o:($ pagamento $=$ 'Recusado')

- $\boldsymbol{c}_{\mathbf{1 0}} \rightarrow$ c_recusa_notificada $:($ pagamento $=$ 'Recusa notificada')

- $\boldsymbol{c}_{\mathbf{1 1}} \rightarrow c_{-}$tentativa_excedida $:$(pagamento = 'Tentativas excedidas')

WED-transitions $-\mathcal{T}=\left\{t_{1}, t_{2}, \ldots, t_{8}, t_{9}\right\}$

- $\boldsymbol{t}_{\mathbf{1}} \rightarrow t$ t_validar_dados : atualiza os atributos cliente e pedido

- $\boldsymbol{t}_{2} \rightarrow t \_r e s e r v a r \_p r o d u t o:$ atualiza o atributo produto

- $\boldsymbol{t}_{\mathbf{3}} \rightarrow t \_$_processar_pagamento $:$atualiza os atributos pedido, produto e pagamento

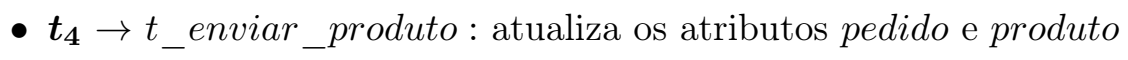

- $\boldsymbol{t}_{5} \rightarrow t_{-}$emitir_notificacao_envio : atualiza o atributo pedido

- $\boldsymbol{t}_{6} \rightarrow t \_a t u a l i z a r \_p f i d e l i d a d e:$ atualiza os atributos cliente e pontos

- $\boldsymbol{t}_{7} \rightarrow t_{\text {_f }}$ fechar_pedido : atualiza o atributo pedido

- $\boldsymbol{t}_{\mathbf{8}} \rightarrow t_{-}$abortar_venda : atualiza o atributo pedido

- $\boldsymbol{t}_{\mathbf{9}} \rightarrow t_{-}$emitir_notificacao_recusa : atualiza o atributo pagamento

WED-triggers $-\mathcal{G}=\left\{g_{1}, g_{2}, \ldots, g_{10}, g_{11}\right\}$

- $\boldsymbol{g}_{\mathbf{1}}=\langle$ c_novo_pedido, t_validar_dados $\rangle$

- $\boldsymbol{g}_{\mathbf{2}}=\left\langle\mathrm{c} \_\right.$pedido_valido, t_reservar_produto $\rangle$

- $\boldsymbol{g}_{\mathbf{3}}=\langle$ c_produto_reservado, t_processar_pagamento $\rangle$

- $\boldsymbol{g}_{4}=\langle$ c_pedido_pago, t_enviar_produto $\rangle$

- $\boldsymbol{g}_{\mathbf{5}}=\langle$ c_produto_enviado, t_emitir_notificacao_envio $\rangle$

- $\boldsymbol{g}_{6}=\langle$ c_produto_enviado, t_atualizar_pfidelidade $\rangle$

- $\boldsymbol{g}_{\mathbf{7}}=\langle$ c_pedido_tratado, t_fechar_pedido $\rangle$

- $\boldsymbol{g}_{\mathbf{8}}=\left\langle\mathrm{c} \_\right.$pedido_invalido, t_abortar_venda $\rangle$

- $\boldsymbol{g}_{\mathbf{9}}=\langle$ c_pagamento_recusado, t_emitir_notificacao_recusa $\rangle$ 
- $\boldsymbol{g}_{10}=\langle$ c_recusa_notificada, t_processar_pagamento $\rangle$

- $\boldsymbol{g}_{\mathbf{1 1}}=\langle$ c_tentativa_excedida, t_abortar_venda $\rangle$

\section{WED-flow:}

- venda_livro: $\left\langle\mathcal{G}, c \_n o v o \_p e d i d o, c \_p e d i d o \_f i n a l i z a d o\right\rangle$

\subsection{Conclusão}

Neste capítulo apresentamos uma releitura da abordagem WED-flow, descrevendo os principais fundamentos e os conceitos que a compõem. A WED-flow é uma abordagem alternativa para modelagem e implementação de processos de negócio, inserida no contexto de linguagens baseadas em regras e propriedades transacionais, que possui como principal objetivo reduzir a complexidade no tratamento de exceções.

Um modelo WED-flow baseia-se em pares WED-condition-WED-transition, chamados de WED-triggers, que avaliam e produzem estados de dados. Quando um WED-state satisfaz a WED-condition de um WED-trigger, a WED-transition associada é disparada. Cada execução de uma WED-transition produz um novo WED-state como saída, o qual pode disparar a execução de outra(s) WED-transition(s), dando prosseguimento à execução da instância do WED-flow. Durante a execução de uma instância de WED-flow, exceções podem ser detectadas, tornando essa instância inconsistente. Com isso, é necessário que a exceção capturada seja tratada a fim de prosseguir a execução da instância conforme planejado no modelo.

A abordagem WED-flow reduz a complexidade no tratamento de exceções permitindo a evolução incremental do modelo projetado e também a utilização de mecanismos de recuperação. $\mathrm{O}$ tratamento de exceções esperadas pode ser modelado de maneira semelhante à modelagem do caminho normal do processo. Como a identificação de todas as possíveis exceções esperadas é uma tarefa complexa, a abordagem permite que novos tratamentos de exceção possam ser integrados ao modelo WED-flow incrementalmente, graças à sua característica flexível inerente às linguagens baseadas em regras. Ademais, para o caso de exceções não esperadas, as quais não exigem que seus tratamentos sejam integrados ao modelo, a abordagem é capaz de prover mecanismos de recuperação baseados em modelos transacionais para restaurar a consistência da instância. 


\section{Capítulo 6}

\section{WED-tool}

Neste capítulo descreveremos uma implementação do arcabouço WED-flow para controlar processos transacionais. Essa implementação corresponde ao núcleo da ferramenta WED-tool

[GSBF12] e está fundamentada nos conceitos apresentados no capítulo anterior. As principais funções do núcleo dessa ferramenta são controlar a execução de processos transacionais, permitir a evolução incremental do modelo do processo de negócio e fornecer a estrutura necessária para apoiar o desenvolvimento do gerenciador de recuperação, implementação realizada paralelamente pelo grupo DATA [SBF12] e que está fora do escopo deste trabalho.

A WED-tool foi implementada utilizando a linguagem de programação orientada a objetos Ruby. O desenvolvimento do núcleo desta ferramenta mostrou-se fundamental para a validação e aprimoramento dos conceitos que constituem a abordagem WED-flow, exibidos no capítulo anterior, e corresponde à principal contribuição deste trabalho.

Como descrito no Capítulo 5, uma vez que o modelo WED-flow que representa o processo de negócio tenha sido produzido, ele precisa ser traduzido para uma linguagem concreta de especificação. Nesta implementação, o modelo WED-flow deve ser descrito em um arquivo no formato XML. Assim, os elementos que compõem o WED-flow, ou seja, WED-attributes, WEDconditions, WED-transitions e WED-triggers, são declarados usando sintaxe XML. Estamos utilizando um XML Schema para descrever a estrutura do documento de especificação do modelo WED-flow, exibido no Código A.1 disponível no Apêndice A.

O arquivo XML que contém a especificação do modelo WED-flow é utilizado para realizar a configuração inicial da WED-tool, o que inclui a criação da estrutura do banco de dados no qual esta implementação é baseada. Após a realização da configuração inicial, o sistema está apto a instanciar o processo de negócio modelado e controlar a execução das instâncias de acordo com a especificação do modelo.

Durante a execução de instâncias do WED-flow, caso uma exceção não esperada seja detectada, a execução da instância será interrompida. Em decorrência da interrupção, o módulo de recuperação assume o controle da instância inconsistente, sendo responsável pelo tratamento 
da exceção e restauração da consistência. Dessa forma, o módulo de controle de execução pode prosseguir com a execução prevista da instância, conduzindo-a a seu estado final. A Figura 6.1 ilustra os módulos da ferramenta WED-tool. Os módulos de configuração e controle de execução, referentes ao núcleo e implementados durante o desenvolvimento deste trabalho, serão detalhados nas seções deste capítulo.

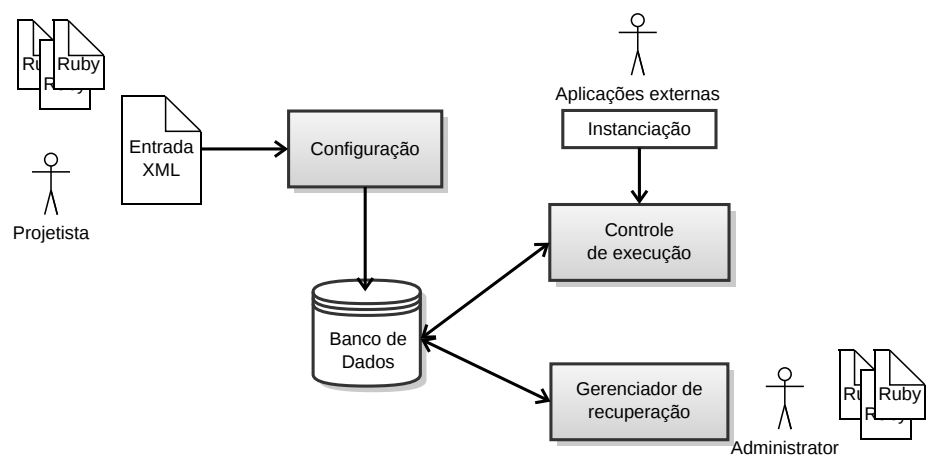

Figura 6.1: Módulos da ferramenta WED-tool

\subsection{Configuração: modelagem e manutenção}

A implementação da WED-tool é baseada em banco de dados relacional. Utilizamos o SGBD de código aberto PostgreSQL [pos] e a biblioteca ActiveRecord [act], que implementa um mapeamento objeto-relacional, associando cada relação do banco de dados a uma classe em Ruby. O modelo conceitual do banco de dados é representado no diagrama entidade-relacionamento (ER) da Figura 6.2. Esse diagrama modela todas as entidades, relacionamentos e restrições que podem ser extraídas das definições apresentadas no capítulo anterior.

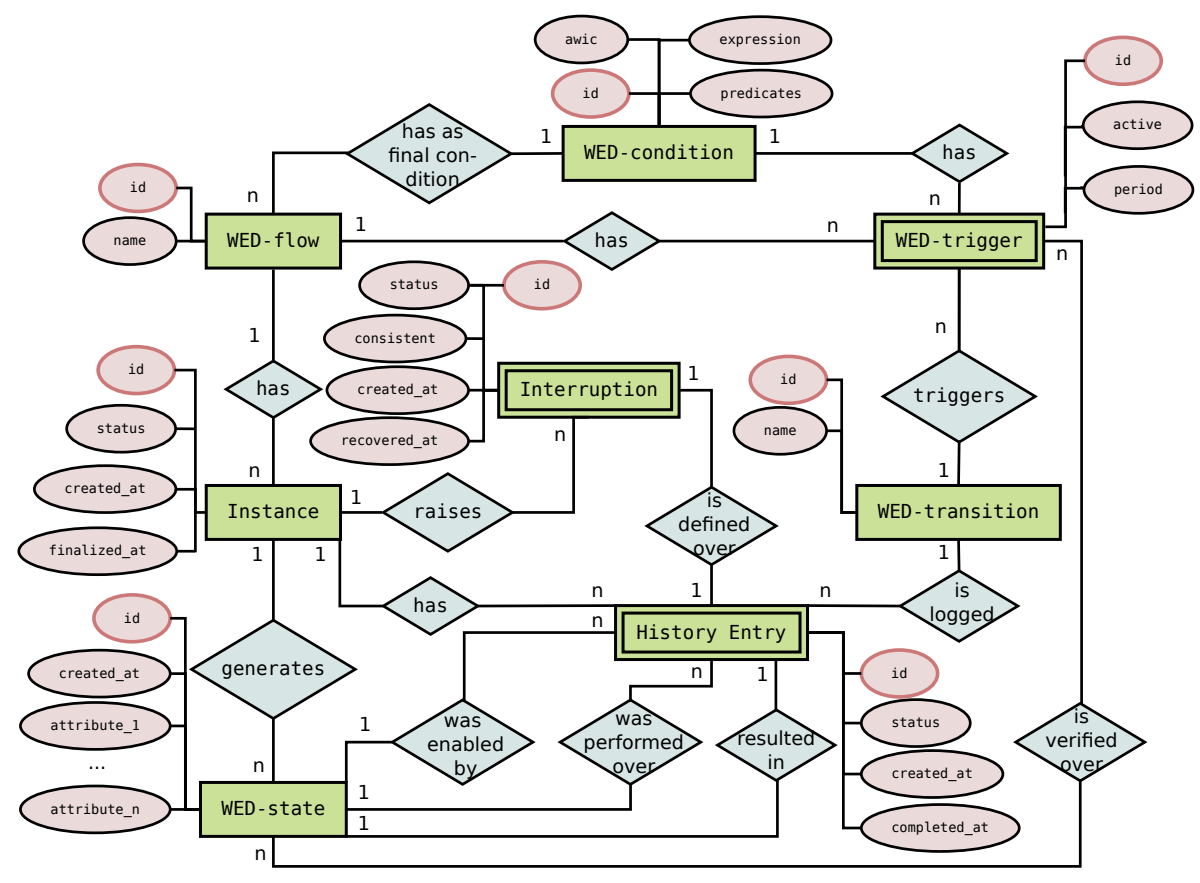

Figura 6.2: Diagrama entidade-relacionamento do sistema WED-tool 
O modelo lógico derivado do diagrama ER é descrito nas Figuras 6.3 e 6.4. A Figura 6.3 exibe as relações associadas à especificação do processo de negócio; cada elemento de um modelo WED-flow está associado à uma relação no banco de dados. Já a Figura 6.4 apresenta as relações criadas para apoiar a execução das instâncias do PN.

\begin{tabular}{|c|c|c|c|c|c|c|c|c|}
\hline \multicolumn{8}{|c|}{ R_WED-States } & \\
\hline id & wed_flo & instance_id & & ted_at & $a_{1}$ & $\ldots$ & $a_{n}$ & \\
\hline \multicolumn{6}{|c|}{ R_WED-Conditions } & & & \\
\hline id & name & predicates & \multicolumn{2}{|c|}{ expression } & awic & & & \\
\hline \multicolumn{9}{|c|}{ R_WED-Transitions } \\
\hline id & name & & & & & & & \\
\hline \multicolumn{9}{|c|}{ R_WED-Flows } \\
\hline id & name & \multicolumn{2}{|c|}{ final_condition } & active & & & & \\
\hline \multicolumn{9}{|c|}{ R_WED-Triggers } \\
\hline id & \multicolumn{2}{|c|}{ wed_condition_id } & \multicolumn{3}{|c|}{ wed_transition_id } & wed_flow_id & active & period \\
\hline
\end{tabular}

Figura 6.3: Relações do BD associadas ao processo de negócio.

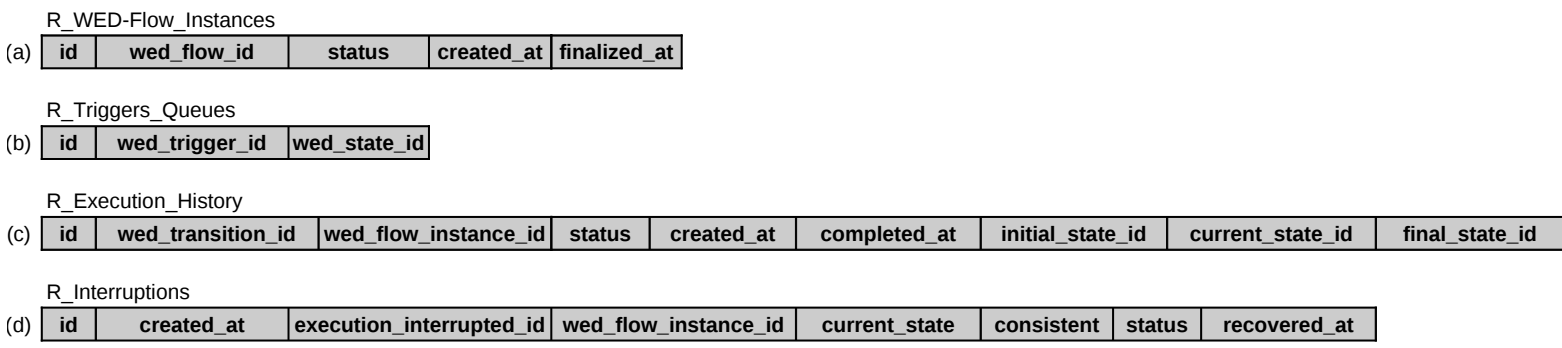

Figura 6.4: Relações do BD criadas para apoiar a execução do processo.

O primeiro grupo, referente às relações associadas à especificação do processo de negócio, é formado pelas relações $R_{-}$WED-States, $R_{-}$WED-Conditions, $R_{-}$WED-Transitions, $R_{-}$WEDFlows e $R_{-} W E D$-Triggers. As quatro últimas possuem estrutura fixa e armazenam informações sobre os elementos do WED-flow extraídos do arquivo XML. Já a relação $R_{-}$WED-States está diretamente relacionada aos conceitos de WED-attributes e de WED-state e possui estrutura definida de acordo com o processo de negócio que está sendo representado.

A estrutura da relação $R_{-}$WED-States é formada, entre outros, pelos atributos pertencentes ao conjunto WED-attributes definido para a aplicação e descrito no arquivo XML de entrada. De maneira concreta, cada atributo pertencente ao conjunto WED-attributes forma uma coluna nessa tabela. Adicionalmente, a relação também possui o atributo "wed_flow_instance_id", que identifica a qual instância de WED-flow o estado pertence, e o atributo "created_at" que indica o momento em que o estado foi criado. A relação $R_{-}$WED-States é responsável por armazenar cada estado de dado da instância produzido pela execução dos passos do processo de negócio. Assim, cada WED-state é uma instância específica dessa relação, ou seja, uma linha da tabela.

A relação $R_{-}$WED-Conditions possui estrutura fixa e armazena todas as WED-conditions que foram descritas no arquivo XML. Os predicados que compõem cada condição são inseridos em forma de lista ordenada no atributo predicates. Já a expressão completa da condição, com- 
posta por predicados conectados por operadores lógicos, é mantida em forma posfixa no atributo expression. Adicionalmente, o atributo booleano awic indica se a WED-condition em questão pertence ao conjunto dos AWICs.

O conceito de WED-transition é mapeado em duas partes nesta implementação: (1) uma

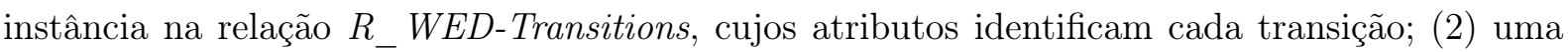
classe Ruby que implementa uma interface. Essa classe deve conter o código de execução associado à transição, ou seja, a ação que a transição deve executar. Além da descrição da ação, é também nessa classe que deve ser especificado quais os novos valores para os atributos que serão atualizados pela execução da transição. Em outras palavras, para cada WED-transition t, é necessário especificar quais os valores para os atributos pertencentes ao conjunto $\mathcal{U}_{t}$ que serão utilizados na produção do novo WED-state.

De acordo com o mapeamento desta implementação, para cada WED-transition $t \in \mathcal{T}$ definida para a aplicação e descrita no arquivo XML de entrada, o módulo de configuração insere uma tupla na relação $R_{-}$WED-Transitions e também gera um modelo de classe em Ruby para o projetista completar. O Código 6.1 exemplifica a especificação de uma WED-transition nomeada "t_exemplo" e o Código 6.2 exibe a classe gerada pela ferramenta WED-tool referente a essa transição. Toda classe associada a uma transição deve implementar o método de classe run de acordo com a ação referente à transição. O método run recebe como entrada um objeto referente ao WED-state que habilitou o disparo da transição e devolve um objeto Hash com os valores para atualização dos atributos pertencentes ao conjunto $\mathcal{U}_{t}$.

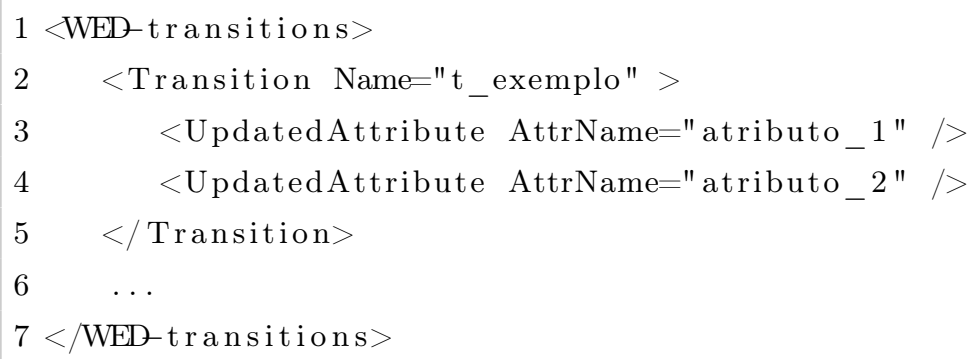

Código-fonte 6.1: Trecho de XML contendo a especificação da WED-transition "t_exemplo".

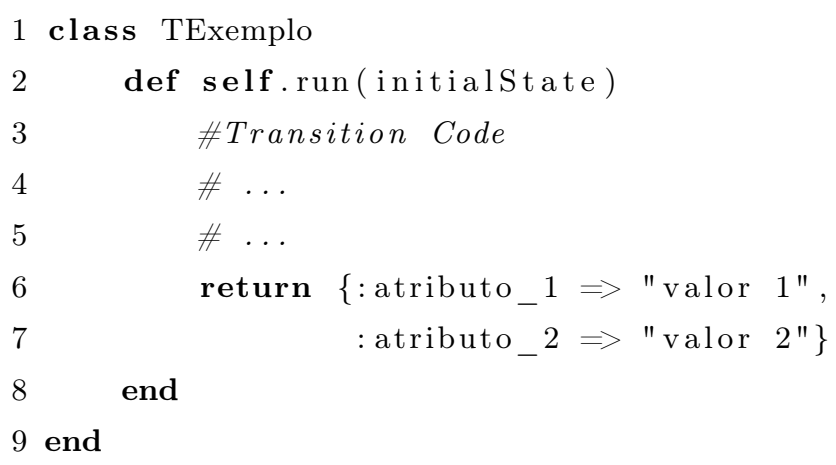

Código-fonte 6.2: Exemplo de classe associada a uma WED-transition. 
Utilizando os elementos inseridos nas relações $R_{-}$WED-Conditions e $R_{-}$WED-Transitions, os WED-triggers do modelo projetado podem ser registrados no banco de dados da ferramenta, na relação $R_{-} W E D$-Triggers. Cada instância contém o identificador da WED-condition e o identificador da WED-transition, relacionados às tabelas $R_{-}$WED-Conditions e $R_{-}$WED-Transitions, respectivamente. Além disso, há também o identificador do WED-flow ao qual o trigger pertence, relacionado a $R_{-}$WED-Flows, e um valor armazenado no atributo period que indica com qual frequência o WED-trigger processará WED-states, ou seja, verificará sua condição sob os novos WED-states que estão na base de dados e disparará sua transição caso necessário.

Por fim, a relação $R_{-}$WED-Flows armazena informações sobre os WED-flows que o sistema é capaz de instanciar e controlar. Nesta implementação, a condição inicial de um WED-flow (denotada por $c_{i}$ na última seção) é implicitamente definida pelo WED-state que é fornecido como estado inicial durante a instanciação do WED-flow. Em outras palavras, consideramos que os WED-states fornecidos como iniciais durante a instanciação já satisfazem a condição inicial do WED-flow escolhido para ser instanciado. Dessa maneira, não é necessário definir a condição inicial na modelagem do processo de negócio.

Vale ressaltar que nosso sistema é capaz de controlar diferentes WED-flows para uma mesma aplicação. Enquanto as definições de WED-triggers são específicas e diretamente relacionadas a um WED-flow, as definições de WED-conditions e WED-transitions são gerais e podem ser reutilizadas para compor diversos WED-triggers de diferentes WED-flows.

Como descrito anteriormente, a modelagem de processos de negócio utilizando a abordagem WED-flow é baseada em regras e feita de forma declarativa, por meio da especificação de WEDconditions, WED-transitions e WED-triggers. De natureza semelhante às regras ECA, descritas na Seção 3.1, a abordagem WED-flow apresenta uma característica flexível, inerente às linguagens baseadas em regras, que favorece a alteração do modelo projetado e permite a evolução incremental do mesmo.

Na WED-tool, a manutenção de um modelo WED-flow previamente cadastrado pode ser realizada por meio da adição ou remoção de WED-conditions e WED-transitions e também da atualização do conjunto de WED-triggers que formam o WED-flow, permitindo a inserção de novos e remoção de antigos pares. A especificação da alteração desejada deve ser descrita em um arquivo XML, o qual deve respeitar a estrutura do XML Schema exibido no Código A.2 disponível no Apêndice A. Além de alterações em WED-flows previamente cadastrados na WED-tool, o XML Schema apresentado também permite a inserção de novos WED-flows ou remoção dos já existentes.

\subsection{Controle de execução}

Após processar a especificação do modelo do WED-flow e criar a estrutura necessária para o funcionamento da ferramenta, o sistema é capaz de instanciar processos de negócio (i.e., instanciar 
os WED-flows que foram especificados) e controlar a execução das instâncias. No escopo deste trabalho, para criar uma instância, um usuário deve fornecer uma valoração para os WEDattributes que produzirá o WED-state inicial e também escolher qual WED-flow será instanciado para manipular o novo estado gerado. Informações sobre cada instância são armazenadas na

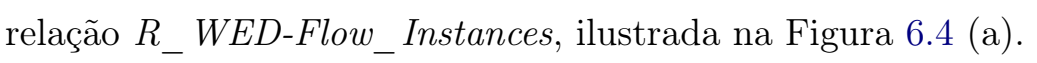

Como descrito no Capítulo 5, na abordagem WED-flow, o fluxo de controle é determinado pelos WED-triggers, ou seja, pela avaliação de WED-conditions sobre WED-states e disparo de WED-transitions quando a condição é satisfeita. Sendo assim, todos WED-states precisam ser monitorados e quando um deles satisfaz a condição de um WED-trigger, a transição associada deve ser disparada. Concretamente, a implementação dos conceitos de WED-condition e WEDtrigger foi baseada nos fundamentos de consultas contínuas [LPT99] e regras ECA.

Consultas contínuas (do inglês continual queries) monitoram atualizações de interesse e retornam o resultado a um usuário quando uma atualização satisfaz uma determinada condição. Formalmente, uma consulta contínua é descrita como uma tripla $\left(Q, T_{c q}, S t o p\right)$, na qual $Q$ é uma consulta comum (geralmente escrita em SQL), $T_{c q}$ é uma condição de gatilho e Stop uma condição de parada. Como exemplo, a consulta contínua exibida na Figura 6.5 determina que a consulta deve ser executada todo dia às $16 \mathrm{~h}$ do ano corrente, recuperando os pedidos de livros com valor maior que 3000. O trecho interno à linha contínua está associado à consulta $Q$ e o retângulo de linha tracejada destaca os elementos $T_{c q}$ e Stop.

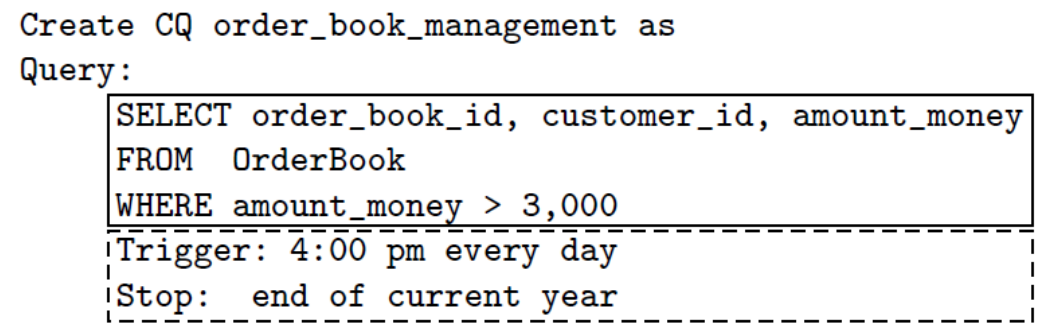

Figura 6.5: Exemplo de consulta contínua

No contexto da abordagem WED-flow, uma WED-condition pode ser vista como uma consulta, a condição de gatilho está associada à frequência de processamento de WED-states (atributo period dos WED-triggers) e a condição de término não é necessária, já que todas as WEDconditions precisam ser avaliadas enquanto o sistema estiver sendo executado. Além disso, o resultado da avaliação contínua também é diferente. Enquanto as consultas contínuas foram projetadas para monitorar atualizações e devolver o resultado da consulta a um usuário, os WEDtriggers monitoram os estados para, quando necessário, disparar as transições apropriadas, de maneira similar às regras ECA.

Na WED-tool, para realizar o monitoramento de estados, cada WED-trigger é responsável por avaliar sua condição e disparar sua transição quando necessário. Em outras palavras, para cada novo WED-state $s$ gerado em uma instância de WED-flow, cada WED-trigger $g=\langle c, t\rangle$ 
associado ao referido WED-flow deve verificar se a WED-condition c é satisfeita pelos valores de $s$ e, em caso verdadeiro, deve disparar a WED-transition $t$. Para isso, cada WED-trigger possui uma fila de WED-states que é processada periodicamente.

Por motivos de integridade, as filas dos WED-triggers são mantidas em uma relação do banco de dados, a qual contém os identificadores do WED-trigger e WED-state. Dessa maneira, é possível garantir que, em caso de queda do sistema, as execuções das instâncias poderão ser retomadas. A estrutura da relação $R_{-}$Triggers_Queues, utilizada para controlar as filas dos WED-triggers, é exibida na Figura 6.4 (b). Essa relação é resultante do mapeamento da relação muitos para muitos entre as entidades WED-trigger e WED-state, exibida no diagrama entidaderelacionamento da Figura 6.2.

O processamento das filas dos WED-triggers ocorre periodicamente e cada WED-trigger possui um valor que determina com que frequência o procedimento deve ocorrer. Esse valor é fornecido pelo projetista, na fase de modelagem do WED-flow, por meio do atributo period contido na especificação do WED-trigger. Nesta implementação, utilizamos a biblioteca Rufusscheduler [ruf] para agendar o processamento das filas dos WED-triggers. Assim, no momento do processamento de um WED-trigger $g=\langle c, t\rangle$, a fila é recuperada da relação $R_{-}$Triggers_Queues e cada WED-state $s$ contido na fila é avaliado em relação à WED-condition c. Caso um estado $s$ satisfaça a condição $c$, a WED-tool cria uma nova thread para realizar a execução da WEDtransition $t$ para a instância a que $s$ pertence.

A avaliação de WED-states por parte dos WED-triggers promove a execução das instâncias de WED-flow. Sendo assim, após a instanciação de um WED-flow, a execução de uma nova instância é inicializada por meio do oferecimento do WED-state inicial para todos os WED-triggers relacionados ao WED-flow escolhido. Concretamente, o WED-state inicial é inserido nas filas dos WED-triggers relacionados ao WED-flow instanciado. O oferecimento aos WED-triggers ativa a avaliação das WED-conditions que, por sua vez, habilita o disparo de WED-transitions. Cada execução de uma WED-transition produz um novo WED-state que pode disparar a execução de outra(s) WED-transition(s) do WED-flow, dando prosseguimento à execução da instância, até que um estado final seja alcançado.

Como descrito no Capítulo 5, uma WED-transition é uma função que recebe um WED-state como entrada e, no fim de sua execução, produz um novo WED-state como saída, o qual torna-se o novo estado atual da instância. A geração do novo estado é realizada por meio da atualização dos valores de um conjunto específico de atributos, denotado por $\mathcal{U}_{t}$ na última seção.

A Figura 6.6 retrata um exemplo de execução de transições para uma instância de WED-flow cujo modelo possui três atributos. No exemplo, o WED-state $s_{0}$ dispara a WED-transition $t_{1}$ que está associada ao conjunto $\mathcal{U}_{t_{1}}=\{$ WED-attribute 1$\}$. Assim, no fim da execução de $t_{1}$, o WEDattribute 1 é atualizado para "valor 1", produzindo o WED-state $s_{1}$. O novo estado $s_{1}$, por sua vez, dispara as WED-transition $t_{2}$ e $t_{3}$, as quais atualizam os atributos 2 e 3 , respectivamente. 
Os valores sublinhados destacam quais atributos foram atualizados na produção do WED-state.

\begin{tabular}{c|c|c|c|}
\cline { 2 - 4 }$s_{s}$ & WED-attribute 1 & WED-attribute 2 & WED-attribute 3 \\
\cline { 2 - 4 }$s_{0}$ & inicial & inicial & inicial \\
\cline { 2 - 4 }$s_{1}$ & valor 1 & inicial & inicial \\
\cline { 2 - 4 }$s_{2}$ & valor 1 & valor 2 & inicial \\
\cline { 2 - 4 }$s_{3}$ & valor 1 & valor 2 & valor 3 \\
\cline { 2 - 4 } & & \multicolumn{2}{c}{}
\end{tabular}

Figura 6.6: Exemplo da execução de WED-transitions em uma instância de WED-flow.

É importante ressaltar que há apenas um estado atual na instância do processo, o qual é sempre utilizado como entrada para a realização das atualizações. Dessa maneira, o estado que habilitou o disparo da transição não necessariamente é o estado que será utilizado como entrada. A Figura 6.7 destaca a atualização do estado atual da instância exibida na Figura 6.6. Quando um estado habilita a execução de apenas uma WED-transition (como $s_{0}$, no exemplo), o estado que será utilizado como entrada e atualizado por essa transição é o mesmo que a disparou. Entretanto, quando um estado habilita mais de uma WED-transition ( $t_{2}$ e $t_{3}$, por exemplo), cada transição utilizará como entrada o estado que foi gerado pela transição que terminou imediatamente antes dela. No exemplo, $t_{2}$ terminou primeiro, produzindo $s_{2}$ e, portanto, a transição $t_{3}$ utilizará $s_{2}$ como entrada e produzirá $s_{3}$.

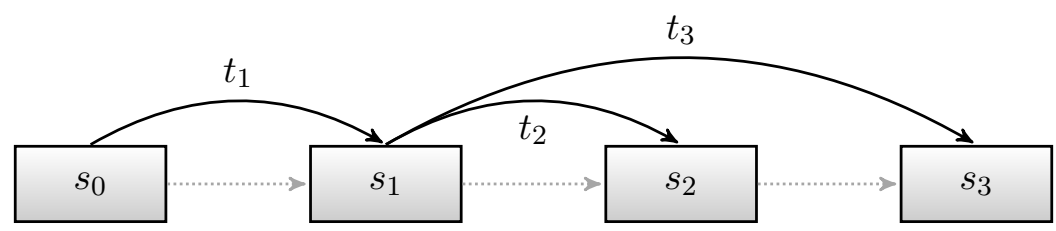

Figura 6.7: Exemplo de atualização do estado atual de uma instância de WED-flow.

Quando um novo WED-state é produzido pela execução de uma WED-transition, este precisa ser oferecido aos WED-triggers do seu WED-flow para o prosseguimento da execução ocorrer. Existem duas possibilidades de oferecimento para as filas: inserir em todas elas, a maneira mais simples e óbvia, ou selecionar os WED-triggers de acordo com os atributos que foram atualizados pela execução da transição e produção do novo estado. Em outras palavras, utilizando a segunda opção, o novo WED-state deve ser inserido na fila de um WED-trigger apenas se a WEDcondition associada avalia pelo menos um atributo de $\mathcal{U}_{t}$, sendo $t$ a WED-transition que produziu o novo estado.

Embora oferecer um novo WED-state para todos os WED-triggers que compõem o WED-flow seja mais simples, este método poderia formar filas mais longas e, consequentemente, causar problemas de desempenho. Ademais, o uso dessa abordagem também causa implicações indesejáveis na fase de modelagem de situações paralelas. Para explicar como o problema ocorre, apresentamos um simples exemplo que explora um cenário com transições que podem ser disparadas paralelamente. 
WED-attributes:

$\mathcal{A}=\left\langle a_{1}, a_{2}\right\rangle$

\section{WED-conditions:}

$c_{1}:\left(a_{1}=X\right)$

$c_{2}:\left(a_{2}=Y\right)$

\section{WED-transitions:}

$t_{1}$ : atualiza $a_{1}$ com valor $X^{\prime}\left(a_{1} \leftarrow X^{\prime}\right)$

$t_{2}$ : atualiza $a_{2}$ com valor $Y^{\prime}\left(a_{2} \leftarrow Y^{\prime}\right)$

\section{WED-triggers:}

$$
\begin{aligned}
& g_{1}=\left\langle c_{1}, t_{1}\right\rangle \\
& g_{2}=\left\langle c_{2}, t_{2}\right\rangle
\end{aligned}
$$

De acordo com o modelo apresentado acima, o WED-state $s_{0}=\langle X, Y\rangle$ dispara ambas as transições $t_{1}$ e $t_{2}$. Caso a transição $t_{1}$ seja finalizada antes de $t_{2}$, sua execução produzirá um novo estado $s_{1}=\left\langle X^{\prime}, Y\right\rangle$, o qual dispararia $t_{2}$ novamente, já que $s_{1}$ satisfaz $c_{2}$. Assim, o valor do atributo $a_{2}$ seria indevidamente processado porque a ocorrência do valor $Y$ em $a_{2}$ seria processada duas vezes em vez de uma. A Figura 6.8 ilustra o disparo das transições para o cenário apresentado. A seta tracejada destaca o segundo disparo da WED-transition $t_{2}$, resultado do processamento indevido do valor do atributo $a_{2}$.

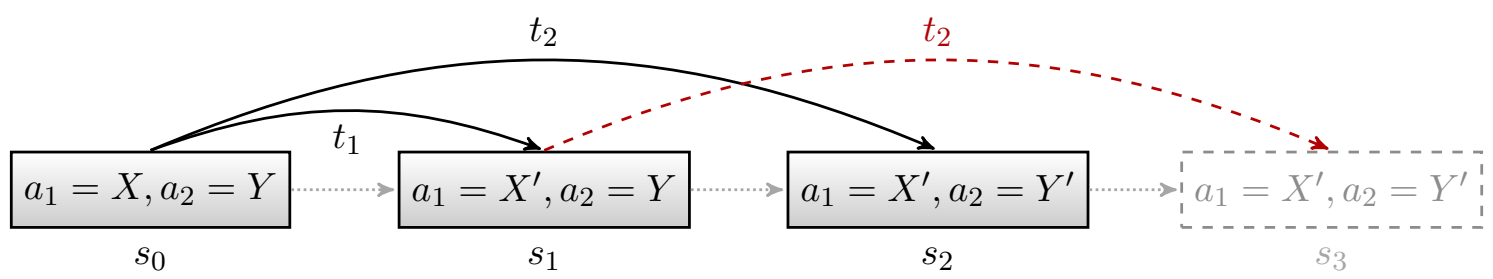

Figura 6.8: Exemplo de disparo indevido de transição.

Para evitar o disparo indevido de transição, ilustrado na Figura 6.8, seria necessário combinar ambas WED-conditions $c_{1}$ e $c_{2}$ em apenas uma com configuração $c=\left(a_{1}=X\right.$ and $\left.a_{2}=Y\right)$ e então, associar a nova condição $c$ às transições $t_{1}$ e $t_{2}$, criando dois WED-triggers diferentes. Considerando que situações paralelas podem envolver diversas condições, a combinação destas aumentaria a complexidade da modelagem e, consequentemente, o risco de erros no modelo.

Cenários paralelos estão presentes em diversos processos de negócio, portanto, nosso sistema deve ser capaz de controlar caminhos paralelos de execução. Com isso, para resolver o problema descrito acima, implementamos a segunda opção de oferecimento de um novo WED-state às filas dos WED-triggers. Assim, não há complexidade adicional na fase de modelagem e o desempenho do sistema também é aprimorado.

Retornando ao modelo apresentado como exemplo, utilizando o oferecimento seletivo, o WEDstate inicial $s_{0}$ deve ser oferecido a todos os WED-triggers, dando início à execução. Entretanto, os demais WED-states, produzidos posteriormente pela execução de WED-transitions, devem ser oferecidos de acordo com os atributos atualizados pelas transições. Por exemplo, $s_{1}=\left\langle X^{\prime}, Y\right\rangle$ foi produzido por $t_{1}$ por meio da atualização do atributo $a_{1}$. Logo, $s_{1}$ será inserido apenas na fila do WED-trigger $g_{1}$ já que a WED-condition associada, $c_{1}$, avalia o atributo $a_{1}$. 


\subsection{Apoio à recuperação}

A abordagem WED-flow combina conceitos de modelos transacionais avançados, eventos e estados de dados para fornecer recuperação transacional e tratamento de exceções. O núcleo da WED-tool deve fornecer toda a estrutura e também informações detalhadas sobre a execução de instâncias para apoiar o desenvolvimento do gerenciador de recuperação, uma atividade realizada paralelamente [SBF12] e que está fora do escopo deste trabalho.

Para desenvolver um sistema capaz de executar mecanismos de recuperação backward e forward, é necessário armazenar os estados de dados de todos os passos da execução das instâncias, assim como detalhes sobre cada execução de transições. Como mencionado anteriormente, na Seção 6.1, todos os WED-states de todas as instâncias de WED-flows são cuidadosamente detalhados e armazenados na relação $R_{-}$WED-States. Já os detalhes sobre as execuções de transições estão diretamente relacionados ao conceito de histórico de uma instância de um WED-flow.

A relação $R_{-}$Execution_History, exibida na Figura 6.4 (c), armazena o identificador da instância do WED-flow, o status da execução, timestamps que indicam os horários em que a transição foi disparada e finalizada e também uma entrada do histórico, contendo o estado que habilitou o disparo da transição, o identificador da transição, o estado que foi utilizado como entrada e também o estado produzido como saída (a tupla $\left\langle s_{c}, t, s_{i}, s_{o}\right\rangle$ ). Assim que uma WED-

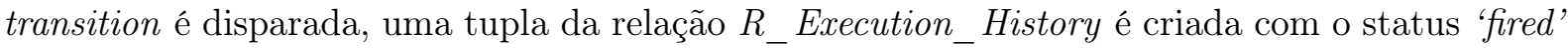
e, assim que a execução é finalizada, o atributo é atualizado para 'completed'.

O objetivo de um WED-flow é transformar o estado inicial de uma instância em um estado final por meio da execução de um conjunto de transições de estados, as quais são disparadas por WED-triggers. Durante o processo de execução de uma instância de um WED-flow, uma exceção pode ser detectada, tornando a instância inconsistente. As exceções capturadas pela WED-tool são referentes à produção de um WED-state inconsistente ou à falha na execução de uma WED-transition.

Como definido anteriormente, na Seção 5.2, um WED-state é dito inconsistente quando ele não satisfaz as condições AWIC e também não habilita o disparo de uma transição ou não há outras transições em execução para a instância ao qual o estado pertence. WED-states inconsistentes normalmente são consequência de erros no projeto do WED-flow, como a ausência de um WED-trigger projetado para tratar o estado produzido, ou de problemas estruturais, como o corrompimento do disco rígido.

A execução de uma WED-transition pode falhar devido ao cancelamento manual, cancelamento por time-out ou conflito de escrita durante a atualização do estado atual da instância. O último caso pode ocorrer em execuções paralelas, já que o WED-state que habilita o disparo de uma transição pode não ser o mesmo fornecido como entrada para a mesma. Uma WEDtransition pode atualizar um atributo apenas se o valor desse atributo não foi alterado desde seu disparo; i.e., o valor do atributo é o mesmo no WED-state responsável pelo disparo da 
WED-transition e no WED-state atual da instância. Quando o valor do atributo foi alterado por uma transição paralela que finalizou anteriormente, existe um conflito de escrita e a execução da WED-transition é abortada. Apresentamos um simples exemplo que explora um cenário com transições que podem ser disparadas paralelamente para exemplificar a ocorrência de um conflito de escrita.

\section{WED-attributes:}

$$
\mathcal{A}=\left\langle a_{1}\right\rangle
$$

\section{WED-conditions:}

$$
c_{1}:\left(a_{1}=X\right)
$$

\section{WED-transitions:}

$t_{1}$ : atualiza $a_{1}$ com valor $X^{\prime}\left(a_{1} \leftarrow X^{\prime}\right)$ $t_{2}$ : atualiza $a_{1}$ com valor $X^{\prime \prime}\left(a_{1} \leftarrow X^{\prime \prime}\right)$

\section{WED-triggers:}

$$
\begin{aligned}
& g_{1}=\left\langle c_{1}, t_{1}\right\rangle \\
& g_{2}=\left\langle c_{1}, t_{2}\right\rangle
\end{aligned}
$$

De acordo com o modelo apresentado, o WED-state $s_{0}=\langle X\rangle$ dispara ambas as transições $t_{1}$ e $t_{2}$. Caso a transição $t_{1}$ seja finalizada antes de $t_{2}$, sua execução produzirá um novo estado $s_{1}=\left\langle X^{\prime}\right\rangle$. Ao final da execução de $t_{2}$, o estado atual da instância é $s_{1}$ e, portanto, este será utilizado na atualização dos valores. A transição $t_{2}$ atualizaria o atributo $a_{1}$ com valor $X^{\prime \prime}$, entretanto, há um conflito de escrita já que o valor de $a_{1}$ em $s_{0}$, o estado que disparou $t_{2}$, e $s_{1}$, o estado atual da instância, são diferentes. Logo, a execução de $t_{2}$ falha e a instância é interrompida. A Figura 6.9 ilustra a ocorrência de conflito de escrita no exemplo apresentado.

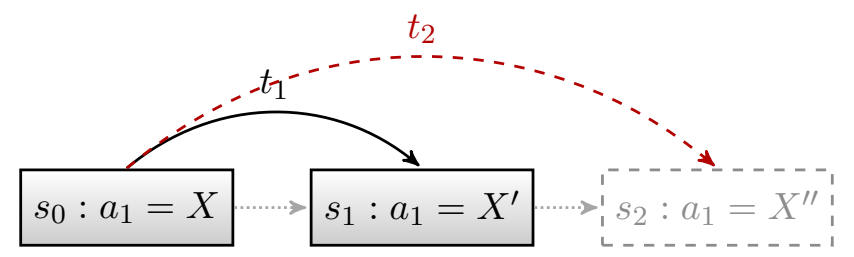

Figura 6.9: Exemplo de ocorrência de conflito de escrita.

A deteç̧ão de uma exceção, seja por produção de WED-state inconsistente ou falha em WED-transition, torna a instância inconsistente e implica na interrupção de sua execução. O núcleo da WED-tool registra a ocorrência por meio da alteração do status da instância para 'interrupted' (atributo da relação $R_{-}$WED-Flow_Instances) e da criação de uma tupla na relação $R_{-}$Interruptions, exibida na Figura $6.4(\mathrm{~d})$.

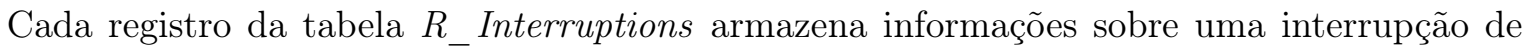
uma instância de WED-flow, como, por exemplo, identificador da instância, momento em que a interrupção foi registrada e o status da mesma. Quando a interrupção está relacionada à falha de execução de uma WED-transition, a tupla também armazena o identificador dessa execução (referente à relação $R_{-}$Execution_History) no atributo execution_interrupted. Além disso, o registro correspondente à execução que falhou tem seu status alterado para 'aborted' na relação $R_{-}$Execution_History. 
A interrupção de uma instância resulta na ativação do gerenciador de recuperação. Com as

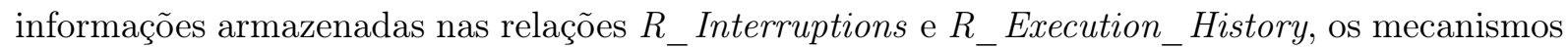
de recuperação são capazes de conduzir a instância e restaurar sua consistência. O gerenciador de recuperação fornece uma coleção de métodos de recuperação e um administrador é responsável pela escolha do método que será utilizado para tratar a interrupção de uma instância. Em linhas gerais, utilizando o gerenciador de recuperação é possível [SBF12]:

- Compensar uma ou mais WED-transitions executadas na instância interrompida por meio da execução das WED-compensations associadas;

- Definir uma nova WED-transition especial, para executar uma recuperação backward ou forward, que produza uma WED-state consistente [FBT ${ }^{+}$12][SBF12];

- Tentar executar novamente uma WED-transition que falhou e ocasionou a interrupção da instância;

- Alterar o modelo do WED-flow projetado para incluir o tratamento da exceção.

Como dito anteriormente, a implementação do gerenciador de recuperação está atualmente em curso [SBF12] e está fora do escopo deste trabalho. Após o tratamento da exceção por parte do gerenciador de recuperação, a interrupção pode ser concluída e o controle de execução reassume a responsabilidade de prosseguir a execução da instância e conduzi-la ao estado final do processo de negócio.

\subsection{Exemplo}

Nesta seção descreveremos como o WED-flow de venda de livros, processo utilizado como exemplo neste trabalho e detalhado na Seção 5.4, foi implementado na WED-tool.

\subsubsection{Modelo}

Como descrito na Seção 5.4, o modelo WED-flow para o processo de negócio de venda de livros é formado por onze WED-conditions e nove WED-transitions que são combinadas em onze WED-triggers. O arquivo XML, exibido no código B.1 do Apêndice B, contém a especificação completa do modelo e foi utilizado como entrada para a WED-tool para realizar a execução deste exemplo. A partir do arquivo XML, os elementos que compõem o WED-flow são extraídos e inseridos no banco de dados da ferramenta.

A Figura 6.10 exibe a relação de WED-conditions e a Figura 6.11 retrata as WED-transitions, preenchidas de acordo com o modelo. Cada WED-transition da relação está relacionada a uma classe em Ruby, disponíveis no Apêndice C. A Figura 6.12 mostra a relação de WED-flows, a qual contém o WED-flow "venda_livro", e a Figura 6.13 exibe os WED-triggers que compõem o modelo, definidos em função dos identificadores das três relações anteriores. 
R_WED-Conditions

\begin{tabular}{|c|c|c|c|c|}
\hline id & name & predicates & expression & awic \\
\hline 1 & "c_novo_pedido" & $\begin{array}{l}\text { - cliente,invalido,= } \\
\text { - pedido,recebido,= }\end{array}$ & 12 and & FALSE \\
\hline 2 & "c_pedido_valido" & $\begin{array}{l}\text { - cliente,validado,= } \\
\text { - pedido,validado,= }\end{array}$ & 12 and & FALSE \\
\hline 3 & "c_produto_reservado" & - produto,reservado,= & 1 & FALSE \\
\hline 4 & "c_pedido_pago" & - pedido,pago,= & 1 & FALSE \\
\hline 5 & "c_produto_enviado" & $\begin{array}{l}\text { - pedido,enviado,= } \\
\text { - produto,enviado,= }\end{array}$ & 12 and & FALSE \\
\hline 6 & "c_pedido_tratado" & $\begin{array}{l}\text { - pedido,envio notificado,= } \\
\text { - cliente,atualizado,= }\end{array}$ & 12 and & FALSE \\
\hline 7 & "c_pedido_finalizado" & $\begin{array}{l}\text { - pedido,concluido,= } \\
\text { - pedido,cancelado,= }\end{array}$ & 12 or & TRUE \\
\hline 8 & "c_pedido_invalido" & - pedido,invalido,= & 1 & FALSE \\
\hline 9 & "c_pagamento_recusado" & - pagamento,recusado,= & 1 & FALSE \\
\hline 10 & "c_recusa_notificada" & - pagamento,recusa notificada,= & 1 & FALSE \\
\hline 11 & "c_tentativa_excedida" & - pagamento,tentativas excedidas,= & 1 & FALSE \\
\hline
\end{tabular}

Figura 6.10: Relação de WED-conditions.

R_WED-Transitions
\begin{tabular}{|c|c|}
\hline id & name \\
\hline 1 & "t_validar_dados" \\
\hline 2 & "t_reservar_produto" \\
\hline 3 & "t_processar_pagamento" \\
\hline 4 & "t_enviar_produto" \\
\hline 5 & "t_emitir_notificacao" \\
\hline 6 & "t_atualizar_pfidelidade" \\
\hline 7 & "t_fechar_pedido" \\
\hline 8 & "t_abortar_venda" \\
\hline 9 & "t_emitir_notificacao_recusa" \\
\hline
\end{tabular}

Figura 6.11: Relação de WED-transitions.

R_WED-Flows

\begin{tabular}{|c|c|c|c|}
\hline id & name & final_condition & active \\
\hline 1 & venda_livro & 7 & TRUE \\
\hline
\end{tabular}

Figura 6.12: Relação de WED-flows.

R_WED-Triggers

\begin{tabular}{|c|c|c|c|c|c|}
\hline id & wed_condition_id & wed_transition_id & wed_flow_id & active & period \\
\hline 1 & 1 & 1 & 1 & TRUE & "1s" \\
\hline 2 & 2 & 2 & 1 & TRUE & "1s" \\
\hline 3 & 3 & 3 & 1 & TRUE & "3s" \\
\hline 4 & 4 & 4 & 1 & TRUE & "3s" \\
\hline 5 & 5 & 5 & 1 & TRUE & "3s" \\
\hline 6 & 5 & 6 & 1 & TRUE & "3s" \\
\hline 7 & 6 & 7 & 1 & TRUE & "1s" \\
\hline 8 & 8 & 8 & 1 & TRUE & "5s" \\
\hline 9 & 9 & 9 & 1 & TRUE & "5s" \\
\hline 10 & 10 & 3 & 1 & TRUE & "5s" \\
\hline 11 & 11 & 8 & 1 & TRUE & "5s" \\
\hline
\end{tabular}

Figura 6.13: Relação de WED-triggers. 


\subsubsection{Execução}

Nesta seção exemplificamos a execução de instâncias do WED-flow cujo modelo foi descrito na seção anterior. A Figura 6.14 retrata a relação de instâncias de WED-flows, contendo dados referentes a cinco instâncias, cada uma com uma característica em destaque, que serão explicadas em detalhes durante esta seção.

R_WED-Flow_Instances
\begin{tabular}{|r|c|c|c|c|}
\hline id & wed_flow_id & status & created_at & finalized_at \\
\hline 1 & 1 & "finished" & "2012-12-18 13:52:54.31" & "2012-12-18 13:53:06.37" \\
\hline 2 & 1 & "finished" & "2012-12-18 13:52:58.44" & "2012-12-18 13:53:21.56" \\
\hline 3 & 1 & "finished" & "2012-12-18 13:53:00.48" & "2012-12-18 13:53:21.57" \\
\hline 4 & 1 & "finished" & "2012-12-18 13:53:09.53" & "2012-12-18 13:53:16.64" \\
\hline 5 & 1 & "interrupted" & "2012-12-18 13:53:26.59" & \\
\hline
\end{tabular}

Figura 6.14: Relação de instâncias de WED-flows.

Cada instância é ilustrada por uma figura que exibe a sequência de WED-states produzidos durante a execução e também as WED-transitions responsáveis pela produção de cada estado. O identificador $i$ de cada estado $s_{i}$ refere-se ao atributo "id" da relação $R_{-}$WED-States, exibida na Figura 6.20, a qual contém todos os estados pertencentes às cinco instâncias. Já o rótulo de cada aresta em preto, $t_{i}$, refere-se a WED-transition $i$, cujo identificador está associado ao atributo "id" da relação $R_{-} W E D$-Transitions. Ademais, a Figura 6.21 exibe a relação $R_{-}$Execution_History preenchida com o histórico de execução de cada instância, o qual é formado por uma sequência de tuplas que contêm, entre outros dados, os identificadores da WED-transition executada e do WED-state que habilitou o disparo da mesma.

\section{Instância 1: Caminho normal}

A primeira instância exemplifica o caminho normal do WED-flow de venda de livro, utilizado na fase de modelagem exibida na Seção 5.3. A execução inicia-se com o recebimento do pedido, representado pelo WED-state inicial $s_{1}$. O estado inicial dispara a execução da WED-transition $t_{1}$, responsável pela validação dos dados do pedido, que produz como saída o estado $s_{2}$. Com os dados válidos, a transição para reserva do livro $\left(t_{2}\right)$ é disparada, e então, após sua conclusão, o pagamento é processado $\left(t_{3}\right)$. Na primeira tentativa o pagamento foi efetuado, produzindo o estado $s_{4}$, o qual provoca o disparo da transição de envio do produto ao cliente $\left(t_{4}\right)$. Após a conclusão e produção do estado $s_{8}$, o cliente foi notificado a respeito do envio e os pontos do programa de fidelidade foram contabilizados, tarefas que são executadas em paralelo (transições $t_{5}$ e $t_{6}$ ). Com a conclusão de ambas, o pedido é fechado por meio da execução da transição $t_{7}$, alcançando seu estado final $s_{16}$.

A Figura 6.15 ilustra a execução da primeira instância. Os WED-states que a compõem correspondem às linhas destacadas na relação $R_{-}$WED-States, exibida na Figura 6.20. Da mesma 
forma, as linhas destacadas na relação $R_{-}$Execution_History, exibida na Figura 6.21, formam o histórico de execução desta instância.

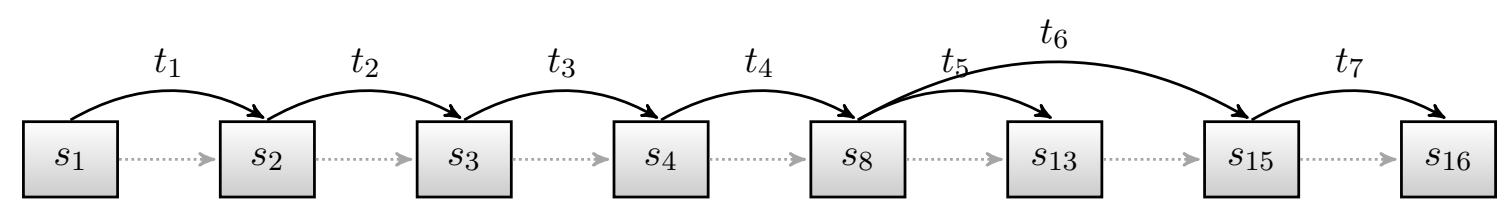

Figura 6.15: Execução da instância 1.

\section{Instância 2: Venda realizada na segunda tentativa de pagamento}

A segunda instância, ilustrada na Figura 6.16, retrata a execução de uma instância com ocorrência de uma exceção esperada, a qual havia sido previamente modelada. Após a conclusão da reserva do livro, o pagamento foi processado, porém recusado. Assim, como projetado no modelo, a recusa foi notificada ao cliente $\left(t_{9}\right)$ e uma segunda tentativa de processamento de pagamento foi executada. Desta vez, o pagamento foi concretizado com sucesso, permitindo que o procedimento de venda prosseguisse como previsto no caminho normal e fosse concluído. É importante ressaltar que, como exibido na Figura 6.16, a transição $t_{3}$, referente ao processamento do pagamento, foi executada duas vezes.

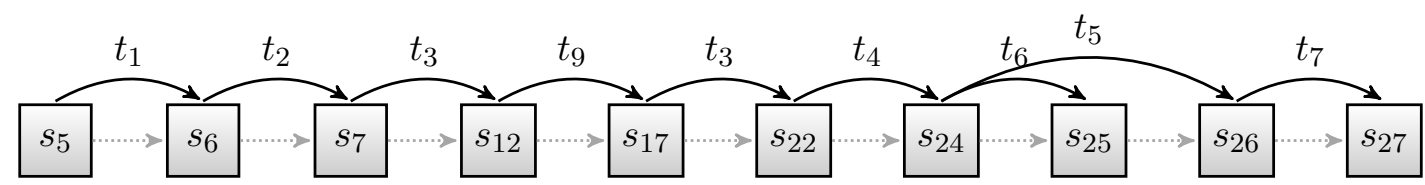

Figura 6.16: Execução da instância 2.

\section{Instância 3: Venda cancelada por pagamento recusado}

A terceira instância exemplifica uma venda cancelada por falta de pagamento. Como ocorreu na instância 2, houve duas tentativas de processamento de pagamento (duas execuções da transição $t_{3}$ ). Entretanto, para esta instância, a segunda tentativa de pagamento também foi recusada e então, como projetado no modelo, a transição para abortar a venda foi disparada, produzindo o WED-state final da instância, o qual caracteriza uma venda cancelada. A Figura 6.17 ilustra a execução da instância 3 , com destaque para a transição $t_{8}$ que aborta a venda do produto, projetada para tratar exceções esperadas.

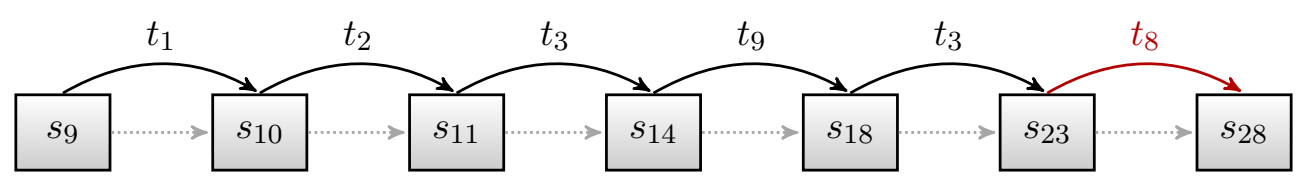

Figura 6.17: Execução da instância 3. 


\section{Instância 4: Venda cancelada por dados inválidos}

A quarta instância também exemplifica o tratamento de uma exceção, decorrente do recebimento de dados inválidos. Para esta instância, a execução da transição de validação do pedido $\left(t_{1}\right)$ verificou que os dados recebidos eram inválidos, causando a produção de um WED-state que não pertence ao caminho normal do WED-flow. Como tratamento de exceção, a transição que aborta a venda $\left(t_{8}\right)$ foi disparada. A Figura 6.18 ilustra este caso. É importante ressaltar que a WEDtransition $t_{8}$, de nome "t_abortar_venda", foi utilizada na definição de dois WED-triggers (com identificadores 8 e 11 na Figura 6.13), ambos utilizados como tratamento de exceções esperadas, como descrito nas instâncias 3 e 4.

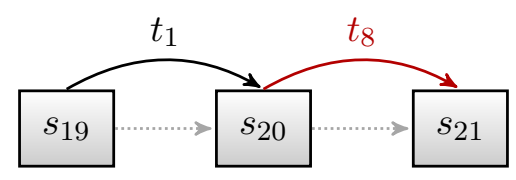

Figura 6.18: Execução da instância 4.

\section{Instância 5: Interrupção por erro}

A quinta instância, ilustrada pela Figura 6.19 retrata a ocorrência da interrupção de uma instância. Como exibido na figura, a transição de validação dos dados foi executada, seguida da reserva do livro. Em decorrência, a transição $t_{3}$ foi disparada, mas não foi concluída com sucesso pois foi cancelada manualmente. Devido à falha de execução da WED-transition, a execução da instância 5 foi interrompida e o tratamento desta exceção (não esperada) passa a ser responsabilidade do gerenciador de recuperação.

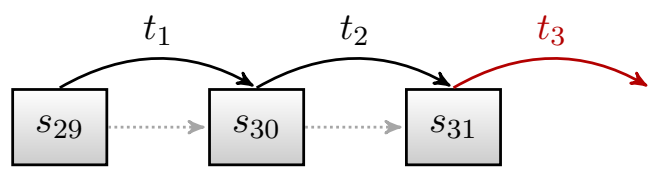

Figura 6.19: Execução da instância 5.

O núcleo da ferramenta WED-tool registra a ocorrência da interrupção por meio da criação de uma tupla na relação $R_{-}$Interruptions, exibida na Figura 6.22. As últimas três tuplas da relação da Figura 6.20 correspondem aos WED-states pertencentes a esta instância e as últimas três tuplas da relação da Figura 6.21 formam o histórico de execução da mesma. Vale ressaltar que a última entrada do histórico da instância 5 (id 27 da relação $R_{-}$Execution_History) indica que a execução da transição $t_{3}$ foi abortada. Com as informações armazenadas nas relações $R_{-}$Interruptions e $R_{-}$Execution_History, os mecanismos de recuperação são capazes de restaurar a instância e reativar sua execução. 


\begin{tabular}{|c|c|c|c|c|c|c|c|c|c|c|}
\hline id & wed_flow_instance_id & created_at & id_cliente & cliente & pontos & id_produto & produto & id_pedido & pedido & pagamento \\
\hline 1 & 1 & "2012-12-18 13:52:54.33" & 42 & "invalido" & 40 & 55 & "requisitado" & 3 & "recebido" & \\
\hline 2 & 1 & "2012-12-18 13:52:55.43" & 42 & "validado" & 40 & 55 & "requisitado" & 3 & "validado" & \\
\hline 3 & 1 & "2012-12-18 13:52:56.41" & 42 & "validado" & 40 & 55 & "reservado" & 3 & "validado" & \\
\hline 4 & 1 & "2012-12-18 13:52:57.39" & 42 & "validado" & 40 & 55 & "vendido" & 3 & "pago" & "recebido" \\
\hline 5 & 2 & "2012-12-18 13:52:58.44" & 25 & "invalido" & 0 & 9 & "requisitado" & 1 & "recebido" & \\
\hline 6 & 2 & "2012-12-18 13:52:59.37" & 25 & "validado" & 0 & 9 & "requisitado" & 1 & "validado" & \\
\hline 7 & 2 & "2012-12-18 13:53:00.39" & 25 & "validado" & 0 & 9 & "reservado" & 1 & "validado" & \\
\hline 8 & 1 & "2012-12-18 13:53:00.40" & 42 & "validado" & 40 & 55 & "enviado" & 3 & "enviado" & "recebido" \\
\hline 9 & 3 & "2012-12-18 13:53:00.48" & 13 & "invalido" & 10 & 23 & "requisitado" & 2 & "recebido" & \\
\hline 10 & 3 & "2012-12-18 13:53:01.40" & 13 & "validado" & 10 & 23 & "requisitado" & 2 & "validado" & \\
\hline 11 & 3 & "2012-12-18 13:53:02.36" & 13 & "validado" & 10 & 23 & "reservado" & 2 & "validado" & \\
\hline 12 & 2 & "2012-12-18 13:53:03.37" & 25 & "validado" & 0 & 9 & "reservado" & 1 & "validado" & "recusado" \\
\hline 13 & 1 & "2012-12-18 13:53:03.37" & 42 & "validado" & 40 & 55 & "enviado" & 3 & "envio notificado" & "recebido" \\
\hline 14 & 3 & "2012-12-18 13:53:03.38" & 13 & "validado" & 10 & 23 & "reservado" & 2 & "validado" & "recusado" \\
\hline 15 & 1 & "2012-12-18 13:53:03.39" & 42 & "atualizado" & 50 & 55 & "enviado" & 3 & "envio notificado" & "recebido" \\
\hline 16 & 1 & "2012-12-18 13:53:04.34" & 42 & "atualizado" & 50 & 55 & "enviado" & 3 & "concluido" & "recebido" \\
\hline 17 & 2 & "2012-12-18 13:53:06.38" & 25 & "validado" & 0 & 9 & "reservado" & 1 & "validado" & "recusa notificada" \\
\hline 18 & 3 & "2012-12-18 13:53:06.40" & 13 & "validado" & 10 & 23 & "reservado" & 2 & "validado" & "recusa notificada" \\
\hline 19 & 4 & "2012-12-18 13:53:09.54" & 71 & "invalido" & 0 & 17 & "requisitado" & 1 & "recebido" & \\
\hline 20 & 4 & "2012-12-18 13:53:10.63" & 71 & "invalido" & 0 & 17 & "requisitado" & 1 & "invalido" & \\
\hline 21 & 4 & "2012-12-18 13:53:11.65" & 71 & "invalido" & 0 & 17 & "disponivel" & 1 & "cancelado" & \\
\hline 22 & 2 & "2012-12-18 13:53:11.65" & 25 & "validado" & 0 & 9 & "vendido" & 1 & "pago" & "recebido" \\
\hline 23 & 3 & "2012-12-18 13:53:11.66" & 13 & "validado" & 10 & 23 & "reservado" & 2 & "validado" & "tentativas excedidas" \\
\hline 24 & 2 & "2012-12-18 13:53:12.64" & 25 & "validado" & 0 & 9 & "enviado" & 1 & "enviado" & "recebido" \\
\hline 25 & 2 & "2012-12-18 13:53:15.61" & 25 & "atualizado" & 15 & 9 & "enviado" & 1 & "enviado" & "recebido" \\
\hline 26 & 2 & "2012-12-18 13:53:15.61" & 25 & "atualizado" & 15 & 9 & "enviado" & 1 & "envio notificado" & "recebido" \\
\hline 27 & 2 & "2012-12-18 13:53:16.64" & 25 & "atualizado" & 15 & 9 & "enviado" & 1 & "concluido" & "recebido" \\
\hline 28 & 3 & "2012-12-18 13:53:16.65" & 13 & "validado" & 10 & 23 & "disponivel" & 2 & "cancelado" & "tentativas excedidas" \\
\hline 29 & 5 & "2012-12-18 13:53:26.59" & 34 & "invalido" & 0 & 46 & "requisitado" & 1 & "recebido" & \\
\hline 30 & 5 & "2012-12-18 13:53:27.54" & 34 & "validado" & 0 & 46 & "requisitado" & 1 & "validado" & \\
\hline 31 & 5 & "2012-12-18 13:53:28.52" & 34 & "validado" & 0 & 46 & "reservado" & 1 & "validado" & \\
\hline
\end{tabular}

Figura 6.20: Relação de WED-states.

\begin{tabular}{|c|c|c|c|c|c|c|c|c|}
\hline id & wed_transition_id & wed_flow_instance_id & status & created_at & completed_at & initial_state_id & current_state_id & final_state_id \\
\hline 1 & 1 & 1 & "success" & "2012-12-18 13:52:55.42" & "2012-12-18 13:52:55.46" & 1 & 1 & 2 \\
\hline 2 & 2 & 1 & "success" & "2012-12-18 13:52:56.40" & "2012-12-18 13:52:56.42" & 2 & 2 & 3 \\
\hline 3 & 3 & 1 & "success" & "2012-12-18 13:52:57.38" & "2012-12-18 13:52:57.42" & 3 & 3 & 4 \\
\hline 4 & 1 & 2 & "success" & "2012-12-18 13:52:59.36" & "2012-12-18 13:52:59.38" & 5 & 5 & 6 \\
\hline 5 & 2 & 2 & "success" & "2012-12-18 13:53:00.38" & "2012-12-18 13:53:00.41" & 6 & 6 & 7 \\
\hline 6 & 4 & 1 & "success" & "2012-12-18 13:53:00.38" & "2012-12-18 13:53:00.42" & 4 & 4 & 8 \\
\hline 7 & 1 & 3 & "success" & "2012-12-18 13:53:01.37" & "2012-12-18 13:53:01.42" & 9 & 9 & 10 \\
\hline 8 & 2 & 3 & "success" & "2012-12-18 13:53:02.34" & "2012-12-18 13:53:02.36" & 10 & 10 & 11 \\
\hline 9 & 3 & 2 & "success" & "2012-12-18 13:53:03.36" & "2012-12-18 13:53:03.39" & 7 & 7 & 12 \\
\hline 10 & 5 & 1 & "success" & "2012-12-18 13:53:03.37" & "2012-12-18 13:53:03.42" & 8 & 8 & 13 \\
\hline 11 & 6 & 1 & "success" & "2012-12-18 13:53:03.37" & "2012-12-18 13:53:03.41" & 8 & 13 & 15 \\
\hline 12 & 3 & 3 & "success" & "2012-12-18 13:53:03.37" & "2012-12-18 13:53:03.41" & 11 & 11 & 14 \\
\hline 13 & 7 & 1 & "success" & "2012-12-18 13:53:04.34" & "2012-12-18 13:53:04.36" & 15 & 15 & 16 \\
\hline 14 & 9 & 2 & "success" & "2012-12-18 13:53:06.37" & "2012-12-18 13:53:06.40" & 12 & 12 & 17 \\
\hline 15 & 9 & 3 & "success" & "2012-12-18 13:53:06.39" & "2012-12-18 13:53:06.40" & 14 & 14 & 18 \\
\hline 16 & 1 & 4 & "success" & "2012-12-18 13:53:10.62" & "2012-12-18 13:53:10.66" & 19 & 19 & 20 \\
\hline 17 & 8 & 4 & "success" & "2012-12-18 13:53:11.64" & "2012-12-18 13:53:11.69" & 20 & 20 & 21 \\
\hline 18 & 3 & 2 & "success" & "2012-12-18 13:53:11.64" & "2012-12-18 13:53:11.70" & 17 & 17 & 22 \\
\hline 19 & 3 & 3 & "success" & "2012-12-18 13:53:11.65" & "2012-12-18 13:53:11.69" & 18 & 18 & 23 \\
\hline 20 & 4 & 2 & "success" & "2012-12-18 13:53:12.63" & "2012-12-18 13:53:12.66" & 22 & 22 & 24 \\
\hline 21 & 6 & 2 & "success" & "2012-12-18 13:53:15.60" & "2012-12-18 13:53:15.62" & 24 & 24 & 25 \\
\hline 22 & 5 & 2 & "success" & "2012-12-18 13:53:15.60" & "2012-12-18 13:53:15.62" & 24 & 25 & 26 \\
\hline 23 & 7 & 2 & "success" & "2012-12-18 13:53:16.64" & "2012-12-18 13:53:16.67" & 26 & 26 & 27 \\
\hline 24 & 8 & 3 & "success" & "2012-12-18 13:53:16.64" & "2012-12-18 13:53:16.67" & 23 & 23 & 28 \\
\hline 25 & 1 & 5 & "success" & "2012-12-18 13:53:27.53" & "2012-12-18 13:53:27.56" & 29 & 29 & 30 \\
\hline 26 & 2 & 5 & "success" & "2012-12-18 13:53:28.52" & "2012-12-18 13:53:28.53" & 30 & 30 & 31 \\
\hline 27 & 3 & 5 & "aborted" & "2012-12-18 13:53:30.52" & "2012-12-18 13:53:30.53" & 31 & & \\
\hline
\end{tabular}

Figura 6.21: Relação de histórico de execução de transições.

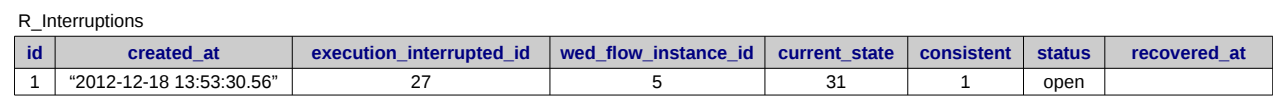

Figura 6.22: Relação de interrupções.

\subsubsection{Alteração do modelo}

Para ilustrar a alteração de modelos WED-flow utilizando a ferramenta WED-tool, faremos duas alterações no modelo de venda de livros apresentado como exemplo neste capítulo: (1) caso 
o pagamento seja recusado na primeira tentativa, não haverá notificação ao cliente e a venda será logo abortada; (2) inclusão de uma transição para atualização do estoque, a qual pode ser executada após o produto ter sido enviado, em paralelo às transições de notificação de envio e atualização do programa de fidelidade. O diagrama da Figura 6.23 retrata o modelo alterado.

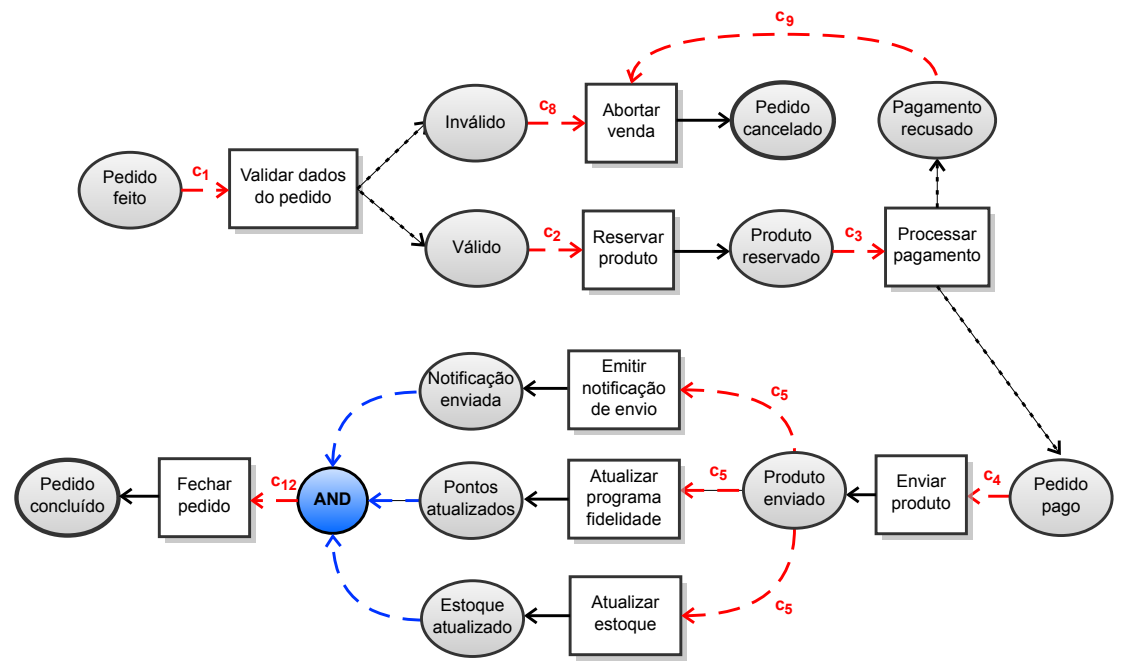

Figura 6.23: Diagrama que ilustra o WED-flow para venda de livros depois da alteração.

O arquivo XML exibido no Código B.2 do Apêndice B contém a especificação completa para a realização da alteração do modelo WED-flow na ferramenta WED-tool. A modificação realizada no modelo é composta por:

\section{- Alteração 1: Remoção da notificação de pagamento recusado.}

- Remoção dos WED-triggers 〈c_pagamento_recusado,t_emitir_notificacao_recusa $\langle$ c_recusa_notificada, t_processar_pagamento $\rangle$ e $\langle$ c_tentativa_excedida, t_abortar_venda $\rangle$;

- Remoção das WED-conditions "c_tentativa_excedida" e "c_recusa_notificada";

- Remoção da WED-transition "t_emitir_notificacao_recusa";

- Adição do WED-trigger 〈c_pagamento_recusado, t_abortar_venda .

\section{- Alteração 2: Adição da atualização do estoque.}

- Remoção do WED-trigger 〈c_pedido_tratado, t_fechar_pedido);

- Remoção da WED-condition "c_pedido_tratado";

- Adição da WED-condition "c_pedido_e_estoque_tratados";

- Adição dos WED-triggers〈c_produto_enviado, t_atualizar_estoque e $\langle$ c_pedido_e_estoque_tratados, t_fechar_pedido $\rangle$. 


\subsection{Experimentos}

Nesta seção descreveremos alguns experimentos que foram executados na WED-tool para uma avaliação inicial do desempenho da implementação. Os testes foram realizados no sistema operacional Ubuntu 12.04 instalado em um computador com processador Intel@ Core i5 de 3.10 Ghz e com $8 \mathrm{~Gb}$ de memória RAM.

\subsubsection{WED-flow de venda de livros}

Utilizando o exemplo de processo de negócio de venda de livros, descrito na Seção 6.4, realizamos a execução de conjuntos de instâncias do WED-flow de tamanhos variados. Nos experimentos, cada grupo composto por $n$ instâncias foi executado separadamente e as instâncias foram criadas sequencialmente, por meio de um laço de repetição.

Os gráficos dos experimentos referem-se ao tempo de execução do caminho normal do WEDflow de venda de livros (descrito na instância 1 da Seção 6.4.2) e os dados utilizados para produzilos foram retirados das colunas "created_at" e "finalized_at" da relação $R_{-}$WED-Flow_Instances. Duas medidas de tempo de execução foram calculadas: tempo médio de execução de uma instância do conjunto e tempo total de execução do conjunto.

O tempo de execução de cada instância do WED-flow foi calculado por meio da diferença entre os instantes de finalização e de criação da mesma. Em outras palavras, para cada instância $i$, o tempo de execução é dado por finalized_at $(i)$ - created_at $(i)$. Assim, com o tempo de execução de cada instância $i$ (com $1 \leq i \leq n$, sendo $n$ o tamanho do conjunto), calculamos o tempo médio de execução de uma instância em cada conjunto de tamanho $n$.

O tempo total de execução do conjunto de instâncias do WED-flow foi calculado pela diferença entre o instante de finalização da última instância a ser concluída e o instante de criação da primeira instância a ser inicializada. Concretamente, em função dos atributos da relação

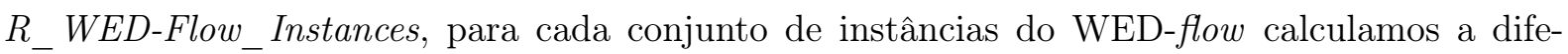
rença finalized_at(instância $\left.a_{u}\right)$ - created_at(instância $\left.a_{p}\right)$, sendo instância $a_{p}$ a primeira instância a ser criada e instância $a_{u}$ a última instância a ser finalizada no grupo.

Os resultados obtidos a partir da execução do WED-flow de venda de livros são descritos a seguir.

\section{- Tempo de execução para até 100 instâncias}

Neste experimento avaliamos o tempo de execução de uma instância de WED-flow e, para isso, utilizamos grupos contendo 1, 10, 20, ., 90 e 100 instâncias. A Figura 6.24 exibe o gráfico que retrata o tempo médio da execução de uma instância do WED-flow em cada grupo e também o tempo total de execução para todas as instâncias do grupo. 


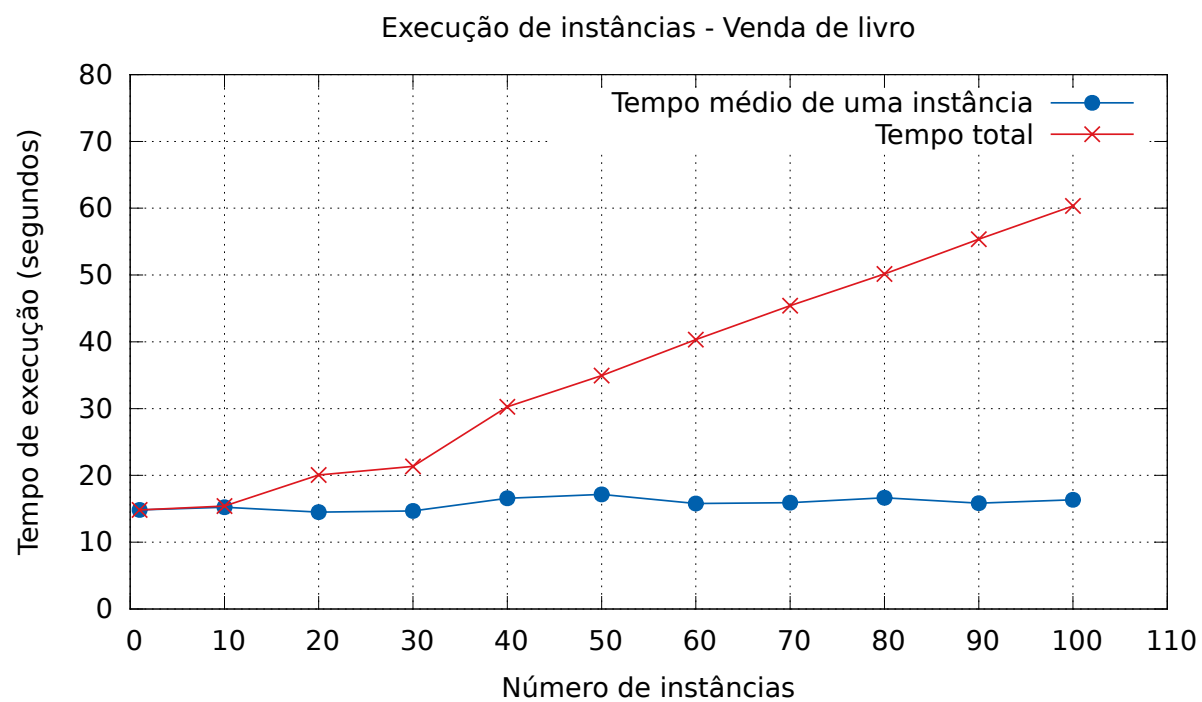

Figura 6.24: Gráfico do tempo de execução de instâncias para o exemplo de venda de livros.

\section{- Tempo de execução para até 5.000 instâncias}

Neste experimento avaliamos apenas o tempo total de execução do grupo de instâncias de WED-flow e, para isso, aumentamos significamente o número de instâncias nos grupos. A Figura 6.25 exibe o gráfico referente a este experimento para grupos contendo 1, 250, 500, $1000,1500, \ldots, 4500$ e 5000 instâncias.

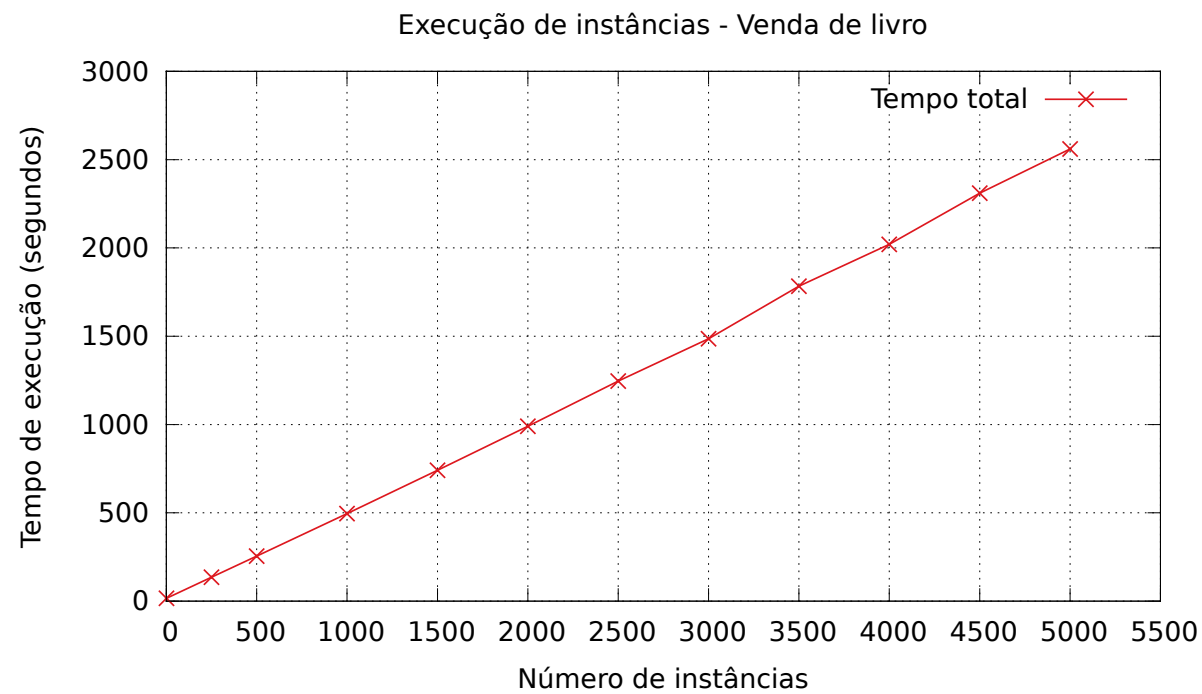

Figura 6.25: Gráfico do tempo de execução de instâncias para o exemplo de venda de livros.

A partir dos gráficos das Figuras 6.24 e 6.25 observa-se que o tempo total de execução de um conjunto de instâncias de WED-flow apresenta crescimento linear em relação ao tamanho dos grupos. Ademais, também pode-se observar que, embora a quantidade de instâncias nos grupos seja variada, o tempo médio de execução de uma instância do WED-flow permanece aproximadamente o mesmo para todos os grupos de instâncias utilizados no experimento. 


\subsubsection{Sequencial versus paralelo}

Além do WED-flow de venda de livros, também realizamos experimentos com outros dois modelos para verificar o comportamento da WED-tool. Os modelos utilizados nos testes não estão associados a nenhum processo de negócio real; eles são compostos por dez WED-triggers que não apresentam valor semântico e foram produzidos especificamente para este experimento, apenas para diversificar a estrutura do WED-flow.

No primeiro modelo utilizado nesse experimento, correspondente à Figura 6.26, todas as transições são executadas sequencialmente. Já o segundo modelo, correspondente à Figura 6.27, possui oito transições que podem ser executadas em paralelo. Assim, na descrição dos resultados dos testes chamaremos o modelo 1 de WED-flow sequencial e o modelo 2 de WED-flow paralelo.

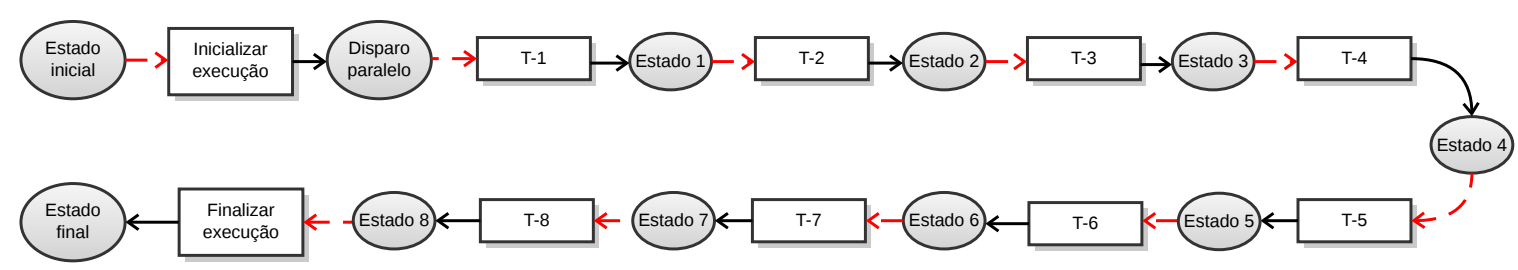

Figura 6.26: Modelo 1: WED-flow com transições sequenciais.

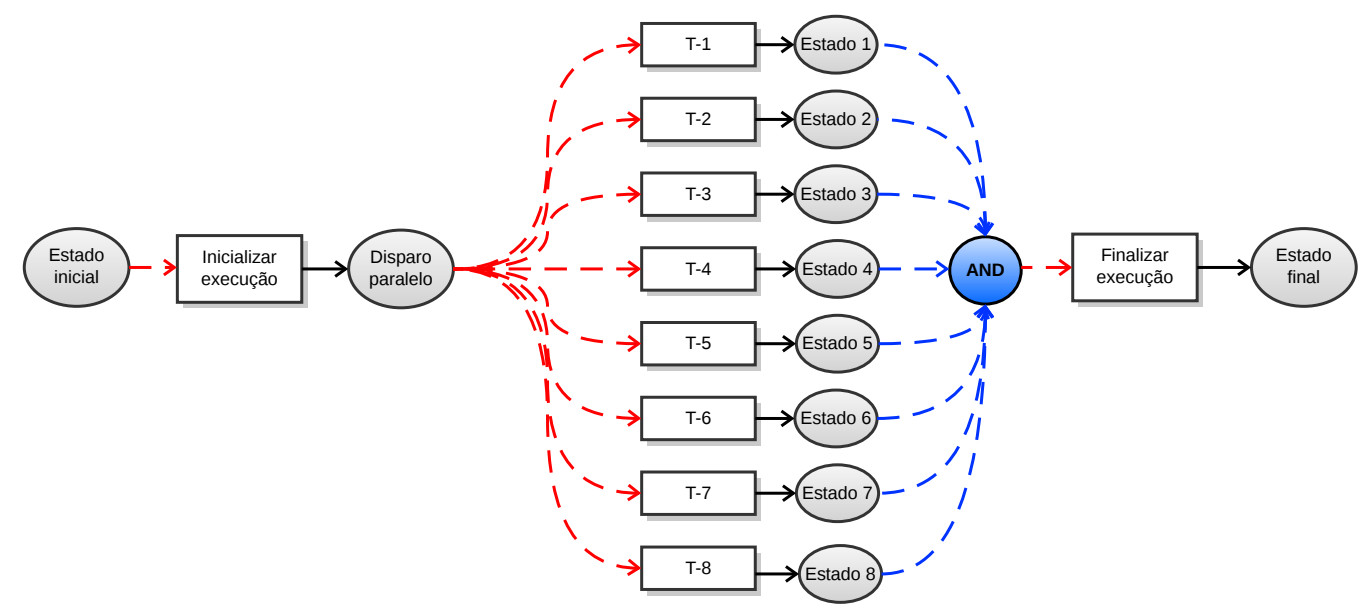

Figura 6.27: Modelo 2: WED-flow com transições em paralelo.

Para os WED-flows associados aos modelos 1 e 2, ilustrados nas Figuras 6.26 e 6.27 respectivamente, realizamos a execução de conjuntos de instâncias de WED-flow de diferentes tamanhos $n$, com $n$ variando de 500 a 5000. Cada grupo composto por $n$ instâncias foi executado separadamente e as instâncias foram criadas sequencialmente, por meio de um laço de repetição. Uma instância é sempre criada por meio do seguinte conjunto de operações: inserção de uma tupla na

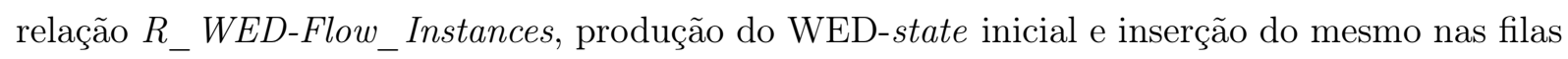
de todos os WED-triggers associados ao WED-flow instanciado.

De maneira análoga aos testes realizados com o WED-flow de venda de livros, neste experimento também foram calculados, para cada conjunto de instâncias de WED-flow, o tempo médio 
de execução de uma instância e o tempo total de execução do conjunto. As Figuras 6.28 e 6.29 retratam os resultados obtidos nesse experimento. Enquanto o primeiro gráfico exibe o tempo médio de execução de uma instância, tanto para o WED-flow sequencial como para o paralelo, o segundo gráfico exibe o tempo total de execução de cada grupo, também para ambos os modelos.

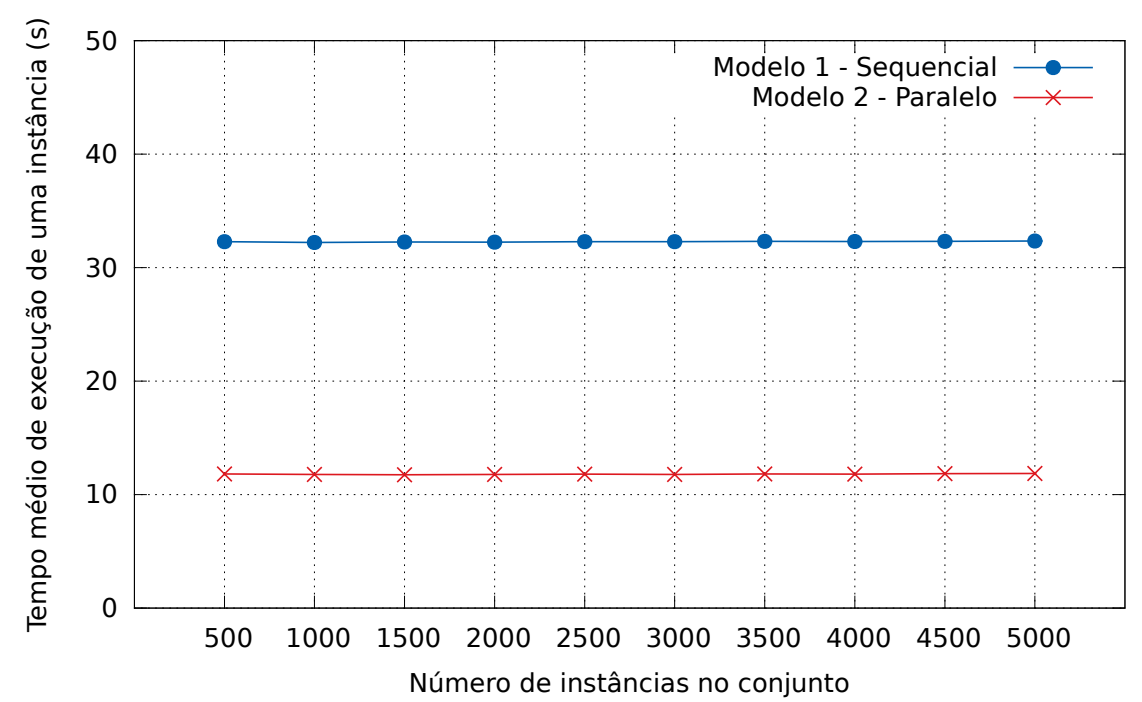

Figura 6.28: Gráfico do tempo médio de execução de uma instância de WED-flow.

A partir do gráfico da Figura 6.28, podemos observar que, como esperado, a execução de uma instância do WED-flow sequencial teve duração maior quando comparada à execução das instâncias do WED-flow paralelo. Além disso, assim como observou-se no experimento do WEDflow de venda de livros, o tempo médio de execução de uma instância para cada WED-flow manteve-se aproximadamente o mesmo em todos os grupos de instâncias deste experimento.

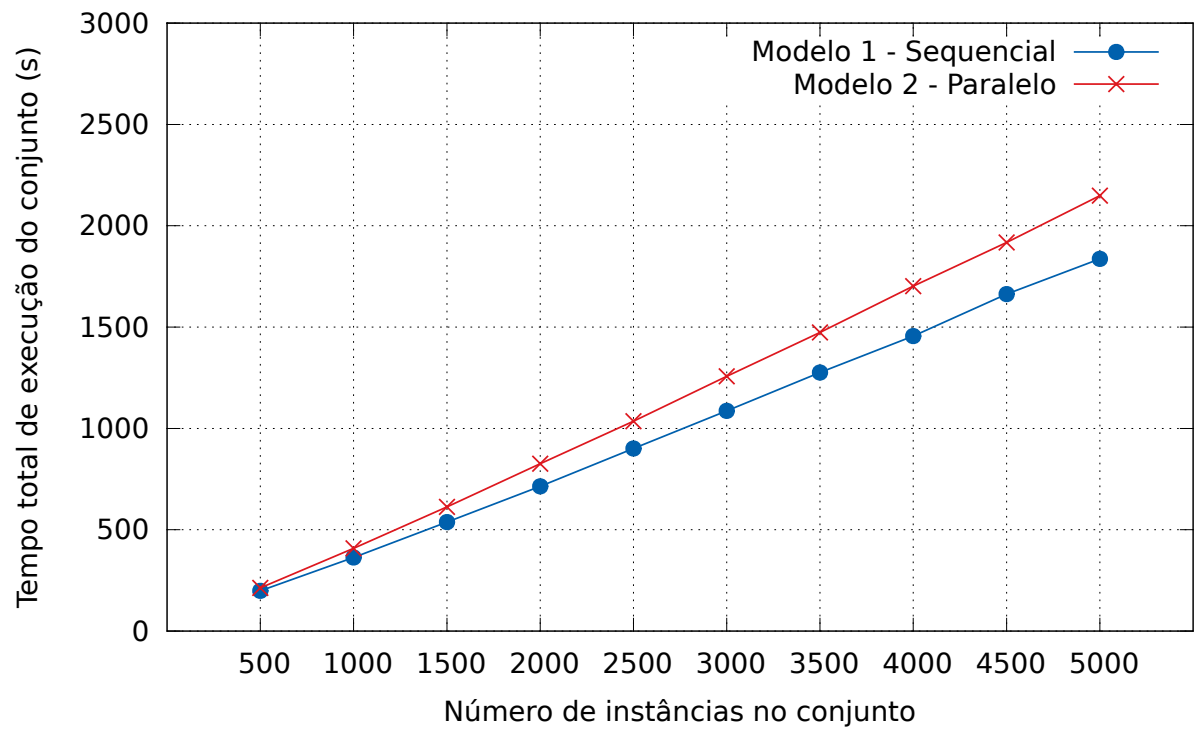

Figura 6.29: Gráfico do tempo total para a execução de um conjunto de instâncias de WED-flow. 
No gráfico da Figura 6.29 observa-se que o tempo total de execução de instâncias do WEDflow paralelo é maior quando comparado ao WED-flow sequencial. A princípio, esse resultado pode parecer contraditório ao retratado no gráfico da Figura 6.28, já que o tempo médio para execução de uma instância do WED-flow paralelo é menor quando comparado ao WED-flow sequencial. Entretanto, isso ocorre porque, neste experimento, a duração da execução de um grupo de instâncias de WED-flow é diretamente influenciada pelo tempo de criação das instâncias e, no WED-flow paralelo, o tempo de instanciação é maior.

Para analisar o resultado obtido no gráfico da Figura 6.29, recuperamos da relação $R_{-} W E D$ Flow_Instances o tempo de criação de todas as instâncias para cada conjunto do experimento. O tempo de criação das instâncias de um conjunto de tamanho $n$ foi calculado pela diferença created_at $\left(i_{n}\right)$-created_at $\left(i_{1}\right)$, sendo $i_{1}$ a primeira instância a ser criada no grupo e $i_{n}$ a última instância a ser criada. O gráfico da Figura 6.30 retrata o resultado obtido com o cálculo efetuado para cada conjunto e, adicionalmente, exibe novamente o tempo total de execução de cada grupo para fins comparativos.

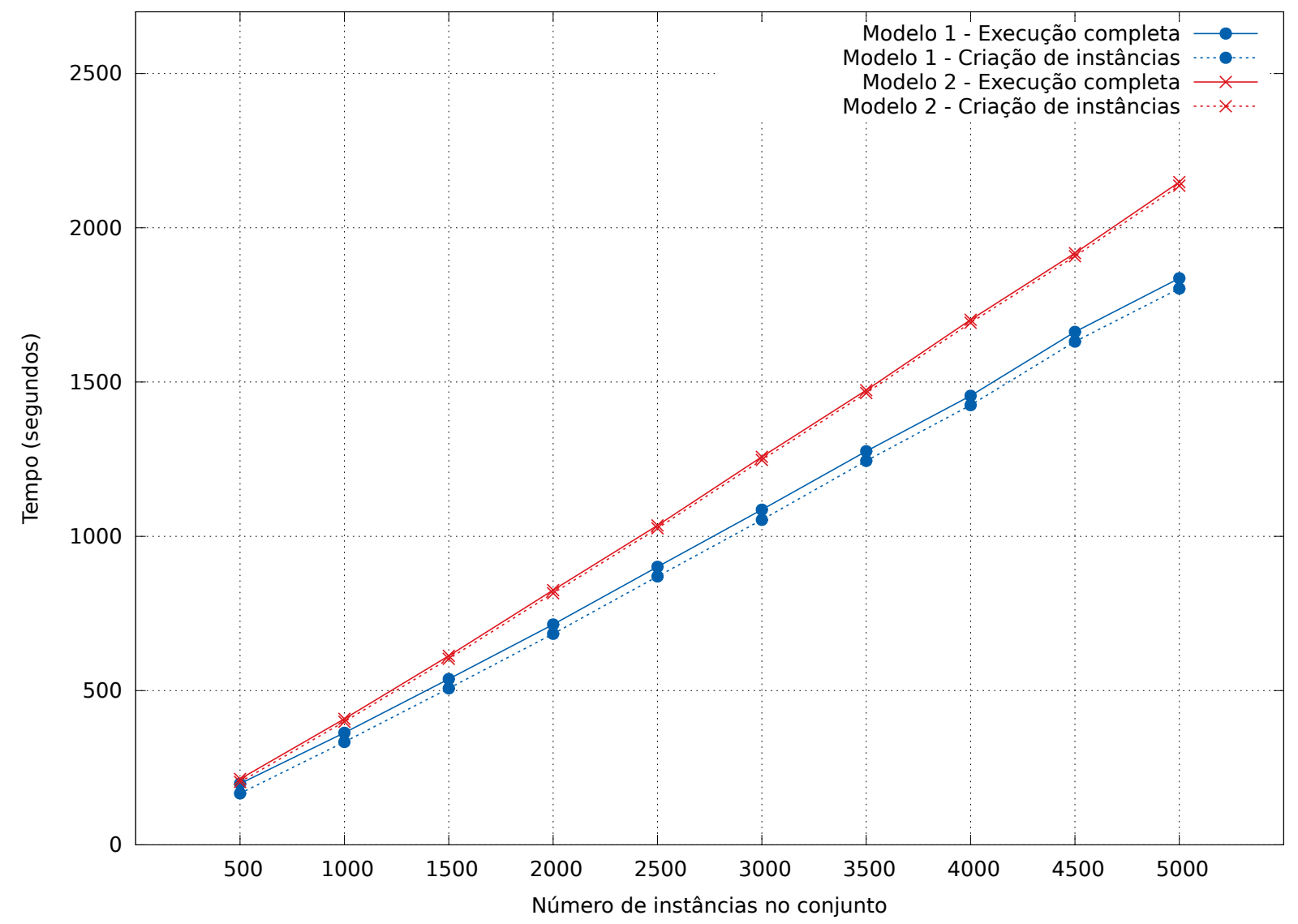

Figura 6.30: Gráfico do tempo de criação e execução de instâncias.

Como pode-se observar no gráfico da Figura 6.30, neste experimento, a maior parte do tempo consumido na execução completa de um grupo de instâncias de WED-flow corresponde à criação das mesmas. Nos experimentos realizados neste trabalho, o procedimento de instanciação de 
WED-flow compartilha os recursos do computador com as instâncias que já estão sendo executadas. Embora o procedimento de instanciação seja exatamente igual para ambos os WED-flows sequencial e paralelo, a instanciação do WED-flow paralelo é mais demorada pois esse procedimento compartilha os recursos do computador com a execução de instâncias que possuem diversas threads ativas devido ao disparo de transições paralelas.

\subsection{Conclusão}

Neste capítulo descrevemos uma implementação do arcabouço WED-flow para controle de processos transacionais. A implementação apresentada corresponde ao núcleo da ferramenta de software WED-tool, o qual é a principal contribuição deste trabalho. A WED-tool pode ser dividida em três módulos que possuem funções específicas: configuração, execução e recuperação.

O elemento inicial para utilização da WED-tool é a escrita da especificação de um modelo WED-flow em formato XML, seguindo a estrutura do XML Schema apresentado no Apêndice A. A partir da especificação em XML, a ferramenta realiza sua configuração inicial, o que inclui a criação da estrutura do banco de dados em que esta implementação se baseia, cujo modelo foi apresentado e detalhado na Seção 6.1. Assim, os dados referentes à especificação do WED-flow podem ser extraídos do XML e inseridos no BD. Adicionalmente, o núcleo da WED-tool também permite que o modelo projetado seja facilmente alterado, possibilitando a evolução incremental do mesmo.

Após a configuração inicial, é possível instanciar os WED-flows projetados e controlar a execução das instâncias no módulo de controle de execução, conforme descrito na Seção 6.2. A execução de uma instância corresponde a uma sequência de transições de estados que são disparadas pelos WED-triggers que compõem o WED-flow. O núcleo da WED-tool armazena detalhadamente todos os WED-states produzidos durante a execução de uma instância e também informações sobre a execução de cada WED-transition. Dessa maneira, a ferramenta possibilita o rastreamento detalhado da execução de todas as instâncias de WED-flow.

Durante a execução de uma instância de WED-flow, uma exceção pode ser detectada tornando a instância inconsistente e provocando sua interrupção. Como detalhado na Seção 6.3, atualmente a WED-tool é capaz de detectar exceções referentes à falha de execução de uma WED-transition e à produção de WED-state inconsistente. Em ambos os casos, o núcleo da WED-tool interrompe a execução da instância e fornece os dados necessários para que gerenciador de recuperação seja capaz de executar mecanismos de recuperação e restaurar a consistência da instância.

Para ilustrar a modelagem de um processo de negócio utilizando a WED-flow, descrevemos na Seção 6.4 o exemplo de venda de livros e apresentamos a especificação completa do modelo no Apêndice B. A partir do modelo WED-flow, realizamos a execução concreta de cinco instâncias utilizando a WED-tool, as quais foram detalhadamente retratadas neste capítulo. Ademais, também exemplificamos a alteração do WED-flow de venda de livros por meio da adição e remoção 
de WED-conditions, WED-transitions e WED-triggers, utilizando o XML.

Por fim, exibimos alguns experimentos executados para realizar uma avaliação inicial do desempenho da implementação desenvolvida, os quais indicam a viabilidade prática da abordagem em relação à eficiência. A partir dos experimentos, podemos observar que, na execução de conjuntos de instâncias de um WED-flow, o tempo médio de execução de uma instância independe do tamanho do grupo e também que o tempo total de execução de um conjunto de instâncias apresenta crescimento linear em relação ao tamanho do conjunto. 
78 WED-TOOL 


\section{Capítulo 7}

\section{Conclusões}

A área de gerenciamento de processos de negócios apresenta-se ativa, trazendo desafios que englobam todas as fases do ciclo de vida de um processo de negócio. Este trabalho abordou principalmente a representação e modelagem de um processo de negócio, a execução com confiabilidade e o tratamento de exceções. Neste capítulo apresentaremos um breve resumo e sugestões para pesquisas futuras.

A modelagem de processos de negócio tem sido estudada durante décadas e diversos conceitos e ferramentas foram propostos para o desenvolvimento dessa fase. Utilizando linguagens de modelagem baseadas em grafos, frequentemente por meio de uma representação gráfica, o processo de negócio é explicitamente definido, permitindo o uso de arcabouços formais para validação do modelo projetado. Já as linguagens de modelagem baseadas em regras permitem que, em tempo de execução, os possíveis caminhos de execução do processo de negócio sejam determinados a partir de um conjunto de regras. Adicionalmente, a natureza flexível das regras admite que elas sejam facilmente alteradas e também que o modelo evolua incrementalmente. As possibilidades para modelagem são inúmeras, cada qual com vantagens e desvantagens que devem ser avaliadas e adequadas de acordo com as características do processo de negócio a ser projetado.

Após a conclusão da modelagem, há a fase de configuração e implementação para possibilitar a execução de instâncias de processos de negócio. Inseridos nesse contexto, sistemas de gerenciamento de workflows são amplamente utilizados para automatizar PNs, permitindo a modelagem, execução e análise do processo. Embora sistemas atuais sejam capazes de controlar processos adequadamente, geralmente eles não oferecem apoio significativo à recuperação e tratamento de exceções. Em contrapartida, os modelos transacionais são projetados para garantir a confiabilidade da execução em caso de falhas, por meio da adaptação das propriedades ACID ao contexto de processos de negócio.

Embora um considerável número de modelos transacionais aplicados a processos de negócio sejam encontrados na literatura, o desenvolvimento de sistemas que apoiem o controle de processos transacionais utilizando os modelos apresentados permanece escasso, podendo indicar invia- 
bilidade prática. A implementação de sistemas para controle de processos transacionais precisa superar diversos desafios, como corretude de execução, integridade das instâncias para execuções paralelas e mecanismos de recuperação. Considerando esses diferentes aspectos, a abordagem WED-flow, inserida no contexto de abordagens baseadas em regras e propriedades transacionais, foi proposta com o principal objetivo de reduzir a complexidade no tratamento de exceções.

\subsection{Contribuições}

Neste trabalho exploramos os fundamentos da abordagem WED-flow e desenvolvemos uma ferramenta de software para controle de processos transacionais baseada nessa nova abordagem. A implementação da ferramenta apoiou o aprimoramento dos fundamentos da WED-flow e foi fundamental para o desenvolvimento de novos conceitos, possibilitando a evolução da abordagem. Sendo assim, neste trabalho apresentamos uma releitura dos conceitos que compõem a WEDflow e também a implementação do núcleo de uma ferramenta de software, chamada WED-tool, a qual indica a viabilidade prática da abordagem.

A implementação do núcleo da WED-tool é a principal contribuição deste trabalho. A partir da especificação de um modelo WED-flow descrito em XML, a ferramenta é capaz de realizar sua configuração inicial, o que inclui a criação da estrutura do banco de dados, cujo modelo foi apresentado e detalhado na Seção 6.1. Após a configuração inicial, é possível instanciar e controlar a execução de processos transacionais conforme descrito na Seção 6.2. Adicionalmente, o núcleo da WED-tool permite que o modelo do WED-flow projetado seja alterado, possibilitando a evolução incremental do mesmo.

O núcleo da WED-tool também é capaz de capturar exceções durante a execução de instâncias de WED-flow. Como apresentado na Seção 6.3, nossa implementação fornece toda a estrutura necessária para apoiar o desenvolvimento do gerenciador de recuperação da WED-tool. Assim, caso uma exceção seja capturada, o núcleo interrompe a execução da instância e esta passa a ser responsabilidade do gerenciador de recuperação, o qual irá tratar a exceção capturada e restaurar a consistência da instância.

Mais informações sobre o projeto WED-flow podem ser encontradas no site http://data.ime. usp.br/wedflow. Em particular, a implementação desenvolvida neste trabalho foi objeto de duas publicações: um artigo [GBPF12] publicado no Journal of Information and Data Management e apresentado na 27ํ edição do Simpósio Brasileiro de Banco de Dados e um artigo [GSBF12] publicado e apresentado na seção de demos do mesmo simpósio.

\subsection{Trabalhos futuros}

O núcleo da WED-tool corresponde à primeira implementação referente ao projeto WED-flow. Como dito anteriormente, o desenvolvimento do gerenciador de recuperação está atualmente em 
curso para tratar a interrupção de execução das instâncias que o núcleo controla. Adicionalmente, outros esforços também são necessários para aprimorar e expandir as funcionalidades da WEDtool. Como possíveis trabalhos futuros, destacamos:

\section{- Validação de modelo WED-flow:}

Como descrito na Seção 6.3, WED-states inconsistentes causam a interrupção da execução da instância e a produção desses estados comumente são consequência de erros no projeto do WED-flow. Assim, um possível trabalho futuro seria o desenvolvimento de um verificador de modelo capaz de analisar a especificação descrita em XML e identificar problemas, como, por exemplo, erros que produzem estados inconsistentes.

\section{- Integração com o módulo de comunicação com serviços Web:}

A implementação de uma WED-transition por meio do desenvolvimento de uma classe Ruby possibilita que a transição execute ações e tarefas diversificadas. Dentre as possíveis ações, podemos destacar a chamada de um serviço Web. Para isso, um módulo para controle de chamadas de serviços Web foi desenvolvido à parte, correspondente a outra dissertação de mestrado [Rod12]. Sendo assim, futuramente será realizado a integração do núcleo da WED-tool com o módulo de comunicação com serviços Web já desenvolvido.

\section{- Metodologia para modelagem:}

Tratando-se de uma abordagem nova, a modelagem de processos de negócio como um WEDflow pode apresentar dificuldades. Assim, outro possível futuro trabalho seria a criação de uma metodologia para auxiliar especialistas na identificação de eventos e dados relevantes ao processo de negócio e também no projeto do modelo WED-flow correspondente. 


\section{Apêndice A}

\section{XML Schema}

Este apêndice contém os arquivos XML Schema que são utilizados na implementação da ferramenta WED-tool. O Código A.1 exibe o esquema que descreve como processos de negócio modelados utilizando a abordagem WED-flow devem ser especificados em arquivos XML. O Código A.2 apresenta a estrutura do arquivo XML utilizado para realização de alterações em modelos WED-flow previamente cadastrados na ferramenta WED-tool.

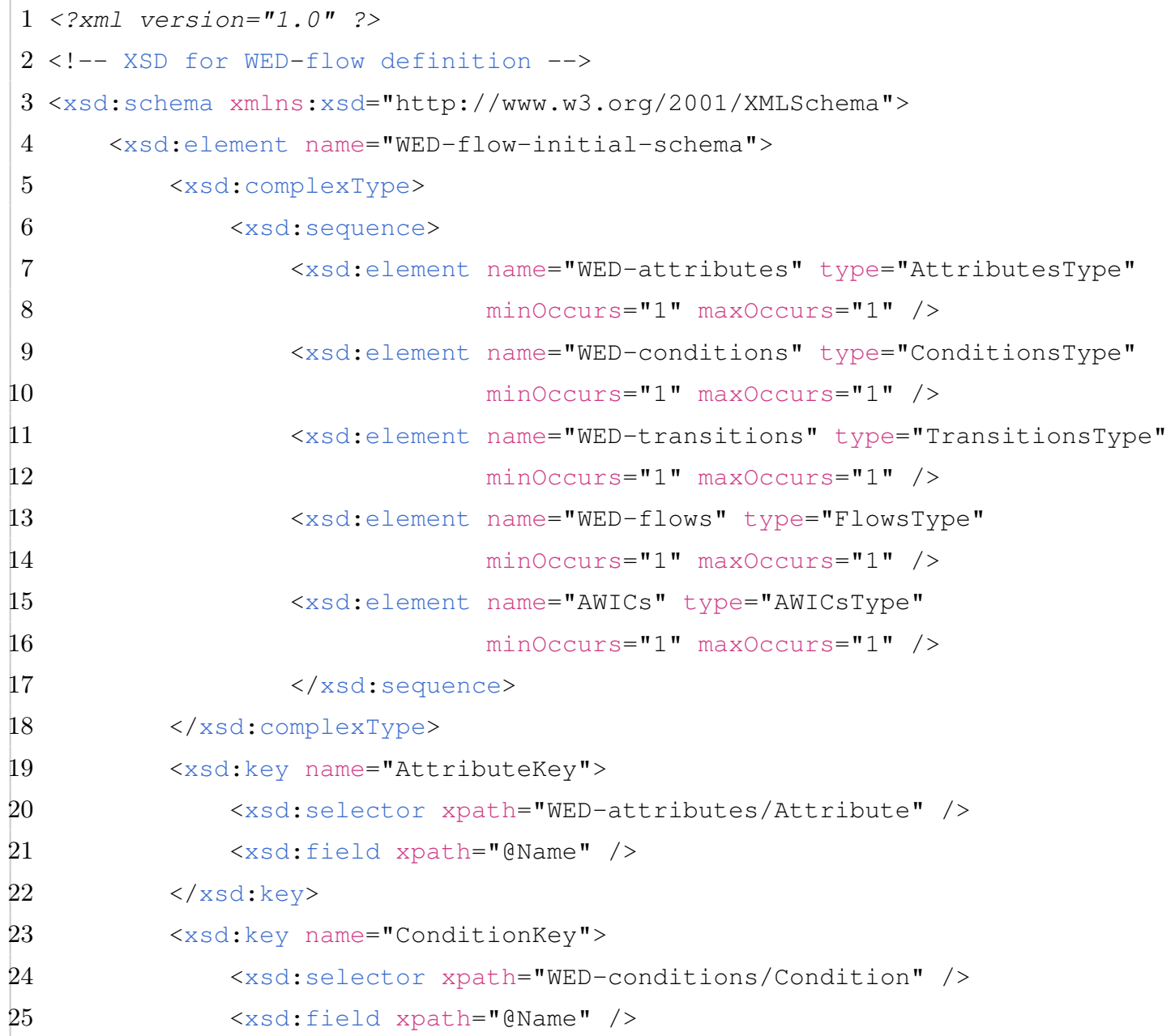


26

27

28

29

30

31

32

33

34

35

36

37

38

39

40

41

42

43

44

45

46

47

48

49

50

51

52

53

54

55

56

57

58

59

60

61

62

63

64

65

66

67

68

69

70

71

$</$ xsd: key $>$

$<x s d:$ key name="Transitionkey">

<xsd:selector xpath="WED-transitions/Transition" />

<xsd:field xpath="@Name" />

$</ \mathrm{xsd}$ :key $>$

$<x$ d:key name="Flowkey">

<xsd:selector xpath="WED-flows/Flow" />

$<x$ d:field xpath="@Name" />

$</ \mathrm{xsd}$ :key $>$

<xsd:keyref name="AttributekeyRef" refer="Attributekey">

<xsd:selector xpath="WED-transition/Transition/UpdatedAttribute" />

<xsd:field xpath="@AttrName" />

$</ x$ sd:keyref $>$

<xsd:keyref name="ConditionkeyRef" refer="Conditionkey" >

<xsd:selector xpath="WED-flows/Flow/Trigger" />

<xsd:field xpath="@CondName" />

$</ x$ sd:keyref $>$

<xsd:keyref name="TransitionkeyRef" refer="Transitionkey">

<xsd:selector xpath="WED-flows/Flow/Trigger" />

<xsd:field xpath="@TransName" />

$</ x$ sd:keyref $>$

<xsd:keyref name="FSConditionKeyRef" refer="Conditionkey">

$<x$ sd:selector xpath="WED-flows/Flow" />

<xsd:field xpath="@FinalstateCondName" />

$</ x$ sd:keyref $>$

<xsd:keyref name="AWICConditionKeyRef" refer="ConditionKey">

<xsd:selector xpath="AWICs/Constraint" />

<xsd:field xpath="@CondName" />

$</ x$ sd:keyref $>$

$</ x$ sd:element $>$

<xsd:complextype name="Attributestype">

$<x$ sd: sequence>

<xsd:element name="Attribute" minoccurs="0" maxOccurs="unbounded" >

$\langle x$ sd: complextype>

<xsd:attribute name="Name" type="xsd:string"

use="required" />

<xsd:attribute name="Type" type="xsd:string"

use="required" />

$</ x$ sd:complextype $>$

$</ x$ sd:element $>$

$</ x$ sd: sequence $>$

$</ x$ sd:complextype $>$

<xsd: complexType name="Conditionstype">

$\langle x s d$ : sequence> 
<xsd:element name="Condition" minoccurs="0" maxOccurs="unbounded" > <xsd: complextype>

$<x$ s $:$ sequence>

<xsd:element name="Predicate" minoccurs="1" maxOccurs="unbounded" >

<xsd:complexType>

$<x$ sd:simplecontent>

<xsd:extension base="xsd: string">

<xsd:attribute name="Id"

type="xsd: integer" use="required" / >

$</$ xsd:extension $>$

$</ x$ sd:simplecontent $>$

$</ x$ sd: complextype $>$

$</ x$ sd:element $>$

<xsd:element name="Expression" type="xsd:string" minoccurs $=" 1 "$ maxoccurs $=" 1 " />$

$</ x$ sd: sequence $>$

<xsd:attribute name="Name" type="xsd:string"

use="required" />

$</ x$ sd: complextype>

<xsd:key name="Predicatekey">

<xsd:selector xpath="WED-condition/Predicate" />

<xsd:field xpath="@Id" />

$</ \mathrm{x}$ sd $:$ key $>$

$</ x$ sd:element $>$

$</ x$ sd: sequence $>$

$</ x$ sd: complextype $>$

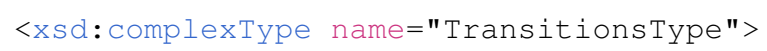


$</ x$ sd: sequence $>$

119

$\langle/ x s d$ :complextype $>$

120

121

<xsd:complexType name="TriggersType">

$<x$ sd: sequence $>$

<xsd:element name="Trigger" minoccurs="0" maxoccurs="unbounded" > $<x$ sd:complexType>

124

125

126

127

128

129

130

131

132

133

134

135

136

137

138

139

140

141

142

143

144

145

146

147

148

149

150

151

152

153

154

155

156

157

158

159

160

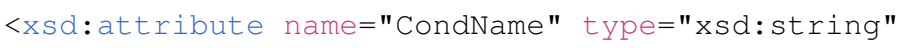

163

$\langle x s d$ : sequence> 
164

165

166

167

168

169

170

171

172

<xsd:element name="Constraint" minoccurs="0" maxOccurs="unbounded" > <xsd:complextype>

<xsd:attribute name="CondName" type="xsd:string" use="required" />

$</ x$ sd: complextype $>$

$</ x$ sd:element $>$

$</ x$ sd: sequence $>$

$</ x$ sd:complextype $>$

$</ x$ sd: schema $>$

Código-fonte A.1: XML Schema para modelo WED-flow.

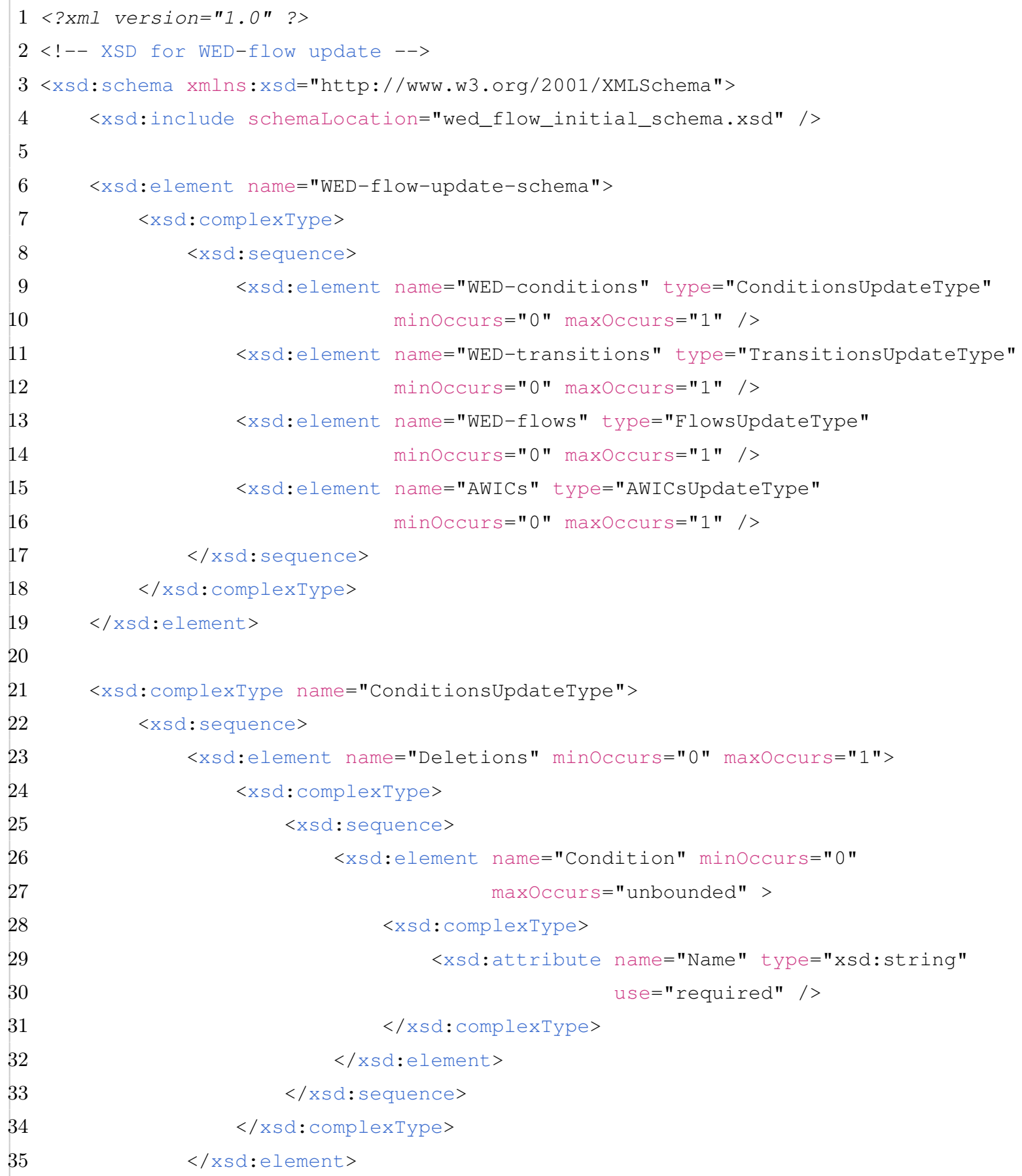


36

37

38

39

40

41

42

43

44

45

46

47

48

49

50

51

52

53

54

55

56

57

58

59

60

61

62

63

64

65

66

67

68

69

70

71

72

73

74

75

76

77

78

79

80

81 <xsd:element name="Insertions" type="ConditionsType" minoccurs="0" maxoccurs="1" />

$</ x$ sd: sequence $>$

$</ x$ sd:complextype $>$

<xsd:complextype name="TransitionsupdateType">

$<\mathrm{xsd}$ : sequence>

<xsd:element name="Deletions" minoccurs="0" maxoccurs="1"> $<x$ sd: complextype>

$<x$ sd: sequence $>$

$<x s d: e l e m e n t$ name="Transition" minoccurs="0" maxOccurs="unbounded" >

$<x$ sd:complextype>

$<x s$ : attribute name="Name" type="xsd:string" use="required" />

$</ x$ sd: complextype $>$

$</ x s$ :element $>$

$</ x$ sd: sequence $>$

$</ x$ sd: complextype $>$

$</ x$ sd:element $>$

$<x s$ : element name="Insertions" type="TransitionsType" minoccurs="0" maxoccurs="1" />

$</ x$ sd: sequence $>$

$</ x$ sd:complextype $>$

$<x$ sd:complextype name="FlowsUpdateType" >

$<x$ sd: sequence>

<xsd:element name="Insertions" type="FlowsType" minoccurs="0" maxoccurs="1" />

<xsd:element name="Deletions" minoccurs="0" maxoccurs="1" >

$<x$ sd: complextype>

$<x$ sd: sequence>

$<x s d:$ element name="Flow" minoccurs="1"

maxOccurs="unbounded" >

$<x$ sd: complextype>

<xsd:attribute name="Name" type="xsd:string" use="required" />

$</ x$ sd: complexType $>$

$</ x$ sd:element $>$

$</ x$ sd: sequence $>$

$</ x$ sd: complextype $>$

$</ x$ sd:element $>$

<xsd:element name="Updates" minoccurs="0" maxOccurs="unbounded" >

$<x$ sd: complextype>

$<x$ sd: sequence>

<xsd:element name="Flow" minoccurs=" 0 " 
104

105

106

107

108

109

110

111

112

113

114
maxOccurs="unbounded" >

$\langle x$ sd: complextype>

$\langle x$ sd: sequence>

$<x s d:$ lement name="Deletions"

type="Triggers Type"

minoccurs $=" 0$ "

maxOccurs="1" />

$<x s d: e l e m e n t$ name="Insertions"

type="Triggers Type"

minoccurs $=" 0$ "

$\operatorname{maxOccurs}=" 1 " \quad />$

$</ x$ sd: sequence $>$

<xsd:attribute name="Name" type="xsd:string"

use="required" />

<xsd:attribute name="FinalstateCondName"

type="xsd:string"

use="required" />

$</ x$ sd: complexType $>$

$</ x$ sd:element $>$

$</ x$ sd: sequence $>$

$</ x$ sd: complextype $>$

$</ x$ sd:element $>$

$</ x$ sd: sequence $>$

$</ x$ sd:complextype $>$

<xsd:complexType name="AWICsUpdateType">

$\langle x$ sd: sequence $>$

<xsd:element name="Deletions" type="AWICsType" minoccurs="0" maxoccurs="1" />

<xsd:element name="Insertions" type="AWICsType" minOccurs="0" maxOccurs="1" />

$</ x$ sd: sequence>

$</ x s d$ :complextype $>$

$115</ x$ sd: schema $>$

Código-fonte A.2: XML Schema para alteração em modelo WED-flow. 

APÊNDICE A 


\section{Apêndice B}

\section{Exemplos XML}

Este apêndice contém os arquivos XML que foram utilizados para especificação e alteração do modelo do processo de negócio de venda de livros, utilizado como exemplo no Capítulo 6. O Código B.1 exibe a especificação inicial do modelo WED-flow, arquivo o qual foi utilizado como entrada na ferramenta WED-tool para a execução do exemplo apresentado na Seção 6.4. Já o Código B.2 exibe a especificação utilizada para realizar a alteração no modelo WED-flow, descrita na Seção 6.4.3.

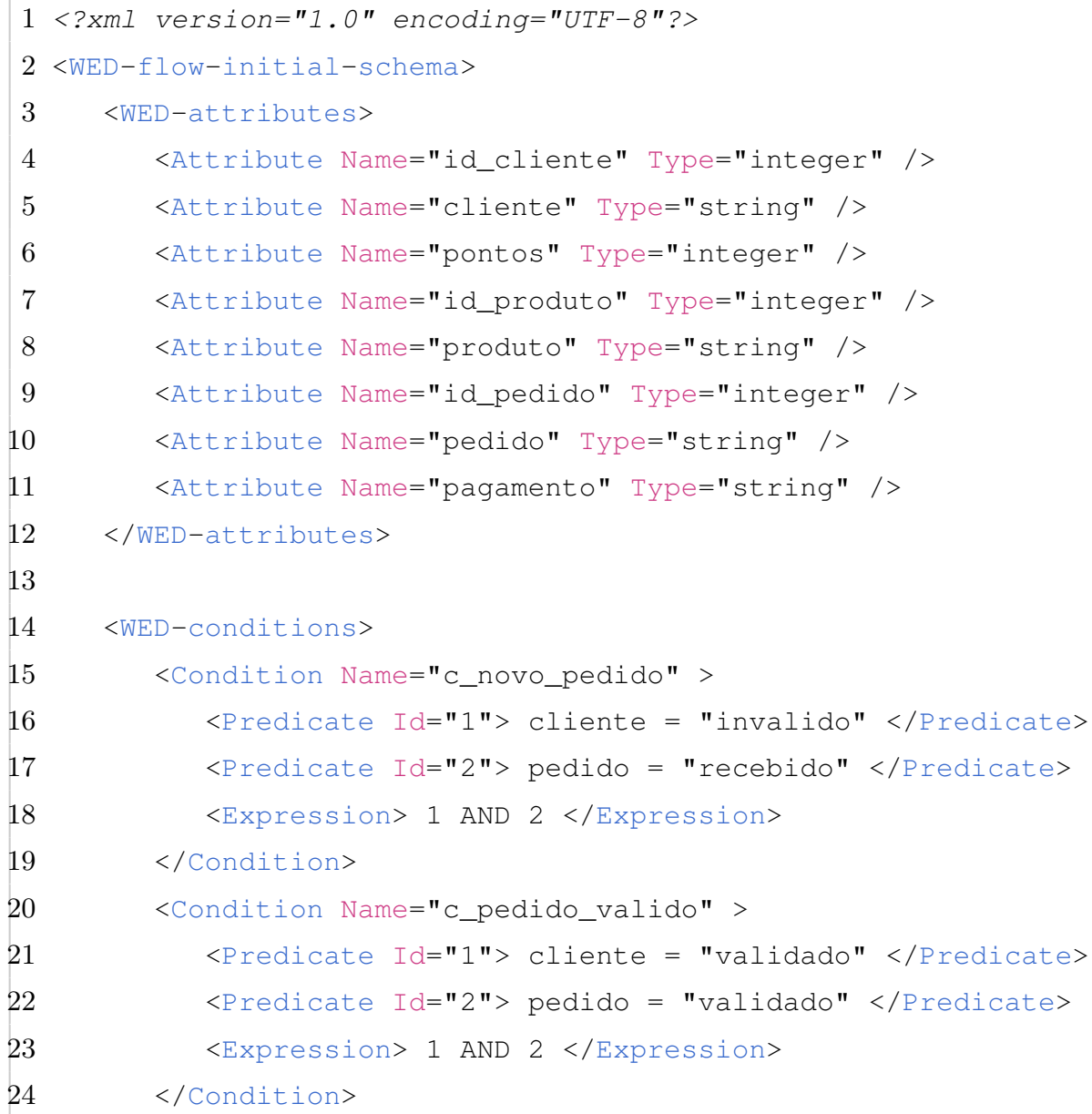




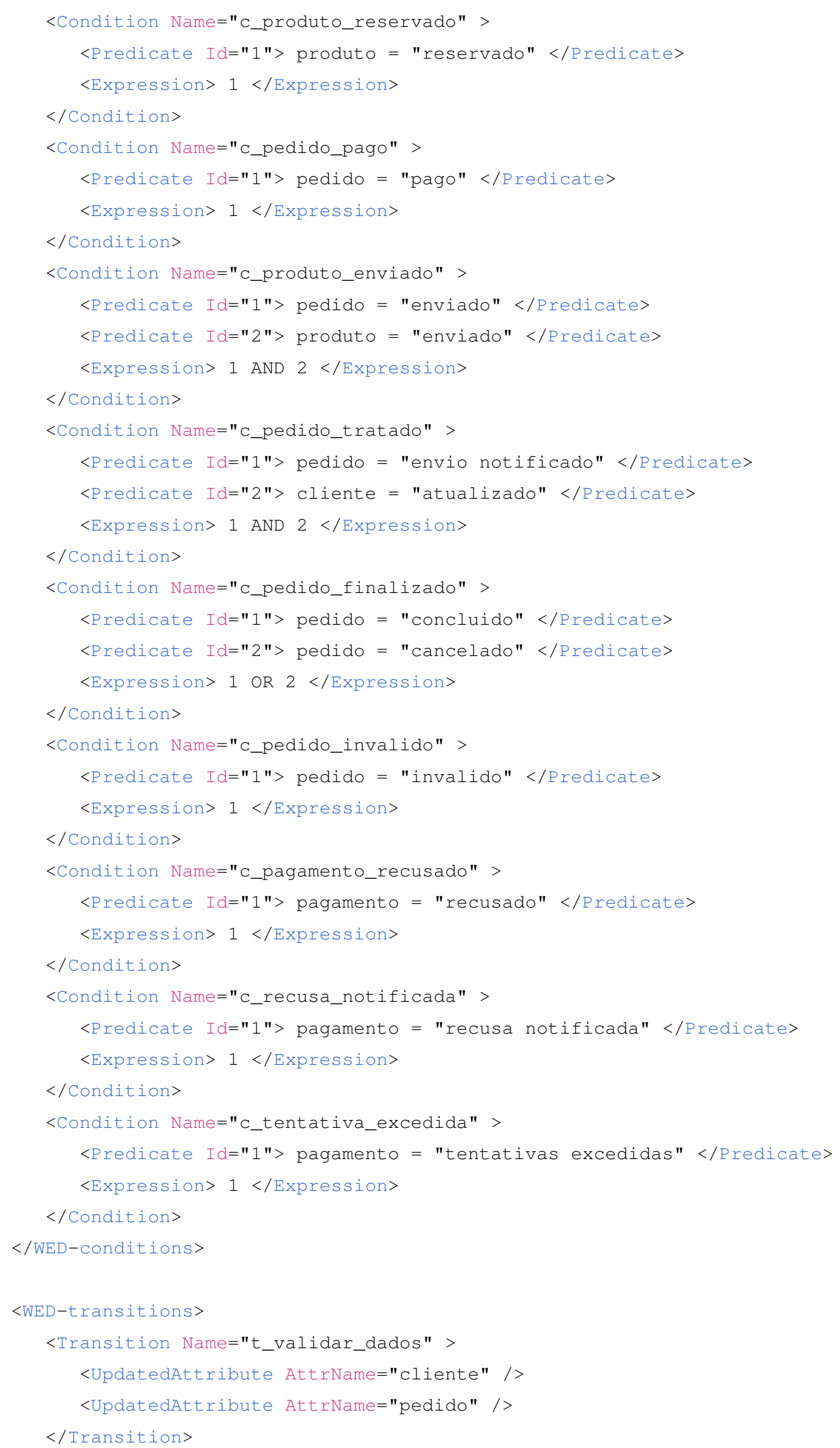




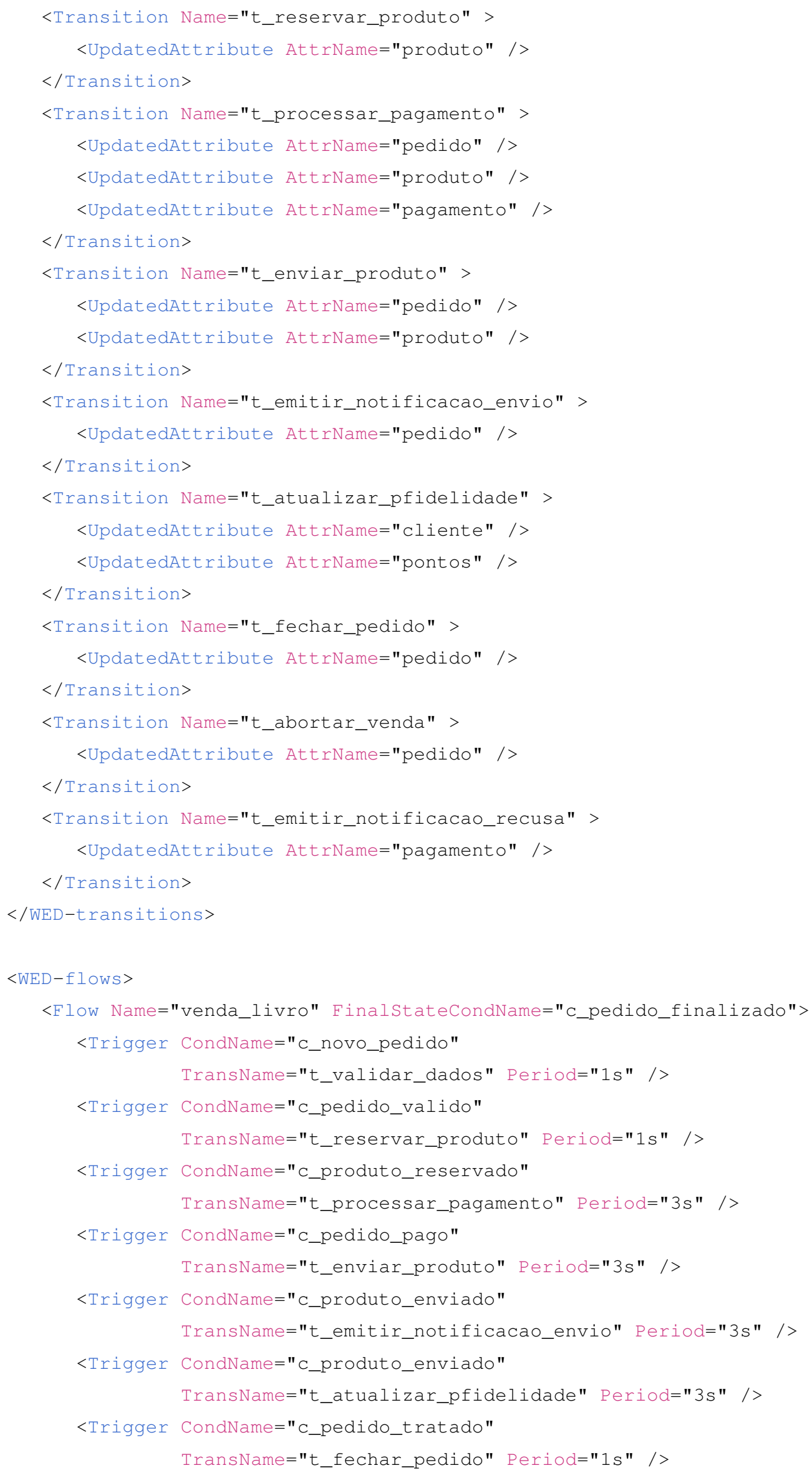


117

118

119

120

121

122

123

124

125

126

127

128

129

130

$131</$ WED-flow-initial-schema>

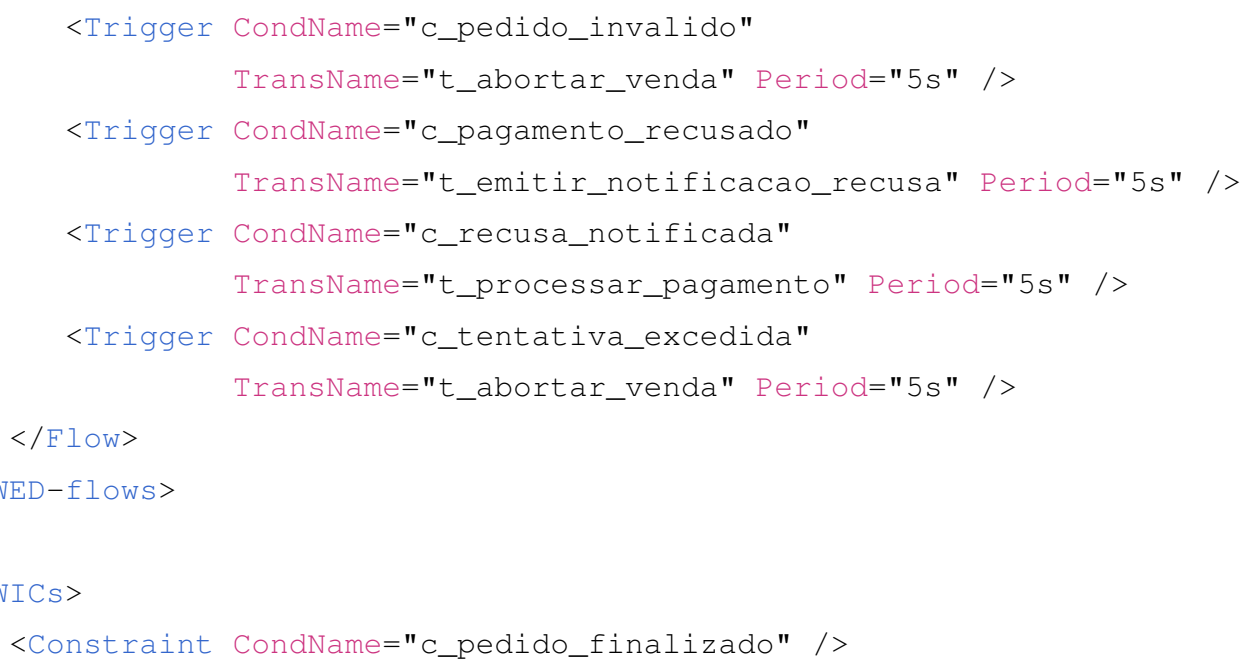

Código-fonte B.1: Arquivo XML com a especificação do modelo WED-flow de venda de livros.

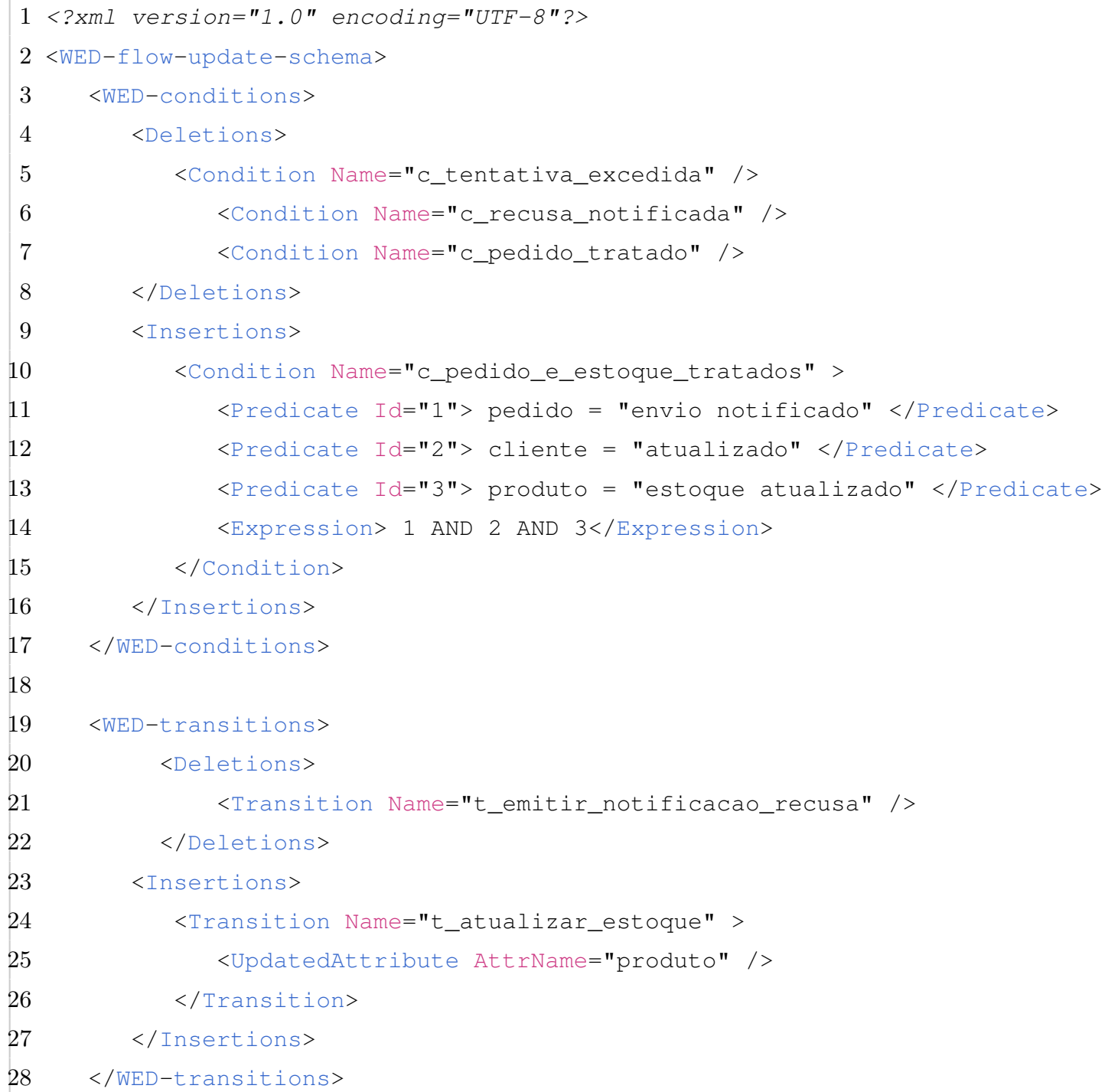


30

31

34

35

36

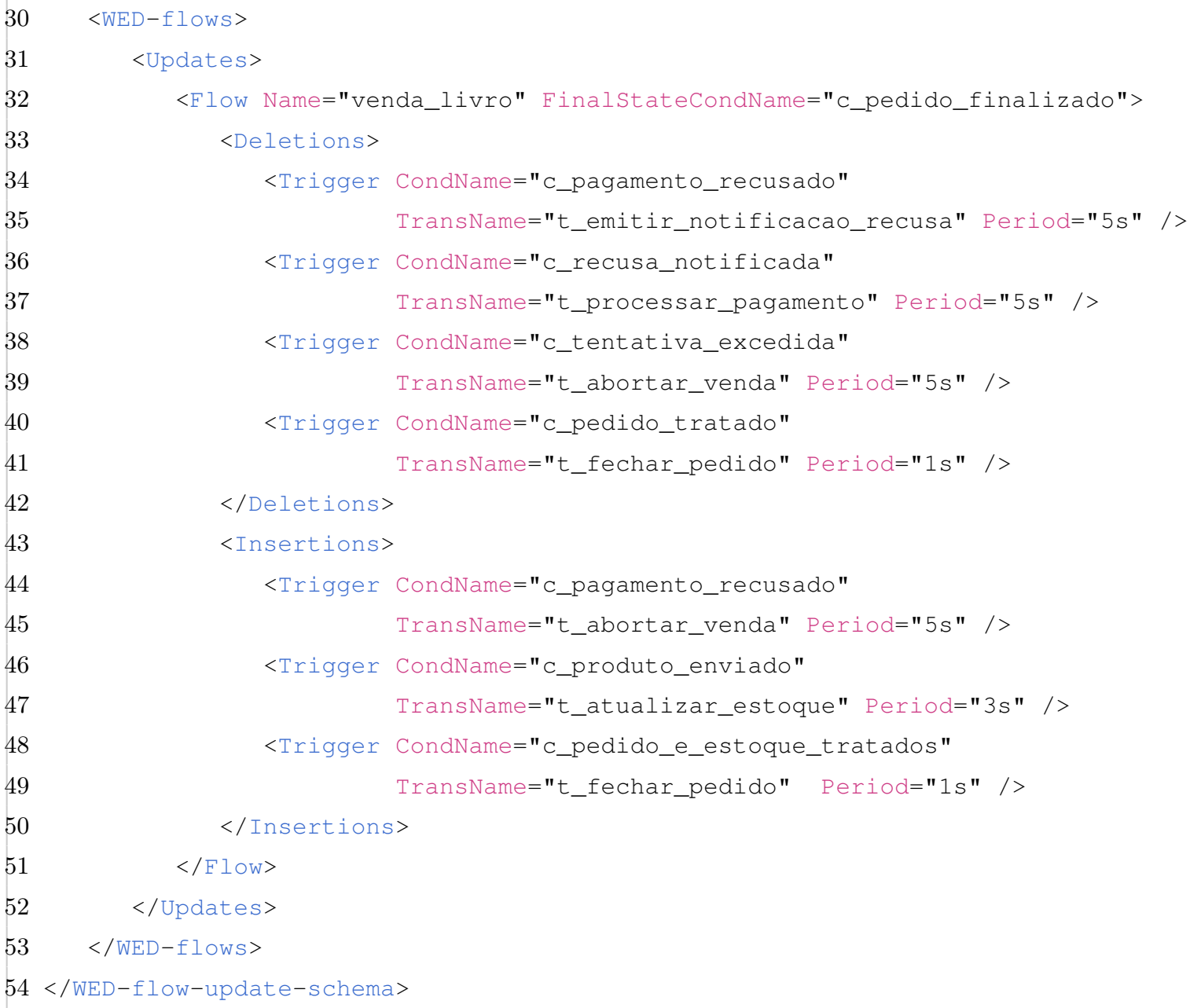

Código-fonte B.2: Arquivo XML com a especificação para alteração do modelo WED-flow de venda de livros. 
APÊNDICE B 


\section{Apêndice C}

\section{Classes associadas a WED-transitions}

Este apêndice contém as classes associadas as WED-transitions do WED-flow de venda livros, descrito na Seção 6.4 .

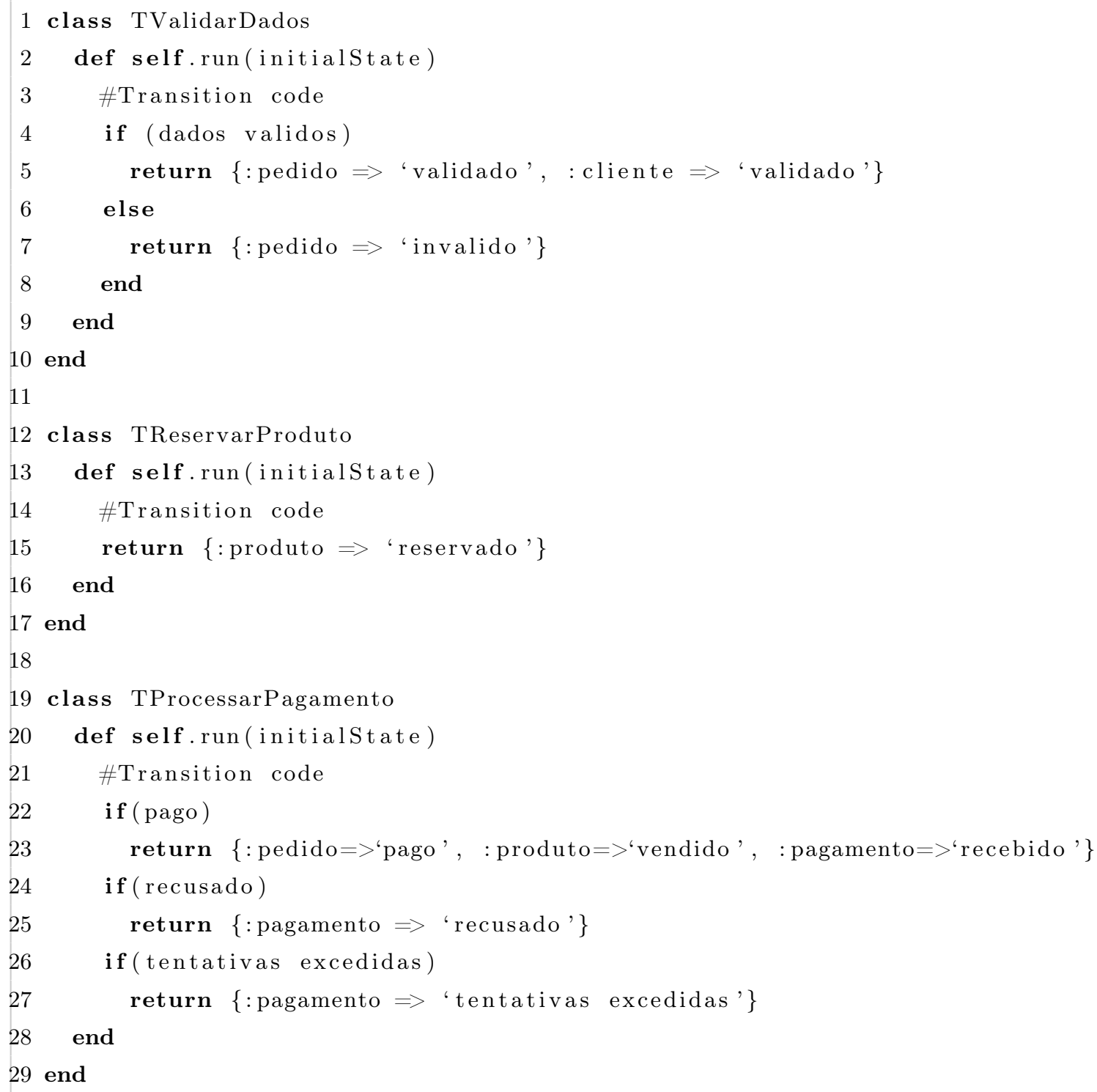


31 class TEnviarProduto

32 def self.run(initialstate)

33 \#Transition code

34 return $\{:$ produto $\Rightarrow$ 'enviado', : pedido $\Rightarrow$ 'enviado'

35 end

36 end

37

38 class TEmitirNotificacao

39 def self.run(initialstate)

$40 \quad$ \#Transition code

41 return $\{$ : pedido $\Rightarrow$ 'envio notificado'

42 end

43 end

44

45 class TAtualizarPfidelidade

46 def self.run(initialstate)

$47 \quad$ \#Transition code

48 pontos $=$ initialstate $\cdot$ pontos +10

49 return $\{$ : cliente $\Rightarrow$ 'atualizado', : pontos $\Rightarrow$ pontos

50 end

51 end

52

53 class TFecharPedido

54 def self.run(initialstate)

$55 \quad$ \#Transition code

56 return $\{$ : pedido $\Rightarrow$ 'concluido'

57 end

58 end

59

60 class TAbortarVenda

61 def self.run(initialstate)

$62 \quad$ \#Transition code

63 return $\{$ : pedido $\Rightarrow$ 'cancelado', : produto $\Rightarrow$ 'disponivel' $\}$

64 end

65 end

66

67 class TEmitirNotificacaoRecusa

68 def self.run(initialstate)

69 \#Transition code

70 return $\{$ : pagamento $\Rightarrow$ 'recusa notificada'

71 end

72 end

Código-fonte C.1: Classes associadas a WED-transitions do WED-flow de venda de livros. 


\section{Referências Bibliográficas}

[AAA ${ }^{+}$96] Gustavo Alonso, Divyakant Agrawal, Amr El Abbadi, Mohan U. Kamath, Roger Günthör e C. Mohan. Advanced transaction models in workflow contexts. Em ICDE, página 574. Published by the IEEE Computer Society, 1996. 3, 29

[act] Activerecord - Object-relational mapping put on Rails. http://api.rubyonrails. org/files/activerecord/README_rdoc.html. Último acesso em 03/01/2013. 54

[Alo05] Gustavo Alonso. Transactional business processes. Em Process-aware information systems, chapter 11. Wiley Online Library, 2005. 29, 30, 31, 32, 33, 36

[BElPR06] François Bry, Michael Eckert, Paula lavinia Pătrânjan e Inna Romanenko. Realizing business processes with ECA rules: Benefits, challenges, limits. Em In Proc. Int. Workshop on Principles and Practice of Semantic Web, 2006. xiii, 23, 24

[BFP09] Kelly R. Braghetto, João E. Ferreira e Calton Pu. NPTool: Towards scalability and reliability of business process management. Em e-Business and Telecommunications, volume 48 of Communications in Computer and Information Science, páginas 99-112. Springer Berlin Heidelberg, 2009. 13

$\left[\mathrm{BGG}^{+} 11\right]$ Sami Bhiri, Walid Gaaloul, Claude Godart, Olivier Perrin, Maciej Zaremba e Wassim Derguech. Ensuring customised transactional reliability of composite services. Journal of Database Management, 22(2):64-92, 2011. 29, 36, 37

[BN09] Philip A. Bernstein e Eric Newcomer. Principles of Transaction Processing. Morgan Kaufmann, segunda edição, 2009. 1

[Bon] Bonita. www.bonitasoft.com. Último acesso em 07/12/2012. 40

[BPS01] Jan A. Bergstra, Alban Ponse e Scott A. Smolka. Handbook of process algebra. Elsevier Science, 2001. 11

[Bra06] Kelly R. Braghetto. Padrões de Fluxos de Processos em Banco de Dados Relacionais. Dissertação de Mestrado, Universidade de São Paulo, 2006. 13

[dat] DATA Group. http://data.ime.usp.br. Último acesso em 18/12/2012. 41

[DBM88] Umeshwar Dayal, Alejandro P. Buchmann e Dennis R. McCarthy. Rules are objects too: A knowledge model for an active, object-oriented database system. Em KlausR. Dittrich, editor, Advances in Object-Oriented Database Systems, volume 334 of Lecture Notes in Computer Science, páginas 129-143. Springer Berlin Heidelberg, 1988. 21

[DGe95] Klaus R. Dittrich, Stella Gatziu e Andreas Geppert (eds.). The active database management system manifesto: A rulebase of ADBMS features. páginas 3-20. Springer, 1995. 22 
[DHW94] Umeshwar Dayal, Eric N. Hanson e Jennifer Widom. Active database systems. Em Modern Database Systems, páginas 434-456. ACM Press, 1994. 22

$\left[\mathrm{FBT}^{+} 12\right]$ João E. Ferreira, Kelly R. Braghetto, Osvaldo K. Takai, Simon Malkowski e Calton $\mathrm{Pu}$. Transactional recovery support for robust exception handling in business process services. Em Proc. of the 19th Int. Conference on Web Services, páginas 303-310, 2012. 41, 42, 45, 64

[Fok07] Wan Fokkink. Introduction to process algebra. Springer Verlag, segunda edição, 2007. 7,11

[FTMP10] João E. Ferreira, Osvaldo K. Takai, Simon Malkowski e Calton Pu. Reducing exception handling complexity in business process modeling and implementation: the WED-flow approach. Em Proceedings of the 2010 international conference on On the move to meaningful internet systems - Volume Part I, OTM'10, páginas 150-167. Springer-Verlag, 2010. 4, 16, 41, 42, 46

[FWMP10] João E. Ferreira, Qinyi Wu, Simon Malkowski e Calton Pu. Towards flexible event-handling in workflows through data states. Em 2010 6th World Congress on Services, páginas 344-351. IEEE, 2010. 41

[GBPF12] Marcela O. Garcia, Kelly R. Braghetto, Calton Pu e João E. Ferreira. An implementation of a transactional model for business process systems. Journal of Information and Data Management, 3(3):271-286, 2012. 5, 80

[GH01] Dimitra Giannakopoulou e Klaus Havelund. Automata-based verification of temporal properties on running programs. Em Proceedings of the 16th IEEE international conference on Automated software engineering, ASE '01, páginas 412-, Washington, DC, USA, 2001. IEEE Computer Society. 25, 26

[GMS87] Hector Garcia-Molina e Kenneth Salem. Sagas, volume 16. ACM, 1987. 31, 32

[Gro] The PostgreSQL Global Development Group. Postgresql 9.1.6 documentation - Create trigger. http://www.postgresql.org/docs/9.1/static/sql-createtrigger. html. Último acesso em 23/11/2012. xiii, 22, 23

[GSBF12] Marcela O. Garcia, Pedro Paulo S.B. Silva, Kelly R. Braghetto e João E. Ferreira. WED-tool: uma ferramenta para o controle de execução de processos de negócio transacionais. Em Proceedings of the 27th Brazilian Symposium on Databases Demos and Applications Session, páginas 19-24, 2012. 5, 53, 80

[Hoa78] Charles A. R. Hoare. Communicating sequential processes. Communications of the ACM, 21(8):666-677, 1978. 11

[JK97] Sushil Jajodia e Larry Kerschberg. Advanced Transaction Models and Architectures. Kluwer Academic Publishers, 1997. 3

[KGR $\left.{ }^{+} 10\right]$ Lucja Kot, Nitin Gupta, Sudip Roy, Johannes Gehrke e Christoph Koch. Beyond isolation: Research opportunities in declarative data-driven coordination. ACM SIGMOD Record, 39(1):27-32, 2010. 31

$\left[\mathrm{L}^{+} 01\right]$ Frank Leymann et al. Web services flow language (WSFL 1.0). IBM Software Group, 2001. 13 
[LPT99] Ling Liu, Calton Pu e Wei Tang. Continual queries for internet scale event-driven information delivery. Knowledge and Data Engineering, IEEE Transactions on, 11(4):610-628, 1999. 58

[LS07] Ruopeng Lu e Shazia Sadiq. A survey of comparative business process modeling approaches. Em Proc. of the 10th international conference on Business information systems, páginas 82-94, 2007. 2, 7, 21, 22, 23

[LSKM00] Zongwei Luo, Amit Sheth, Krys Kochut e John Miller. Exception handling in workflow systems. Applied Intelligence, 13:125-147, 2000. 44

[Mil82] Robin Milner. A Calculus of Communicating Systems. Springer-Verlag New York, Inc., Secaucus, NJ, USA, 1982. 12

[Mil99] Robin Milner. Communicating and mobile systems: the pi-calculus, volume 13. Cambridge university press CambridgeUK, 1999. 11

[Mur02] Tadao Murata. Petri nets: Properties, analysis and applications. Proceedings of the IEEE, 77(4):541-580, 2002. 9, 10

[NE02] Shamkant B. Navathe e Ramez Elmasri. Fundamentals of Database Systems. Addison-Wesley, 2002. 29

[oas] OASIS - Organization for the Advancement of Structured Information Standards. http://www.oasis-open.org. Último acesso em 03/09/2011. 13

[OMG11] OMG. Business process model and notation. http://www.omg.org/spec/BPMN/ 2.0, 2011. OMG Document Number formal/2011-01-03 - Último acesso em 03/09/2011. 16, 17, 18

[pos] PostgreSQL. www.postgresql.org. Último acesso em 20/12/2012. 54

[Rod12] Mauricio Chui Rodrigues. Tratamento de eventos aplicado à composição de serviçõs web. Dissertação de Mestrado, Universidade de São Paulo, 2012. 81

[ruf] Rufus-scheduler. http://rufus.rubyforge.org/rufus-scheduler. Último acesso em 15/01/2013. 59

[Saa93] Heikki T. Saastamoinen. Rules and exceptions. Em Information Modeling and Knowledge Bases IV: Concepts, Methods and Systems, páginas 271-286. 1993. 44

[SABS02] Heiko Schuldt, Gustavo Alonso, Catriel Beeri e Hans-Jörg Schek. Atomicity and isolation for transactional processes. ACM Trans. Database Syst., 27(1):63-116, 2002. xi, 32, 33, 36

[SBF12] Pedro Paulo S.B. Silva, Kelly R. Braghetto e João E. Ferreira. Uma abordagem ad-hoc para o tratamento de exceções em processos transacionais. Em Proceedings of the 27th Brazilian Symposium on Databases - Short Papers, páginas 153-160, 2012. 43, 44, 45, 53, 62, 64

[Sil13] Pedro Paulo S. B. Silva. Uma abordagem transacional para o tratamento de exceções em processos de negócio. Dissertação de Mestrado, Universidade de São Paulo, 2013. 45

[Sta] OASIS Standard. Business process execution language for web services - Version 2.0. http://docs.oasis-open.org/wsbpel/2.0/OS/wsbpel-v2.0-OS.pdf. Último acesso em 20/01/2013. 13, 14 
[vdAP06] Wil M. P. van der Aalst e Maja Pesic. Decserflow: Towards a truly declarative service flow language. páginas 1-23. Springer, 2006. xi, 27

[vdAPS07] Wil M. P. van der Aalst, Maja Pesic e Helen Schonenberg. Declare: Full support for loosely-structured processes. Em In Proceedings of the 11th IEEE International Enterprise Distributed Object Computing Conference (EDOC), páginas 287-298, Washington, DC, USA, 2007. IEEE Computer Society. 25

[vdAPS09] Wil M. P. van der Aalst, Maja Pesic e Helen Schonenberg. Declarative workflows: Balancing between flexibility and support. Computer Science - RED, 23(2):99113, 2009. 25

[vdAtHW03] Wil M. P. van der Aalst, Arthur H. M. ter Hofstede e Mathias Weske. Business process management: A survey. Business Process Management, páginas 10191019, 2003. xi, 1, 2

[vdAvH04] Wil M. P. van der Aalst e Kees M. van Hee. Workflow management: models, methods, and systems. The MIT press, 2004. 9, 10

[w3c] W3C - Web services glossary. www.w3.org/TR/ws-gloss. Último acesso em $07 / 12 / 2012$. 13,14

[wed] WED-flow website. http://data.ime.usp.br/wedflow. Último acesso em 18/12/2012. 41

[Wes12] Mathias Weske. Business Process Management: Concepts, Languages, Architectures. Springer Verlag, 2012. xi, 1, 2, 3

[WfM99] WfMC. Workflow Management Coalition - Terminology \& glossary. http: //www.wfmc.org/standards/docs/TC-1011_term_glossary_v3.pdf, 1999. (Document Number WFMC-TC-1011) - Último acesso em 03/09/2011. 1, 3

[WvdADtH02] Petia Wohed, Wil M. P. van der Aalst, Marlon Dumas e Arthur H. M. ter Hofstede. Pattern-based analysis of BPEL4WS. 2002. 13, 14

[xch] Xchange. http://reactiveweb.org/xchange/. Último acesso em 23/11/2012. 23, 24

[xla] XLANG. http://msdn.microsoft.com/en-us/library/aa577463(v=BTS.70).aspx. Último acesso em 03/09/2011. 13

[ZNBB94] Aidong Zhang, Marian Nodine, Bharat Bhargava e Omran Bukhres. Ensuring relaxed atomicity for flexible transactions in multidatabase systems. Em Proceedings of the 1994 ACM SIGMOD international conference on Management of data, SIGMOD '94, páginas 67-78, New York, NY, USA, 1994. ACM. 33, 37 